Andrews University

Digital Commons @ Andrews University

\title{
The Relationship Between Perspectives ofSpiritual Care and Organizational Climate in Seventh-day Adventist Baccalaureate Nursing Programs in North America
}

Edelweiss Ramal

Andrews University

Follow this and additional works at: https://digitalcommons.andrews.edu/dissertations

Part of the Christian Denominations and Sects Commons, Education Commons, and the Nursing Commons

\section{Recommended Citation}

Ramal, Edelweiss, "The Relationship Between Perspectives ofSpiritual Care and Organizational Climate in Seventh-day Adventist Baccalaureate Nursing Programs in North America" (2002). Dissertations. 648. https://digitalcommons.andrews.edu/dissertations/648 https://dx.doi.org/10.32597/dissertations/648

This Dissertation is brought to you for free and open access by the Graduate Research at Digital Commons @ Andrews University. It has been accepted for inclusion in Dissertations by an authorized administrator of Digital Commons@ Andrews University. For more information, please contact repository@andrews.edu. 


\section{Andrews \$university}

Seek Knowledge. Affirm Faith. Change the World.

Thank you for your interest in the

\section{Andrews University Digital Library of Dissertations and Theses.}

Please honor the copyright of this document by not duplicating or distributing additional copies in any form without the author's express written permission. Thanks for your cooperation. 


\section{INFORMATION TO USERS}

This manuscript has been reproduced from the microfilm master. UMI films the text directly from the original or copy submitted. Thus, some thesis and dissertation copies are in typewriter face, while others may be from any type of computer printer.

The quality of this reproduction is dependent upon the quality of the copy submitted. Broken or indistinct print, colored or poor quality illustrations and photographs, print bleedthrough, substandard margins, and improper alignment can adversely affect reproduction.

In the unlikely event that the author did not send UMI a complete manuscript and there are missing pages, these will be noted. Also, if unauthorized copyright material had to be removed, a note will indicate the deletion.

Oversize materials (e.g., maps, drawings, charts) are reproduced by sectioning the original, beginning at the upper left-hand comer and continuing from left to right in equal sections with small overlaps.

Photographs included in the original manuscript have been reproduced xerographically in this copy. Higher quality $6^{-} \times 9^{-}$black and white photographic prints are available for any photographs or illustrations appearing in this copy for an additional charge. Contact UMI directly to order.

ProQuest Information and Learning 300 North Zeeb Road, Ann Arbor, MI 48106-1346 USA 800-521-0600

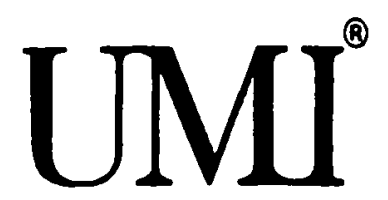


Andrews University

School of Education

THE RELATIONSHIP BETWEEN PERSPECTIVES OF SPIRITUAL CARE AND ORGANIZATIONAL CLIMATE IN SEVENTH-DAY ADVENTIST BACCALAUREATE NURSING

PROGRAMS IN NORTH AMERICA

\author{
A Dissertation \\ Presented in Partial Fulfillment \\ of the Requirements for the Degree \\ Doctor of Philosophy
}

by

Edelweiss Ramal

June 2002 
UMI Number: 3058313

Copyright 2002 by

Ramal, Edelweiss Rocco

All rights reserved.

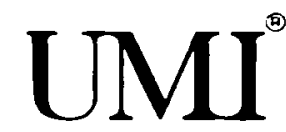

UMI Microform 3058313

Copyright 2002 by ProQuest Information and Learning Company.

All rights reserved. This microform edition is protected against unauthorized copying under Title 17, United States Code.

ProQuest Information and Learning Company

300 North Zeeb Road

P.O. Box 1346

Ann Arbor, MI 48106-1346 
C Copyright by Edelweiss Ramal 2002

All Rights Reserved

Reproduced with permission of the copyright owner. Further reproduction prohibited without permission. 


\title{
THE RELATIONSHIP BETWEEN PERSPECTIVES OF SPIRITUAL CARE AND ORGANIZATIONAL CLIMATE IN SEVENTH-DAY ADVENTIST BACCALAUREATE NURSING PROGRAMS IN NORTH AMERICA
}

\author{
A dissertation \\ presented in partial fulfillment \\ of the requirements for the degree \\ Doctor of Philosophy
}

by

Edelweiss Ramal

APPROVAL BY THE COMMITTEE
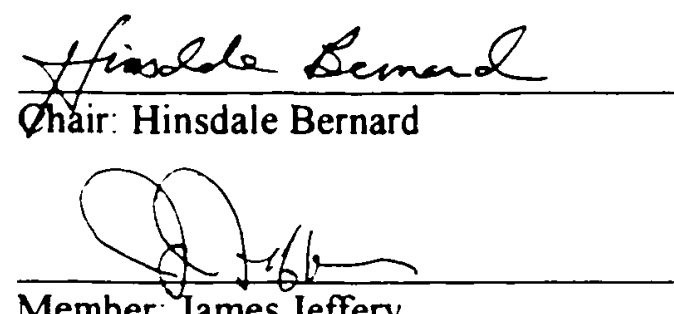

Member: James Jeffery

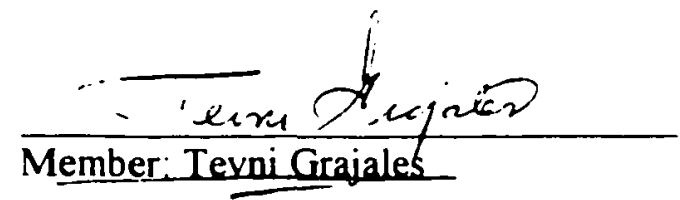

Atemes E fow External: Frances Johnson

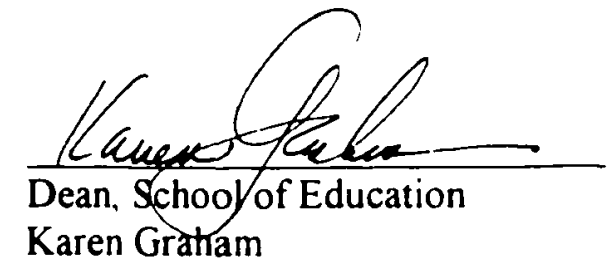

Karen Gratam 


\begin{abstract}
THE RELATIONSHIP BETWEEN PERSPECTIVES OF SPIRITUAL CARE AND ORGANIZATIONAL CLIMATE IN SEVENTH-DAY ADVENTIST BACCALAUREATE NURSING

PROGRAMS IN NORTH AMERICA
\end{abstract}

by

Edelweiss Ramal

Chair: Hinsdale Bernard 


\title{
ABSTRACT OF GRADUATE STUDENT RESEARCH
}

\section{Dissertation}

\author{
Andrews University \\ School of Education
}

Title: THE RELATIONSHIP BETWEEN PERSPECTIVES OF SPIRITUAL CARE AND ORGANIZATIONAL CLIMATE IN SEVENTY-DAY ADVENTIST BACCALAUREATE NURSING PROGRAMS IN NORTH AMERICA

Name of the researcher: Edelweiss Ramal

Name and degree of faculty chair: Hinsdale Bernard. Ph.D

Date completed: June 2002

\section{Problem}

The purpose of this study was to explore the relationship between perspectives of spiritual care held by students and faculty in Seventh-day Adventist baccalaureate nursing programs and their perception of the school climate and compare these between faculty and students, Seventh-day Adventists and non-Seventh-day Adventists, and males and females.

\section{Methodology}

The University Version of the Kettering School Climate scale and the Role of Spiritual Care in Nursing Subscale answered by 49 faculty and 159 students of nine Seventh-day Adventist baccalaureate nursing programs provided the data. Pearson 
correlation, one-way analysis of variance, and $t$ tests at a .05 level of significance were used to find the relationships and differences.

\section{Findings and Conclusions}

1. Organizational climate is not related to perspectives of spiritual care.

2. Students' perspectives of spiritual care are related to climate factors: "respect," "school renewal," and "caring" whereas faculty's perspectives of spiritual care are not related to any of the climate factors.

3. There is no difference in perception of the organizational climate or perspectives of spiritual care between nursing programs.

4. Faculty perceive the actual climate factors "opportunity for input" and "trust" closer to the desired climate in these two areas than students do.

6. Seventh-day Adventist faculty perceive more "oppontunity for input" than non-Seventh-day Adventist faculty do.

5. There is no difference in the perception of overall organizational climate and the individual climate factors between Seventh-day Adventist and non-Seventhday Adventist students and between male and females students.

9. Faculty's perspectives of spiritual care are more positive than students' perspectives.

10. There is no difference in perspectives of spiritual care between Seventhday Adventist and non-Seventh-day Adventist faculty or students, or between male and female students. 
To my beloved husband, Hector;

To our precious children Joy and Tony;

To my dear father, a caring physician, Anthony Rockwell;

To all my nursing colleagues, who desire to make the "caring connection" 


\section{TABLE OF CONTENTS}

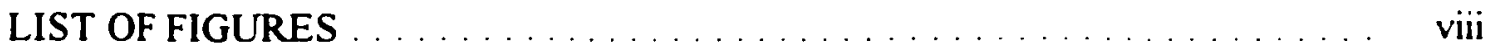

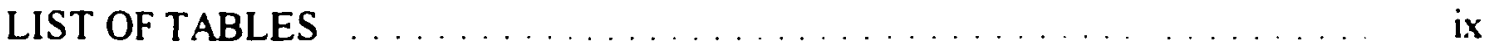

ACKNOWLEDGMENTS $\ldots \ldots \ldots \ldots \ldots \ldots \ldots \ldots \ldots \ldots \ldots \ldots$

Chapter

1. INTRODUCTION ........................ I

Background to the Problem . . . . . . . . . . . . . . . . 1

Statement of the Problem . . . . . . . . . . . . . . . . . . 3

Purpose of the Study . . . . . . . . . . . . . . . . . 4

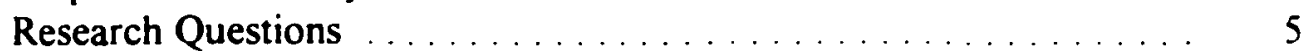

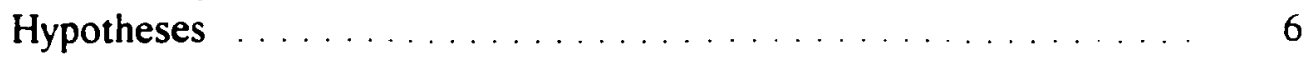

Rationale for the Study . . . . . . . . . . . . . . . . . . . 7

Conceptual Framework . . . . . . . . . . . . . . . . . . . . . . 8

Researcher's Personal Worldview .................... 10

Significance and Importance of the Study . . . . . . . . . . . 12

Definitions of Terms . . . . . . . . . . . . . . . . . . . . . . 13

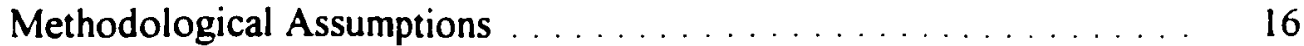

Delimitations of the Study . . . . . . . . . . . . . . . 16

Limitations of the Study . . . . . . . . . . . . . . . . . . 17

Overview of the Chapters . . . . . . . . . . . . . . . 18

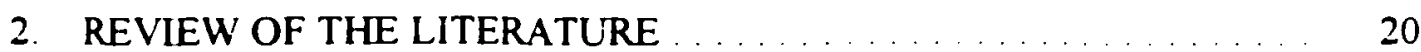

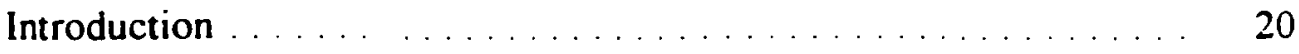

Spiritual Care . . . . . . . . . . . . . . . . . . . . . . . . 21

History and Evolution of the Concept of "Wholism" ...... 21

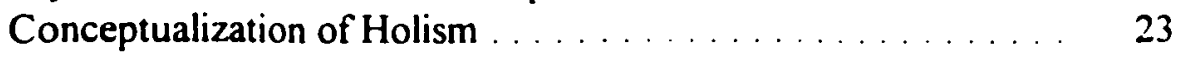

Evolution of Holistic Health Care . . . . . . . . . . . . . 26

Seventh-day Adventist Concept of "Wholistis" Health . . . . . 30

Health Paradigms and Nursing Theories .............. 35

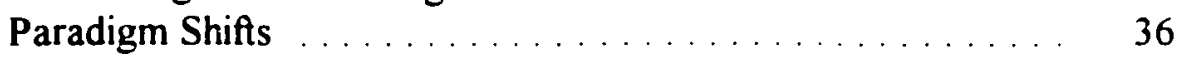

Holistic Paradigm in Nursing . . . . . . . . . . . . . . 37

Meaning of holistic nursing $\ldots \ldots \ldots \ldots \ldots \ldots \ldots$

Principles of holistic nursing $\ldots \ldots \ldots \ldots \ldots \ldots$

iv 
Holistic model versus traditional model . . . . . . . . . . 40

Critical-Holistic model ................. 41

Spiritual Caregiving . . . . . . . . . . . . . . . . . . 41

Meaning of Spirituality . . . . . . . . . . . . . . . . . 42

Christian spirituality .................. 44

Nursing Theories and Models That Support Spiritual Care . . . . 47

Neuman Systems Model . . . . . . . . . . . . . . . . . 48

Health as Expanding Consciousness . . . . . . . . . . 49

Theory of Human Caring $\ldots \ldots \ldots \ldots \ldots \ldots$

Implementation of Spiritual Care ............... 51

Approaches to spiritual caregiving . . . . . . . . . . 52

Spiritual needs and nursing interventions . . . . . . . 53

Organizational Climate . . . . . . . . . . . . . 55

Evolution of Organizational Climate . . . . . . . . . . . . 56

Definition of Organizational Climate . . . . . . . . . . . . 57

School Climate Assessment Instruments . . . . . . . . . . . . . 59

Organizational Climate Description Questionnaire ........ 61

Other School Climate Assessment Instruments . . . . . . . . . 64

University Version of Charles F. Kettering Climate Scale . . . . 65

Research on Organizational Climate . . . . . . . . . . . . 66

Structure and Climate in Schools of Nursing . . . . . . . . . 67

Organizational Climate and Employee Involvement . . . . . . . 68

Organizational Climate and Health Behavior . . . . . . . . . . 69

School Climate and Organizational Health . . . . . . . . . 70

Leadership and School Climate . . . . . . . . . . . . . . 71

Management Practice, Organizational Climate, and Performance ...................... 72

Organizational Climate and Perception of Caring ....... 73

Chapter Summary ........................... 74

3. METHODOLOGY ....................... 77

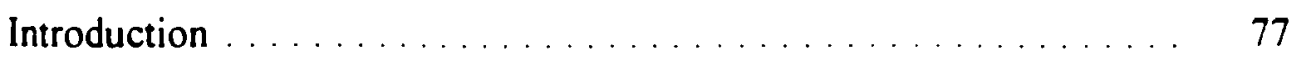

Population and Sample ......................... 78

Statement of Null Hypotheses . . . . . . . . . . . . . . . . . . . . 79

Instrumentation ........................ 80

The University Version of the Charles F. Kettering School

Climate Scale . . . . . . . . . . . . . . . . . . . . . 80

The Spiritual Care Perspectives Scale . . . . . . . . . . . . . . . 83

Research Design ......................... 84

Procedures .............................. 85

Statistical Analysis of the Null Hypotheses . . . . . . . . . . . . . 86

Chapter Summary . . . . . . . . . . . . . . . . 87 
4. ANALYSIS OF THE DATA $\ldots \ldots \ldots \ldots \ldots \ldots \ldots \ldots$

Introduction $\ldots \ldots \ldots \ldots \ldots \ldots \ldots \ldots \ldots \ldots \ldots \ldots \ldots . \ldots \ldots$

Description of Participants . . . . . . . . . . . . . . . . 88

Characteristics of the Faculty . . . . . . . . . . . . . . 89

Characteristics of the Students . . . . . . . . . . . . . . 90

Description of the Characteristics of the Variables . . . . . . . . . . 91

Organizational Climate . . . . . . . . . . . . . . . . . 91

Spiritual Care . . . . . . . . . . . . . . . . . . . . . . 93

Testing of the Hypotheses . . . . . . . . . . . . . . . . . . . 95

The Relationship Between Organizational Climate and

Perspectives of Spiritual Care . . . . . . . . . . . . . . . . . 95

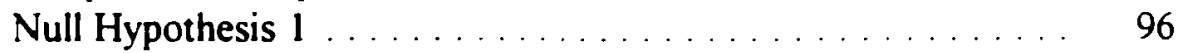

Null Hypothesis $2 \ldots \ldots \ldots \ldots$

Difference in Organizational Climate and Perspectives of Spiritual

Care Between Programs . . . . . . . . . . . . . . . . . . . . . 100

Null Hypothesis $3 \ldots \ldots \ldots$. . . . . . . . . . . . . . . . 100

Null Hypothesis $4 \ldots \ldots \ldots 101$

Difference in Organizational Climate Subscale and Total Climate

Score Between Different Participant Categories . . . . . . . . 102

Null Hypothesis $5 \ldots \ldots \ldots \ldots \ldots \ldots \ldots \ldots$

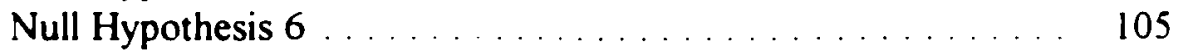

Null Hypothesis $7 \ldots \ldots \ldots \ldots$. . . . . . . . . . . . . . . 107

Null Hypothesis $8 \ldots \ldots$. . . . . . . . . . . . . . . . . . . . . . 109

Difference in Perspectives of Spiritual Care Between the

Different Participant Categories ................. 112

Null Hypothesis $9 \ldots \ldots \ldots \ldots \ldots \ldots$

Null Hypothesis $10 \ldots \ldots \ldots \ldots \ldots \ldots \ldots \ldots \ldots$

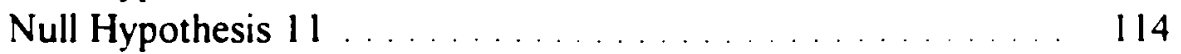

Null Hypothesis $12 \ldots \ldots \ldots \ldots \ldots \ldots \ldots \ldots \ldots$

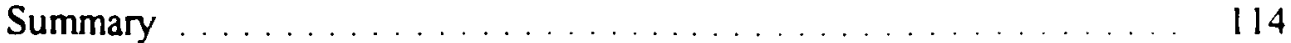

5. SUMMARY, DISCUSSION, CONCLUSIONS, AND

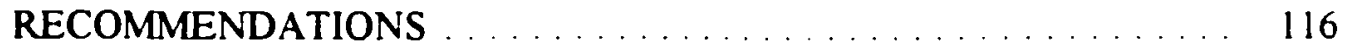

Summary . . . . . . . . . . . . . . . . . . . . . 116

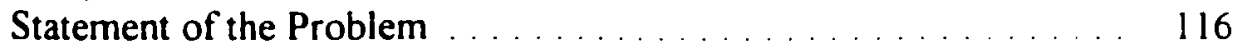

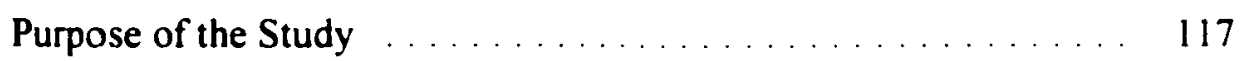

Overview of the Literature . . . . . . . . . . . . . . . . . . . 117

Overview of Spiritual Care . . . . . . . . . . . . . . 118

Overview of Organizational Climate . . . . . . . . . . . 120

Methodology ... . . . . . . . . . . . . . . . . . . . 122

Summary of the Findings $\ldots \ldots \ldots \ldots \ldots \ldots$

Hypothesis 1 ........................ 123

vi 


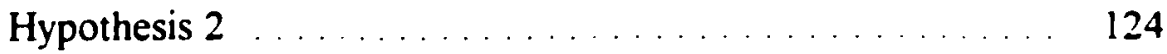

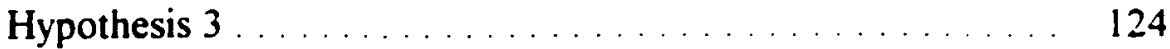

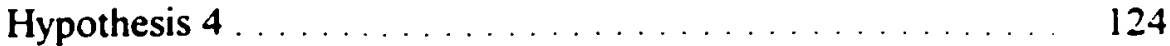

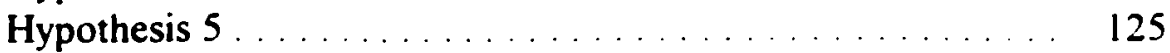

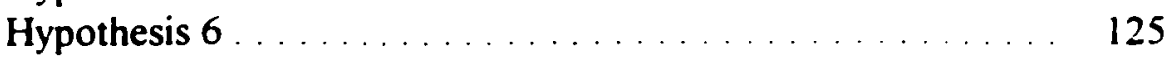

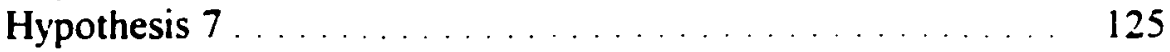

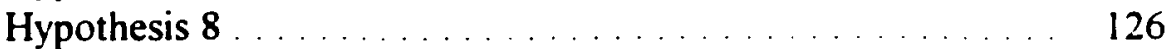

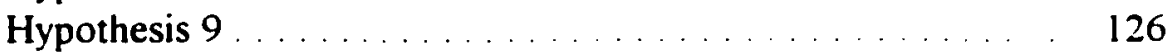

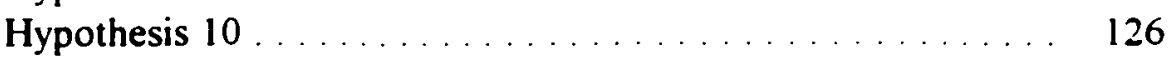

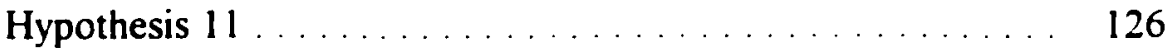

Hypothesis $12 \ldots \ldots \ldots \ldots \ldots \ldots \ldots \ldots \ldots \ldots \ldots$

Discussion of the Findings ..................... 127

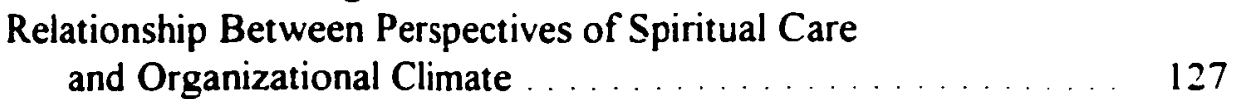

Difference in Perspectives of Spiritual Care and Organizational

Climate Between Nursing Programs . . . . . . . . . . . . 131

Difference in Organizational Climate Between the Different

Participant Categories ...................... 133

Difference in Perspectives of Spiritual Care Between

Different Participant Categories ................ 136

Conclusions ............................. 141

Implications . . . . . . . . . . . . . . . . . . . . . . . 143

Recommendations ......................... 144

Relationship Between Perspectives of Spiritual Care and a Caring

Environment ............................. 144

Research Protocol .......................... 145

Further Research $\ldots \ldots \ldots \ldots \ldots \ldots \ldots \ldots \ldots \ldots \ldots \ldots$

Appendix

A. INSTRUMENTS . . . . . . . . . . . . . . . . . . 148

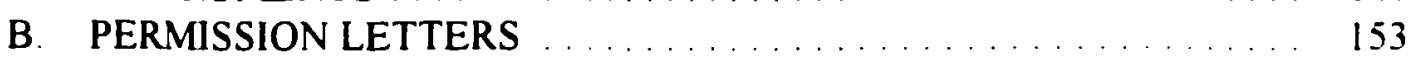

C. COVER LETTER TO NURSING PROGRAM DIRECTORS ...... 156

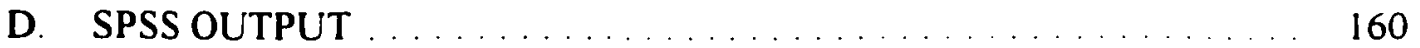

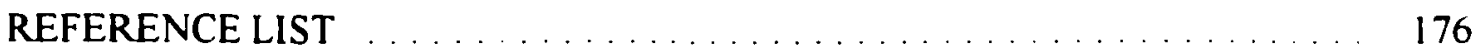

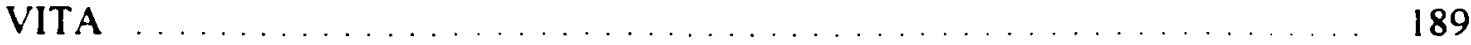

vii 


\section{LIST OF FIGURES}

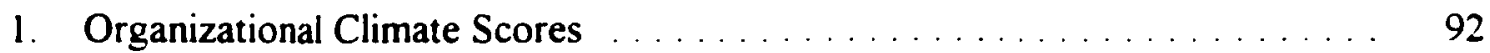

2. Perspectives of Spiritual Care Scores . . . . . . . . . . . . . . . . . 94

viii 


\section{LIST OF TABLES}

1. Seventh-day Adventist NLN Accredited Baccalaureate Nursing Programs in North America in 2001

2. Percentage of Faculty and Students From Each Program Who Participated in the Study and Percentage of Participants Who Were SDA, non-SDA, Female, and Male

3. Overall Mean, Standard Deviation, and Range of Organizational Climate and Subscale Scores

4. Organizational Climate Mean Score, Standard Deviation, and Skewness of Nursing Programs

5. Perspectives of Spiritual Care Mean Score, Standard Deviation, and Skewness of Nursing Programs

6. Overall, Faculty, and Student Mean and Standard Deviation of Items on the Role of Spiritual Care in Nursing Subscale

7. Pearson Correlation of Students' Perspectives of Spiritual Care and Organizational Climate Scale and Subscales

8. Pearson Correlation of Faculty's Perspectives of Spiritual Care and Organizational Climate Scale and Subscales

9. ANOVA of Organizational Climate Scores of Selected Nursing Programs .

10. ANOVA of Perspectives of Spiritual Care Scores of Selected Nuring Programs

11. Mean and Standard Deviation of Organizational Climate and Subscale Scores of Faculty and Students

12. $\quad$ T Test Values for Organizational Climate and Subscale Scores Between Faculty and Students 
13. t Test Values for Organizational Climate and Subscale Scores Between SDA and non-SDA Faculty

14. tTest Values for Organizational Climate and Subscale Scores Between SDA and non-SDA Students

15. t Test Values for Organizational Climate and Subscale Scores Between Males and Females

16. Mean, Standard Deviation, and Range of Perspectives of Spiritual Care Scores for Different Participant Categories

17. $t$ Test Values for Perspectives of Spiritual Care for Different Participant Categories 


\section{ACKNOWLEDGMENTS}

I am foremost thankful to my Creator, Redeemer, and Friend for being by my side each step of the way. I am grateful to God for the spiritual growth I have experienced throughout this dissertation process and for the wonderful people He provided in my life who have assisted me in this research project.

Dr. Hinsdale Bernard was a continuous inspiration and example of a caring professor. As chairman of my dissertation, he had a way of encouraging me and of smoothing the tempestuous waters of uncertainty when the process got rough.

Dr. Tevni Grajales patiently guided me through the entire dissertation providing time and tutorial support. I always will be indebted to him for what I learned through his guidance.

Dr. James Jeffery provided me with valuable feedback and Dr. Frances Johnson gave a nurse's touch to the final manuscript for which $l$ am thankful.

This research would not have been possible without the willingness and collaboration of the nursing program directors. I am especially grateful to them for encouraging their students and faculty to participate in the study.

I am thankful for family and friends who cheered me along. My friend and prayer partner, Sylvia Gonzalez, was a constant source of encouragement.

Finally, I am grateful to Montemorelos University for granting me the financial support to pursue this doctorate degree and for Andrews University's collaboration with Montemorelos. May God reward each one of you 


\section{CHAPTER I}

\section{INTRODUCTION}

\section{Background to the Problem}

An intimate interrelationship exists among the concepts of health, caring, and spirituality (Davidhizar, Bechtel, \& Cosey, 2000; Keighley, 2001; Levin, 2001; Montgomery, 1992; Puchalski, 1999; White, 1977). Swift (1994) states that healing itself is a spiritual event. "Health care professionals are increasingly recognizing the importance of spiritual health as a precursor of physical health" (Espeland, 1999, p. 19). Health care clients, however, have not recognized the importance of spiritual wellness because, for too long, health care professionals have focused their attention on physical and emotional aspects of care, neglecting the spiritual component of wholeness, argues Espeland. Reasons cited for the neglect of spiritual nursing care include: (1) inadequate training and skill, (2) anxiety about spiritual matters, (3) lack of understanding of the meaning, (4) perceived incompatibility between spirituality and science, (5) lack of a theoretical framework, (6) lack of time, (7) lack of desire, (8) negative personal experiences from the past, (9) equating spirituality with religion, (10) concern over introducing mysticism into science-based nursing, and (11) not realizing the importance and interconnections of spirituality with the physical and emotional aspects of the human being (Ameling \& Povilonis, 2001; Emblen \& Pesut, 2001; Espeland, 1999; Maddox, 2001 ; Price, Stevens, \& LaBarre, 1995). 
Despite the excuses given for relegating spiritual care to a low priority, health care providers are becoming more aware of the need to incorporate spiritual concepts into their plan of care. Furthermore, clients are expecting to be recipients of spiritual care regardless of the values of their health care provider. For this reason, Joint Commission on Accreditation of Healthcare Organizations has not only included in its standards the "right to receive care that respects diversity in values" (Davidhizar et al., 2000, p. 24C) but has also mandated the delivery of the Patient Bill of Rights that states that care of the patient must include psychological, spiritual, and cultural aspects (Dossey, 1998). Among the accepted nursing diagnoses by the American Nurses Association are "potential for enhanced spiritual well-being" and "spiritual distress" (Beare \& Myers, 1990; Carpenito, 1995). The Code for Nurses established by the International Council of Nurses states that it is the nurse's responsibility to create an environment in which the spiritual beliefs of individuals are respected (Wright, 1998).

Noticeably, a greater acceptance and even demand for spiritual care is permeating today's health care paradigm. Nonetheless, a great gap still remains between "the prominent place allocated to spirituality by nursing tradition, nurse theorists, codes of professional conduct. and professional organizations" and the spiritual caregiving that actually takes place (Stranahan, 2001, p. 91).

Both nursing curricula and practice need to place more emphasis on spirituality and spiritual caregiving (Thomas \& Retsas, 1999). Nursing programs upholding a philosophy sustaining that humankind was created in the image of God will seek ways of transmitting to the student the importance of spiritual care. This is especially true if, like Sheldon (2000), nursing educators believe that "in order to provide spiritual care to 
another, a person must be aware of his or her own sense of spirituality" (p. 103). Thus, it seems reasonable to accept that these programs would strive to create an open and warm school climate that facilitates spiritual sensitivity and well-being among its members.

\section{Statement of the Problem}

In accordance with the philosophy of the Seventh-day Adventist Church, spiritual caregiving is part of the official curriculum of Seventh-day Adventist nursing programs. However, a look at how the hidden curriculum impacts the transmission of this concept and the attitudes that nursing students acquire regarding spiritual care, and whether students' and faculty's perceptions vary significantly need to be considered. Currently, nursing education is believed to provide adequate preparation for performing physical and psychological intervention skills, but insufficient preparation for performing spiritual care skills (Piles, 1990; Ross, 1995). Therefore, it is imperative that "nurse educators must demonstrate to students how to deal with spiritual health" (Price, et al., 1995). Through its members' behavior, the organizational climate of a nursing program could be a factor influencing the perception of caring (Hughes, 1993) and consequently the perspectives of spiritual care of its students and faculty.

The impact of school climate on primary and secondary education has been widely studied (Freiberg, Driscoll, \& Knight, 1987; Hoy \& Hannum, 1997; Webb \& Norton, 1999). Organizational culture in academics has also been extensively researched (Parker, 2000). Not as much work has been done however on organizational climate in higher education (Johnson, Johnson, Kranch, \& Zimmerman, 1999). "In spite of the emphasis in the literature concerning the importance of climate research, climate in nursing education settings rarely has been investigated" (Lubbert, 1995, p. 317). 
A positive relationship between education and attitudes toward spiritual care has been documented (Sheldon, 2000; Taylor, Highfield, \& Amenta, 1994). Hughes's (1993) study on the Relationships Among the Organizational Characteristics of Baccalaureate Schools of Nursing and the Student-Perceived Organizational C'limate for Caring has revealed the need for further investigation in this area. Among the recommendations based on Hughes's findings is the need to conduct studies "to investigate relationships between the organizational climate for caring and the ability of students to enact in the nursing role as one caring" (p. 341).

This research study focused on a specific and central component of the total caring package-spiritual care. Spiritual well-being is central to the concept of wholeness (White, 1905, 1977). The relationship between spirituality and wholeness is portrayed in the definition of spiritual well-being given by the National Interfaith Coalition of Aging: "the affirmation of life in a relationship with God, self, community and environment that nurtures and celebrates wholeness" (Maddox, 2001, p. 134). Therefore, it becomes relevant to question whether the environment of nursing programs that celebrate wholeness is related to its members' perspectives of spiritual care.

\section{Purpose of the Study}

Attitudes about caring and spiritual caregiving are not acquired in a void. It is known that a positive school climate fosters learning and the dispersion of influence (Hoy \& Hannum, 1997; Lubbert, 1995). The student-perceived organizational climate for caring is a "variable that mediates the relationship between the organizational characteristics of baccalaureate schools of nursing and student outcomes" (Hughes, 1993. p. 337). Hughes's statement suggests that the students' perception of the environment in 
which they develop may influence their perception of caring, of which spiritual care is an imporant component in Seventh-day Adventist philosophy.

The purpose of this study was to explore the interrelationships between the perspectives of spiritual care held by students and faculty in Seventh-day Adventist baccalaureate nursing programs and their perception of the program's organizational climate. This study also allowed a comparison of perspectives of spiritual care and perception of organizational climate between faculty and students, Seventh-day Adventists and non-Seventh-day Adventist, males and females as well as between nursing programs.

\section{Research Questions}

1. Is there a relationship between each organizational climate subscale and total score and the nursing students' perspectives of spiritual care?

2. Is there a relationship between each organizational climate subscale and total score and the faculty's perspectives of spiritual care?

3. Is there a difference in perception of the school's organizational climate between nursing programs?

4. Is there a difference in perspectives of spiritual care between nursing programs?

5. Is there a difference in each organizational climate subscale and total score between faculty and students?

6. Is there a difference in each organizational climate subscale and total score between Seventh-day Adventist and non Seventh-day Adventist faculty?

7. Is there a difference in each organizational climate subscale and total score 
between Seventh-day Adventist and non Seventh-day Adventist students?

8. Is there a difference in each organizational climate subscale and total score between male and female students?

9. Is there a difference in perspectives of spiritual care between students and faculty?

10. Is there a difference in perspectives of spiritual care between Seventh-day Adventist and non Seventh-day Adventist faculty?

11. Is there a difference in perspectives of spiritual care between Seventh-day Adventist and non Seventh-day Adventist students?

12. Is there a difference in perspectives of spiritual care between male and female students?

\section{Hypotheses}

1. There is a significant relationship between each organizational climate subscale and total score and nursing students' perspectives of spiritual care

2. There is a significant relationship between each organizational climate subscale and total score and the faculty's perspectives of spiritual care.

3. There is a significant difference in perception of the school's organizational climate between nursing programs.

4. There is a significant difference in perspectives of spiritual care between nursing programs.

5. There is a significant difference in each organizational climate subscale and total score between faculty and students.

6. There is a significant difference in each organizational climate subscale and 
total score between Seventh-day Adventist and non Seventh-day Adventist faculty.

7. There is a significant difference in each organizational climate subscale and total score between Seventh-day Adventist and non Seventh-day Adventist students.

8. There is a significant difference in each organizational climate subscale and total score between male and female students

9. There is a significant difference in perspectives of spiritual care between students and faculty.

10. There is a significant difference in perspectives of spiritual care between Seventh-day Adventist and non Seventh-day Adventist faculty.

11. There is a significant difference in perspectives of spiritual care between Seventh-day Adventist and non Seventh-day Adventist students

12. There is a significant difference in perspectives of spiritual care between male and female students.

\section{Rationale for the Study}

The Seventh-day Adventist Church has a "wholistic" mission (Jemison. 1955) that combines a balanced, harmonious education (White, 1923, 1952) with a "wholistic" health message (White, 1905, 1912) in which spiritual well-being is a vital component White (1952) urges educators to broaden their concept of "wholistic" education

Our ideas of education take too narrow and too low a range. There is need of a broader scope, a higher aim. True education means more than the pursual of a certain course of study. It means more than a preparation for the life that now is. It has to do with the whole being, and with the whole period of existence possible to man. It is the harmonious development of the physical, the mental, and the spiritual powers. It prepares the student for the joy of service in this world and for the higher joy of wider service in the world to come. (p. 13) 
Hand in hand with "wholistic" education is "wholistic" health. White (1977) also refers to the positive relationship between the development of the intellect and a healthy body.

Between the mind and the body there is a mysterious and wonderful relation They react upon each other. To keep the body in a healthy condition to develop its strength, that every part of the living machinery may act harmoniously, should be the first study of our life. To neglect the body is to neglect the mind. (p. 373)

To accomplish the "wholistic" mission of the Seventh-day Adventist Church, a very clear understanding of spirituality and spiritual care is needed. If the organizational climate in nursing programs affects the transmission of this important concept it is consequential that this be known.

\section{Conceptual Framework}

A common denominator of the different nursing theories is that "human beings comprise various dimensions and that each dimension is related to health and well-being" (Taylor, 2002, p. 38). Consequently, all nursing theories uphold multidimensional caregiving (Barnum, 1996) and must therefore address health issues in each one of the human dimensions. Among the nursing theorists who specifically emphasize the importance of the spiritual dimension and spiritual caregiving are Betty Neuman. Margaret Newman, and Jean Watson (Parker, 2001). Their theories are presented in chapter 2 .

Teaching the importance of the spiritual dimension and of spiritual caregiving to nursing students is a particular curricular concern of nursing programs that uphold a Christian worldview. Dillard and Laidig (1998) explain that several curricula occur concurrently: the official, the operational, the hidden, and the null. 
"The official curriculum includes the stated curriculum framework with philosophy, and mission, recognized lists of outcomes, competencies, and objectives for the program and individual courses, course outlines, and syllabi" (Dillard \& Laidig, 1998, p. 72). These official written documents give proof, to accrediting agencies and all others concerned, of what supposedly is being taught.

The operational curriculum, explain Dillard and Laidig (1998), consists of what teachers actually get across to the students which includes "knowledge, skills, and attitudes emphasized by faculty in the classroom and clinical settings" (p. 72). For example, the teachers' attitudes regarding spiritual care will be transmitted to the students by the importance they place on spirituality and spiritual caregiving

It is through the faculty's interaction with students, however, that the hidden curriculum is communicated (Dillard \& Laidig, 1998). Of all the types of curricula, it is the one that probably has the most lasting effect (Bevis \& Watson, 1989), and the one faculty may be the most unaware of. Teachers' interactions with students and with each other will define the perceptions of behavior of both faculty and students, and determine the permeating quality of the school environment referred to as school climate or organizational climate (Hoy \& Miskel, 2001). Via their expressions, priorities, and interaction with students, faculty may be transmitting attitudes about spirituality and spiritual caregiving that are making a greater impact than what is being taught through the official and operational curricula.

Finally, the mull curriculum consists of the content, attitudes, and behaviors that are not transmitted. By omission, nursing faculty could be teaching that spiritual care is not important. 
This study focused more on the transmission of the hidden curriculum and possibly the null curriculum. By assessing the members' perception of the overall organizational climate and selected climate factors and whether these relate to their perspectives of spiritual care, an initial appreciation can be obtained of the possible impact of the hidden curriculum.

\section{Researcher's Personal Worldview}

To provide a deeper epistemological meaning for the conceptualization of organizational climate and spirituai care in this study, I present my underlying worldview.

Long before the development of theories by humankind, God was governing the Universe in an organizational climate of perfect harmony. The structure was immaculate, the environment was flawless, and the relationship between the Creator and created beings as well as among the created beings was perfect (White, 1888, 1947) Inexplicably, a created being became dissatisfied with this perfect condition, producing disequilibrium in the relationship with his Creator. Until then no created being had felt the desire to question God's ruling. But now, the fundamental principle of God's government the very character of the supreme God-unconditional love-began to be doubted. The perfect climate that once existed in the Universe was now disturbed and a new, strange, evil element was introduced into the system-hatred. Thus began the great controversy between good and evil, love and hatred, God and Satan in which human beings now play a central part.

Human beings were created by God in His image (Gen 1:26 NIV), with the purpose of glorifying God (Isa 24:15 NIV), of producing good fruits (Matt 5:16; John 
15:8 NIV), and of fulfilling a specific purpose on this earth (Eph 4:11-15 NIV). A perfect balance and interconnectedness among the dimensions of humankind's being existed. All individuals' needs were provided for in a perfect environment. This wholeness remained intact until the direct relationship with the Creator was marred by humankind's distrust in God (Gen 3, NIV) consequently altering all the dimensions of the individual, causing imbalance and disintegration.

God desires to restore the perfect climate that once existed in the entire Universe as well as to restore complete wholeness in humankind. However, the principles of His government will not permit Him to do it forcibly; He allows each individual to choose whose side to be on. By means of the death of His Son on the cross, eternal life is accessible to all that desire. Furthermore, He reveals Himself to us through Jesus' example while on earth, by means of revelation and through nature. By the channel of prayer and the gift of the Holy Spirit, humans can receive strength to live a victorious life here on earth and progress towards the complete wholeness-restoration of the image of God in humankind, that will occur at Jesus' second coming to those who have chosen to trust in Him.

In accord with my personal worldview, Ellen White (1890) expressed the objective of education in the following manner:

The true object of education is to restore the image of God in the soul. In the beginning God created man in His own likeness. He endowed him with noble qualities. His mind was well balanced, and all the powers of his being were harmonious. But the Fall and its effects have perverted these gifts. Sin has marred and well-nigh obliterated the image of God in man. It was to restore this that the plan of salvation was devised and a life of probation was granted to man. To bring him back to the perfection in which he was first created is the great object of life-the object that underlies every other. It is the work of parents and teachers, in the education of the youth, to cooperate with the divine purpose; and in so doing they are "laborers together with God." (p. 595) 


\section{Significance and Importance of the Study}

Wholism and spiritual well-being are significant to the mission of the Seventh-day Adventist church. The message of health is a significant part of the third angel's message (Dysinger, 1997; White, 1938). The importance that the Seventh-day Adventist denomination places on health is in part manifested by the number of health related institutions it owns and operates around the world. In the $/ 38^{\prime \prime}$ Ammual Statisfical Report of the General Conference of Seventh-day Adventists (2000), a total of 174 hospitals and sanitariums, 393 clinics and dispensaries, 158 nursing homes and retirement centers, orphanages and children's homes were reported. Worldwide, there are 53 nursing schools and nursing departments run by the Seventh-day Adventist Church (King. Jones, \& Zhang, 2000), all of which uphold the importance of spiritual well-being

"Little is known about what contributes to nurses' spiritual care perspectives and practices" (Taylor, Highfield, Amenta, 1999, p. 30). Therefore, it is relevant to search for factors that may contribute to the spiritual care perspectives that students in Seventh-day Adventist baccalaureate nursing programs are acquiring and investigate the relationship between the students' perspectives of spiritual care and the environmental climate in which they prepare for their profession.

This research has generated data that are helpful in identifying school climate factors that are related to the nursing students' perspectives of spiritual care. Furthermore, the results of this study have helped identify differences in students' and faculty's perspectives of spiritual care and organizational climate factors. Special attention can be given to these climate factors by nursing service administrators and nursing educators 
who wish to establish an environment that will promote a more positive attitude toward spiritual care among students.

\section{Definitions of Terms}

Baccalaureate Nursing Program is a program of studies culminating in a bachelor's degree with a major in nursing.

Holistic Health Care is defined by Mosby's Medical, Nursing, \& Allied Health Dictionary (1998) as "a system of comprehensive or total patient care that considers the physical, emotional, social, economic, and spiritual needs of the person; his or her response to iliness: and the effect of the iliness on the ability to meet self-care needs" ( $p$. 4165).

"Holistic" is a word derived from the Greek work "holos," meaning whole, healthful, healing and holy. The definition of holistic nursing recognizes the sacredness of wholeness. The holistic paradigm views everything in the universe as connected to everything else. Every "thing" is separate and yet one at the same time. Everything is part of the larger whole. (Simpson, 1999, p. 16)

Vasquez (1993) differentiates the terms holistic and wholistic:

"Holistic" is the New Age spelling for "wholistic," which refers to the whole body-physical mental, and spiritual. While Christians also believe that human beings are a three-fold unity, and while Christians also believe in treating the whole person, they cannot adopt the underlying beliefs and philosophies of the New Age holistic medicine. On the surface some of these beliefs may seem to be similar to those held by Christians, but the underlying occult philosophies are still there, and are in fact, even more dangerous because of their clever disguise. ( $p$. 94).

Wholistic Health Care, in this study, refers to whole person care, care that will help restore the balance that was lost in all human dimensions when sin entered this world. In this context, spiritual care is central to "wholistic" care. Except when citing 
another author, the term "wholistic" will be used with reference to a Christian perspective of spirituality and spiritual care.

Spiritual Care is care that promotes spiritual health, a sense of meaningfulness, a sense of connectedness, or harmony with the self, others, and God (Taylor et al., 1999).

Spiritual Care Perspectives are the attitudes that an individual has toward spiritual caregiving.

Seventh-day Adventist is a Christian organization that holds two vital beliefs as a Church:

Adventist reflects the passionate conviction in the nearness of the soon return (advent) of Jesus. Seventh-day refers to the Biblical Sabbath which from Creation on has always been on the seventh day of the week, or Saturday.

The mission of the Seventh-day Adventist Church is to proclaim to all peoples the everlasting gospel in the context of the three angels' messages of Revelation 14:612, leading them to accept Jesus as personal Savior and to unite with His church, and nurturing them in preparation for His soon return. In harmony with the great prophecies of the Scriptures, we see as the climax of God's plan the restoration of all His creation to full harmony with His perfect will and righteousness.

We pursue this mission under the guidance of the Holy Spirit through: Preaching: Accepting Christ's commission (Matthew 28:18-20), we proclaim to all the world the message of a loving God, most fully revealed in His Son's reconciling ministry and atoning death. Recognizing the Bible to be God's infallible Revelation of His will, we present its full message, including the second advent of Christ and the continuing authority of His Ten Commandment law with its reminder of the seventh-day Sabbath.

Teaching: Acknowledging that development of mind and character is essential to God's redemptive plan, we promote the growth of a mature understanding of and relationship to God, His Word, and the created universe.

Healing: Affirming the biblical emphasis on the well-being of the whole person, we make the preservation of health and the healing of the sick a priority and through our ministry to the poor and oppressed, cooperate with the Creator in His compassionate work of restoration.

In harmony with the great prophecies of the Scriptures, we see as the climax of God's plan the restoration of all His creation to full harmony with His perfect will and righteousness. (Seventh-day Adventist Church, 2002, para. 1-4)

National League for Nursing is an accrediting body for all types of nursing education within the U.S. 
New Age refers to "a late 20th century social movement drawing on ancient concepts especially from Eastern and American Indian traditions and incorporating such themes as holism, concern for nature, spirituality, and metaphysics" (Merriam-Webster's Collegiate Dictionary, 2001)

Nursing Service Administrator is a person in an administrative or management position in charge of nursing care in a health care institution.

Nursing Educator in this study refers to any person involved in clinical or theoretical nursing instruction at any level from Assistant Instructor to Professor of Nursing.

Organizational Climate refers to the "perceptions that individuals have of various aspects of the environment in the organization" (Owens, 1998, p. 169).

School Climate refers to the internal characteristics of each particular school that influence the attitudes and behavior of each member (Hoy \& Miskel, 2001).

Organizational Climate of a Nursing Program is the set of internal environmental characteristics of a particular nursing program as perceived by its members (students and faculty) and which influence the behavior and attitudes of each member.

Upper Division Student refers to an individual enrolled in junior or senior college courses. 


\section{Methodological Assumptions}

Survey research is the most appropriate methodological design for this study Pinsonneault and Ktaemer (1993) explain that survey research is a suitable method to use when the phenomena of interest have to be studied in their natural setting and the study examines what is happening and how and why it is happening. Furthermore, when the variables have been clearly defined and the expected relationships-which are tested against observations of the phenomenon-are hypothesized, survey research is an appropriate method.

An experimental design for this study would not be suitable because control of the variables' organizational climate and spiritual care is inappropriate. However, a correlational, causal-comparative study that attempts to identify relationships where a comparison is made between two or more groups that are already formed and are already different on the independent variable is appropriate (Gay \& Airasian, 2000). In this study the grouping into faculty and students and into the different participating nursing programs is already formed and cannot be manipulated. The effect of the status of the respondent (faculty or student) and the nursing program on the perception of school climate and perspective of spiritual care can be explored by using a comparative design.

Whereas a qualitative study would add a deeper dimension, I wished to first establish through survey research that a relationship between the variables does exist, subsequently opening the way for conducting qualitative research to obtain a deeper understanding of the phenomena.

\section{Delimitations of the Study}

1. The schools invited to participate in this study were delimited to the 
Seventh-day Adventist baccalaureate nursing programs in North America that offer an NLN accredited program. The reason for this delimitation was to decrease as much as possible philosophical and curricular differences among the participating schools.

2. The nursing students delimited to participate in this study were upper division students enrolled in the 2001-2002 school year, in that students' exposure to the curricular content of the nursing program, to the organizational climate, and to patient care is limited prior to their junior year.

3. Although the preferred method for data collection would have been administration of the survey questionnaire myself, the distribution of the instrument was assigned to each participating program director.

\section{Limitations of the Study}

1. A limitation in this study was the self-selection bias because the decision to participate depended on the Director of each nursing program invited to participate and subsequently on the faculty and students of the participating programs who chose to respond to the survey questionnaire

2. A relatively low yet acceptable Cronbach's alpha coefficient of 0.75 on the subscale used for measuring the perspective of spiritual care was a limiting factor in this study

3. The need to adjust to the operational conditions of the participating nursing programs was a limiting factor. Rather than comply with my original plan for data collection, program directors requested different procedures for administering and collecting the answered questionnaires. These are discussed in chapter 3

4. The unavailability of other research studies that link the same two 
variables in this investigation (spiritual care and organizational climate) limits the possibility of comparing the results of this study to previous findings.

\section{Overview of the Chapters}

Chapter 1 is a brief introduction to the study of the relationship between perspectives of spiritual care and organizational climate in Seventh-day Adventist baccalaureate nursing programs. The background and statement of the problem, purpose of the study, research questions and hypotheses, rationale for the study, conceptual framework, significance and importance of the study, definitions of terms, methodological assumptions, and limitations and delimitations of the study are also included.

The review of the literature pertaining to organizational climate and spiritual care is presented in chapter 2 . Each construct is broadly defined and narrowed down to its significance to nursing. Various instruments to assess organizational climate are discussed. Health paradigms and nursing theories that support spiritual care are addressed. Research related to these constructs is presented.

Chapter 3 describes the methodology that was used in this descriptive, correlational, comparative study using a survey design. A description of the population and sample, the statement of the null hypotheses, an explanation of the instrumentation and research design, as well as the procedures for data collection, recording, and analysis, are presented.

Chapter 4 presents a description of the participants, a description of the characteristics of the variables, and the results of the statistical analysis performed to test the hypotheses. 
In chapter 5 a summary of the study and a discussion of the findings, as well as the conclusions, implications, and recommendations are presented. 


\section{CHAPTER 2}

\section{REVIEW OF THE LITERATURE}

\section{Introduction}

The review of the literature for this study, designed to explore the relationship between perspectives of spiritual care and organizational climate as well as compare perspectives of spiritual care and perception of organizational climate between different participant categories, focused on identifying, locating, and analyzing documents related to these two constructs. Databases searched included EBSCO, OCLC FirstSearch, ERIC, Medline, CINAHL, Dissertation Abstracts, and other electronic resources available through the James White Library at Andrews University. Documents not physically present at the James White Library were obtained through interlibrary loan.

The first part of the literature review addresses spiritual care by first looking at the broader concept, "wholism," of which the spiritual dimension is a vital part. The use and meaning of the terms "wholistic" and "holistic" are discussed. Spirituality from a Christian perspective is examined and differentiated from the New Age perspective. Nursing theories and models that support "wholism" and spiritual caregiving as well as implementation of spiritual care are discussed. Research studies that have been conducted on spiritual care and holistic care are presented.

The second part of this chapter addresses the concept of organizational climate. The evolution of the organizational climate concept, the growing interest of the impact of 
school climate on student learning, instruments used to assess climate, and research conducted in this field are discussed.

\section{Spiritual Care}

Spiritual care is an essential component of whole person care (Shelly \& Miller, 1999; Taylor, 2002; Thornton \& Gold, 2000). In her study on spiritual caregiving, Piles (1990) found that $96.5 \%$ of 176 nurses agreed that wholistic care includes spiritual care. An understanding of the broader concept- "wholism"-of which spirituality is central to (White, 1977), is important in this research study. This section of the literature review will begin by addressing the concept of "wholism."

\section{History and Evolution of the Concept of "Wholism"}

The roots of "wholism" go as far back as the beginning of the existence of humankind (Gen 1:26-27, NIV). Man and woman were created whole. There was a perfect balance and interconnectedness among the dimensions of their being. All their needs were provided for in a perfect environment (White, 1947). This wholeness remained intact until the direct relationship with their Creator was marred (Gen 3, NIV) consequently altering all the dimensions of their being, causing imbalance and disintegration. Since then, the quest for the restoration of wholeness has led men and women down endless, convoluted paths that promise what some refer to as "holism" and others, "wholism."

Although both terms wholistic (Jones, 2001: Piles, 1990; Schuster, 1997) and holistic (Alster, 1984; Bishop \& Scudder, 1997; Dossey, 1998; Estby \& Freel, 1994; Johnson, 1988; Laffrey \& Kulbok, 1999; Plawecki, 1996; Schubert, 1989; Simpson, 
1999; Smuts, 1926; Springett, 1989; Wright, 2000) can be found in the literature, there is an increasingly marked preference for the omission of the " $w$." On the surface, both may appear to have the same connotation being that both spellings derive from words meaning whole, entire, or complete. Merriam-Webster's Collegiate Dictionary (2001) states that "wholistic" is a variant of "holistic" and defines "wholisitc" as relating to holism or "relating to or concerned with wholes or with complete systems rather than with the analysis of, treatment of, or dissection into parts, holistic medicine attempts to treat both the mind and the body."

Although the dictionary does not distinguish between the two terms, and many nurses believe they can be used interchangeably, Schubert (1989) explains that there is a significant difference.

Nursing is often presented as having a "wholistic" approach since the person is viewed as a bio-psycho-social being with many dimensions. This view is based on von Bertalanffy's (1968) System Theory that the whole is greater and different than the sum of the parts. There is emphasis on the dynamic interaction of parts within the whole. "Holism," in contrast, reflects the view that "all is one," that the whole is manifested in each part and the parts throughout the whole. There is emphasis on interpenetrating processes of integration and organization within the whole, the whole encompassing the entire universe. (p. 10)

Vazquez (1996) signals a difference in preference: "New Agers prefer to use 'holistic' spelled without the ' $w$ ' whereas Christians traditionally have used the term 'wholistic' spelled with a ' $w$ ' ' (p. 5)

Although on the surface, the terms holism and wholism may appear to be synonymous, a deeper study of these two concepts reveals definite differences in the conceptualization and the underlying ideologies of the users. The concept of holism, generally traced to the Greek philosopher Plato, and believed to have been coined by Jan Smuts in 1926, like wholism, acknowledges the integrated, inseparable human 
dimensions of mind, spirit, and body (Robins, 1999). However, the term has a different connotation to those who hold a biblical worldview than to the originators and postmodern advocates of holism (Vasquez, 1996). Regardless of the underlying philosophy, humans seek the restoration of wholeness even through reductionism if they could (Robins, 1999). The choice of the word holistic or wholistic, holism or wholism itself, is not as significant to spiritual care and the restoration of wholeness as is each author's underlying worldview and conceptualization of spirituality.

Except when citing another author, the spelling wholistic and wholism. throughout this study, will be reserved for the Christian conceptualization of spirituality, while holistic and holism will be used when referring to the New Age conceptualization of spirituality.

\section{Conceptualization of Holism}

"The difficulty of finding a clear statement of the central ideas of holism in the literature is notorious, and there is a corresponding difficulty in evaluating them" (Phillips, 1976, p. 2). Much has been written about holism since this declaration (Alster, 1984; Bishop \& Scudder, 1997; Dossey, 1998; Estby \& Freel, 1994; Johnson, 1988; Laffrey \& Kulbok, 1999; Plawecki, 1996; Reed, 1998; Schuber,, 1989; Simpson, 1999; Springett, 1989; Wright, 2000). However, a clear conceptual understanding of the term still awaits disclosure and added to the confusion is the lack of clarity in distinguishing between the terms wholistic and holistic.

Estby and Freel (1994) point out that Bertalanffy's General System Theory and what Phillips (1976) terms "Holism I" share the following fundamental tenets: "(1) The whole is more than the sum of its parts; (2) the whole determines the nature of its parts; 
(3) the parts cannot be understood if considered in isolation from the whole; (4) the parts are dynamica!ly interrelated or interdependent" (p. 6). Where Schubert (1989) uses von Bertalanffy's System Theory to differentiate wholistic from holism, Estby and Freel use the same theory for describing the basic tenets that it shares with holism.

The concept of wholeness as defined by Smuts (1926, p. 317), the "ultimate, synthetic, ordering, organizing, regulative activity in the universe which accounts for all the structural groupings and synthesis in it," is becoming increasingly prevalent at all levels of organization. This concept provides the organizing principle that moves from the smallest cell to the evolving universal whole. Under this conceptualization, the environment, seen as a whole, has a reality independent of and greater than the sum of its parts (Dossey, Keegan, Guzzetta, \& Kolkmeier, 1995). This is consistent with the holistic view of nursing (Laffrey \& Kulbok, 1999) where the focus is the perfection of the whole person and the whole environment. Selanders (1998) poses that the role of the nurse in this case is to alter the environment in such a way as to achieve perfection of the whole. Ideas of the oneness of body, mind, spirit, and environment however, have not always been prevalent. As worldviews evolve, as philosophers come and go, human thought has run from one extreme of the dualism-holism continuum to the other and back again. Ideas have varied all the way from Plato's thoughts regarding the connection between soul and body, to Descartes who heralded in the holistic Dark Ages by introducing Cartesian dualism, and back to the New Age advocating the interconnectedness of body, mind, and spirit (Alster, 1984). This diversity has made the study of holism challenging as Phillips (1976) pointed out:

There is an enormous body of literature on holism, but a student . . is unlikely to encounter it in any ordered way. He is almost certain to meet at least a few 
holistic theses, and probably some of the arguments against them; but he is likely to remain ignorant of the full scope of holism. He may not realize that debates over methodological individualism or the place of psychological explanations in sociology are related to those over system theory, over oganicism in biology and psychology, over internal relations in philosophy. And he can easily become confused: the difficulty of finding clear statement of the central ideas of holism in the literature is notorious, and there is a corresponding difficulty in evaluating them. (pp. 1-2)

In his book Holism and Evolution, Smuts (1926) attempted to show that holism "is the principle which makes for the origin and progress of wholes in the universe" and that "evolution is nothing but the gradual development and stratification of progressive series of wholes, stretching from the inorganic beginnings to the highest levels of spiritual creation" (p. v). Contrary to the reductionistic thought prevalent at the beginning of the $20^{\text {th }}$ century, Smuts believed that the whole was more than the sum of its parts and that the parts of a system were dynamically interrelated and interdependent.

For Smuts, holism was a basic concept of life and the core of his philosophy (Lean,

1964). He saw in holism the key to the confusion in science, philosophy, and religion. In the biography of his father, Smut's son (1952) writes that "holism will stand out as a message of perfection, building up and leading to still greater perfection, of fragments leading to wholes which are superior to the mere sum total of their constituent parts" (p. 287)

If holism leads to greater perfection, who or what determines the measure of this perfection? Where does the "whole" begin and/or end. The answers to these questions will depend on one's underlying worldview (Martsolf \& Mickley, 1998; Patterson, 1998).

During a time in history when Darwin's theory of evolution and Einstein's theory of relativity were causing a complete revolution in worldviews, Smuts was attempting to harmonize these innovative ideas with his holistic belief that everything in nature works 
toward synthesizing and organizing to greater wholes (Johnson, 1988). Trying to reconcile mechanical evolution with creative evolution without troubling himself over the issue of materialism versus spiritualism Smuts (1926) wrote the following concerning the transformation in the conceptualization of matter:

The matter which holds the secret of life and mind is no longer the old matter which was merely the vehicle of motion and energy. . . The point to grasp and hold on to firmly is that the fuli and complete acceptance of Evolution must produce a great change in the significance of the fundamental concepts for us. Life and mind now, instead of being extraneous elements in the physical universe, become identified with the physical order, and they are all recognized as very much of a piece. ... If evolution is right, if life and mind have arisen in and from matter then the universe ceases to be a purely physical mechanism, and the system which results must provide a real place for the factors of life and mind. (pp. 1011)

With Darwin taking God entirely out of the picture as Creator and Maintainer of

life, and consequently of health, the emerging concept of holism could hardly be expected to be connected with moral accountability to a higher being and even less to the restoration of the image of God in human beings.

Thus, the concept of "holism" has evolved and continues evolving, making its impact on the concept of "holistic health care" and consequently on the conceptualization of spirituality and spiritual caregiving.

\section{Evolution of Holistic Health Care}

"The widespread interest in holistic health is a recent development in the United States and elsewhere, but the central philosophy is as old as medicine itself" (Pelletier, 1990, p. xiv). Holistic ideas of health care can be identified throughout the history of modern nursing. Florence Nightingale, considered the originator and guardian of modern nursing, advocated tending to the psychological and spiritual needs of patients (Dossey \& 
Dossey, 1998) and set her imprint on the holistic vision of nursing (LeVasseur, 1998).

"For Nightingale, spirituality is intrinsic to human nature and is our deepest and most potent resource for healing" (Macrae, 1995, p. 8).

Nightingale's holistic legacy to nursing has not remained dormant. After reviewing definitions of spirituality in nursing literature from 1970 to the present, Taylor (2002) concludes that the concept is very much alive and summarizes by stating, "Spirituality is an innate, universal aspect of being human. Everyone has a spiritual dimension. This dimension integrates, motivates, energizes, and influences every aspect of a person's life" (pp. 4-5)

The renewed interest in spiritual care as part of holistic health at the turn of the millennium is made notorious by the creation and growth of organizations committed to the diffusion of the holistic paradigm in nursing and the increase in literature related to holism (Johnson, 1988). As the concept diffuses, the meaning of holism along with spiritual caregiving acquires greater importance in the field of nursing. Johnson points out that the evolution of this concept has accompanied the evolution of the prominent philosophical ideologies as well as beliefs and values underlying the delivery of health care services. Postmodern "society is demanding a more equitable, humanistic, accountable, flexible, wellness oriented approach that will allow for individual responsibility and growth within the context of the whole person" (Johnson, 1988, p. 6) This growing acceptance of a holistic health care approach that differs from the traditional health care model is reflected in the six aspects of holistic health identified by the Berkely Holistic Health Center, which are based on the General System Theory and holism tenets (Estby \& Freel, 1994): 
(a) healtin is an expression of the individual functioning as an integrated whole; (b) the spiritual dimension is integrated to the personal expression of health and disease; (c) wellness focuses on optimal health and not on the absence of disease; (d) each person is a natural healing system and this system has a remarkable capacity for self-healing; (e) the individual is a responsible participant in both health and illness rather than merely a passive victim in the development of disease; and ( $f$ ) an interdisciplinary approach to health care includes exploration of ancient and alternative systems of healing as well as the modern allopathic approach. (pp. 406-407)

Holistic health care has been equated with "alternative" medicine, a concept that can no longer be considered faddish, which has penetrated the realm of spirituality, and requires the attention of all those concerned with spiritual caregiving. To such an extent is the acceptance of alternative therapies that in 1992 the National Institute of Health established the Office of Alternative Medicine for the purpose of conducting research on holistic medicine in an attempt to son "fact from fiction" (Dossey, 1998; Pelletier, 2000). In 1998 this office was upgraded to a national center to evaluate the effectiveness of alternative therapies related to nutrition, lifestyle changes, mind-body interventions, alternative healing systems, bioelectromagnetic applications in medicine, manual healing methods, pharmacological and biological treatments, and herbal medicine (Pelletier, 2000). Pelletier mentions that there are currently more than 600 specific alternative medicine therapies that are under scrutiny, but that the mind-body therapies are the ones that have received the greatest attention, have been researched the most, and thus have obtained the widest acceptance within the traditional health care system

The disenchantment with conventional Western Medicine has led to a mesmerizing attraction toward exotic and occult Eastern modes of treatment that delve into mind-altering methods. "America's loss of faith in the medical establishment gave a strong symbolic push to the paradigm shift from institutional help to self-help" Naisbitt 
\& Naisbitt, 1990, p. 133). New Age holistic medicine has been heralded in with great enthusiasm under the banner of self-healing, covering a gamut of alternative healing therapies (Vasquez, 1993). Alternative holisitc therapies such as meditation, imagery, acupuncture, acupressure, electropressure, applied k'nesiology, aromatherapy, auriculotherapy, aura readings, ayurvedic medicine, biofeedback, chakra balancing, homeopathy, hypnosis, macrobiotic diet, pendulum divination, reflexology, rolfing, Shiatsu, yoga, Reiki, biofeedback, crystals, magnets, herbs, therapeutic touch, and iridology are some of the treatment modalities that have become widely accepted (Vasquez, 1996). Some of these therapies even have scientific backing, claiming a certain degree of effectiveness in treating diverse disorders (Moylan, 2000; Pelletier, 2000).

In her critical analysis of the holistic health movement, Alster (1984) questioned whether the enthusiasm about the movement was a faddish outgrowth of the counterculture that would not last the decade. This movement obviously has outlasted the $80 \mathrm{~s}$, the $90 \mathrm{~s}$, and continued into the new millennium with more fervor than ever, influencing people's attitudes, behavior, and expectations regarding the health care delivery system. The frenetic search for the missing piece to wholeness seems to be the driving force. Awareness of the need to integrate the long neglected spiritual dimension into the whole picture is increasing. But how can one find the missing piece unless one knows what the "whole" is supposed to look like? How can one integrate the spiritual dimension if one is not clear as to whether the missing piece is Christian spirituality or "a psychic self-awareness, higher self, the god within us" (Vasquez, 1996, p. 28) that is 
missing? Alster (1984) describes the fruitless effort of holists to achieve the perfect wholeness.

The holists propose that by seeking and applying the universal rules relating to wholeness, humans can become more nearly perfect. Like any overarching system, this one fails to explain everything. Ambiguity and randomness remain. When their appearance is not tolerated, the odd event is jammed into the holistic scheme like a size 8 foot into a size 7 shoe. Holists illuminate the faults in their own system when they pit it against the disorderly universe, insisting that it cohere. (p. 49)

Sadly the diversity present in the conceptualization of the "whole person"-the essential nature of the human being-has produced distortion and confusion as to the meaning of "holism" and distance from the original meaning of "wholism" as designed by the Creator of humankind. As the concept of holistic health care becomes widespread, and a greater number of aiternative therapies become popular, more discrepancies are bound to arise especially in what pertains to spirituality and spiritual caregiving.

\section{Seventh-day Adventist Concept of "Wholistic" Health}

The meaning of "wholistic health" in the message and mission of the Seventh-day Adventist Church varies greatly from the "holistic health" concepts based upon New Age or Eastern religious philosophies (Vazquez, 1996) and even from the health concepts of other Christian denominations (Jacobs, 1993). In his brief look at Adventist doctrines related to health in the light of doctrines of other faith traditions, Jacobs points out that of the 27 fundamental doctrines of the Adventist Church, 17 contribute to the development of a gospel or message of health. Ten of these-(1) the nature of man, (2) the great controversy, (3) the remnant and its mission, (4) the gift of prophecy, (5) the law of God, (6) the Sabbath, (7) Christian behavior, (8) Christ's ministry in the heavenly sanctuary, 
(9) the Second coming of Christ, (10) and humankind's death and resurrection, the viewpoint held by Adventists-differ significantly from other Protestant churches. The other seven fundamental beliefs which contribute to the gospel of health-(11) the Word of God, (12) creation, (13) the life, death, and resurrection of Christ, (14) the experience of salvation, (15) the church, (16) spiritual gifts and ministries, and (17) stewardshipare questioned and even rejected by many other denominations. Therefore, because of its biblical worldview and unique concept of health, the Seventh-day Adventist Church's interpretation of wholistic care practically stands alone.

The Seventh-day Adventist Church also differs from other ideologies in regard to the relationship between mind and body. God, being creator and owner of the whole person-body, mind and spirit-lends us life so we can serve Him and reach the highest degree of excellence (White, 1977), which is only possible by being connected to the Divine Source (John 15, NIV). This contrasts with postmodernism's emphasis on selfactualization through the person's own efforts to achieve oneness with the inner self (Springett, 1989), which is believed to be intrinsically good or neutral rather than bad (Maslow, 1968). Humanistic psychology has influenced the present-day concept of holism. Alster (1984) suggests that humanistic psychologists such as Maslow and Rogers have "provided the theoretical framework for much of the holistic health movement" (p. 35).

Whether based on humanistic psychology or on a biblical worldview, spirituality is considered an important aspect of holism (Johnson, 1988) thus holistic nursing care must address the spiritual dimension. The idea of treating all of the dimensions of the being to achieve total health is shared by Christians as well as holists. However, there is 
a dramatic difference in each's conception of the spiritual component. Spirit, to the holists, is "an immoral, mystical 'spirit' or 'soul' associated with out-of-the-body experiences and reincarnation" (Vasquez, 1996, p. 37). Spirituality based on a biblical worldview involves an intimate, growing relationship with the Creator (Carney \& Long, 1997, Johnson \& Dreitcer, 2001; Schaeffer, 1971)

In his doctoral dissertation, "New Age Holistic Health: Implications for Seventhday Adventist Faith and Practice," Manuel Vasquez (1996) outlines the differences between Seventh-day Adventist wholistic health philosophy and the New Age holistic health philosophy:

1. The Adventist philosophy is undergirded and supported by a biblical theistic worldview, in which God is the only sovereign Creator and Sustainer of the universe and everything in it. In New Age holistic health, there is a blending of nonbiblical worldviews, such as monism, pantheism, animism, etc.

2. The ultimate aim of Seventh-day Adventist wholistic health philosophy is to make man whole, that is, to restore him to the image of his Creator. The goal of New Age holistic philosophy is to transform man to a new paradigm of seeing himself as a demi-god and as a body-mind self-healer.

3. Seventh-day Adventist wholistic health philosophy teaches that humanity should depend on God for life and healing, whereas New Age holistic health teaches a dependence on mystical energies and self. (pp. 31-32)

A few decades before Smuts coined the term "holistic," Ellen White (18271915), a contemporary of Florence Nightingale (1820-1910), had much to say about "wholistic development" and the restoration of God's image in humankind. A prolific writer in many areas, Ellen White is considered the most translated American author, and the third most translated author in history (Douglass, 1998).

Being a creationist, with a biblical worldview, White (1905) believed that God endows human beings with a certain amount of vital energy and then makes them responsible for maintaining this energy by following the natural laws of health 
established by God at creation. With amazing simplicity, White $(1905,1912,1938)$ wrote of the principles of health that lead to optimum health or wholeness. In her books Ministry of Healing, Medical Ministry, Counsels on Diets and Foods, and other publications, she identifies the following eight principles of health: (1) nutrition, (2) exercise, (3) internal and external use of water, (4) sunlight, (5) temperance, (6) fresh air, (7) rest, and (8) trust in God. She recognized the interrelationship between the dimensions of the human being, giving the spiritual dimension an important role as seen in the eighth principle.

Of the relationship between spirituality and health, White (1977) wrote: "Health of body depends largely upon health of soul" (p. 27) and described how a relationship with God, the Creator, brings healing to the soul:

Pure and undefiled religion is not a sentiment, but the doing of works of mercy and love. This religion is necessary to health and happiness. It enters the polluted soul temple and with a scourge drives out the sinful intruders. Taking the throne, it consecrates all by its presence, illuminating the hear with the bright beams of the Sun of righteousness. It opens the windows of the soul heavenward, letting in the sunshine of God's love. With it comes serenity and composure. Physical, mental, and moral strength increase, because the atmosphere of heaven as a living, active agency fills the soul. (p. 27)

For Ellen White the spiritual dimension played a central role in "wholistic"

health. She advocated that health care professionals were guardians of both physical and moral health and that they should teach and encourage clients to obey the laws of nature which she regarded as natural remedies for healing (White, 1905).

Like White, Florence Nightingale also referred to the laws of nature as being the laws of health and believed that suffering was not solely the cause of disease but of the lack of an appropriate environment that included fresh air, light, warmth, quiet, cleanliness, and a proper diet (Dunphy, 2001: Schubert, 1989). Nightingale argued that it 
is humankind's responsibility to discover these laws as part of an evolutionary process and apply them for health and wholeness (Dunphy, 2001). She referred to these "laws or organizing principles of the universe as the "Thoughts of God"' (Macrae, 1995, p. 9) and regarded obedience to these as an even greater spiritual act than praying. In Notes on Nursing (1860/1969), Nightingale underscored each individual's responsibility: "God lays down certain physical laws. Upon his carrying out such laws depends our responsibility (that much abused word)... Yet we seem to be continually expecting that He will work a miracle-i.e. break his own laws expressly to relieve us of responsibility" (p. 25).

While Nightingale can be considered to have been highly spiritual, a searcher of religious truth, and a devout believer in God (Dunphy, 2001), her concept of God differed significantly from Ellen White's. Nightingale believed that "the universe is the embodiment or incarnation of a transcendent God" (Macrae, 1995, p. 9). Based on this belief, Nightingale would have preferred to replace the word "God," which to her suggests irreverent association, with the term "Universal Spirit of Right," which she believed can be found within each individual (Macrae, 1995). Several authors cite Nightingale as being a mystic (Dossey, 1998; Dunphy, 2001; Macrae, 1995).

Both concepts, "wholism" and "holism," with the diverse underlying worldviews of their originators and propagators, have affected the creation and evolution of health paradigms and nursing theories as well as the meaning of spirituality and the perspectives of spiritual care of health care recipients and providers 


\section{Health Paradigms and Nursing Theories}

The concept of wholeness, as mentioned previously, originated with God, the Creator of humankind (Gen 2:7 NIV). Health paradigms and nursing theories, however, are human inventions. A metaparadigm is considered the most abstract level of knowledge and provides the foundation for developing models and theories (Parker, 2001). A theory, in turn, is a mental pattern of "constructs created to help understand and find meaning from our experience, organize and articulate our knowing, and ask questions leading to new insights" (Parker, 2001, p. 4).

The word paradigm, similar to worldview (Sire, 1997; Walsh \& Middleton, 1984), is commonly used to signify the way we perceive, understand, and interpret our world. Our lives are controlled by our own mental model of the world (Sire, 1990). Covey (1990) uses the metaphor of a map as a simple way to understand paradignıs. A map is a diagram that can help us reach a certain destination. Similarly, a paradigm is a mind-set or mental map that helps us interpret everything we experience. A health paradigm, therefore, can be viewed as a mental map of how we expect to achieve and maintain health. Our way of thinking about health and illness, our values and beliefs regarding well-being, how we interpret the experiences associated with health and disease, and the choices we make that affect our health will all be influenced by our health paradigm. Covey points out that if we have the correct map we are more likely to reach our desired destination. Likewise, if we have the right health paradigm, our probabilities of achieving "wholism" are greater.

Health paradigms are at the foundation of nursing theories, and nursing theories in turn will affect the health paradigms of health care professionals (Parker, 2001) and 
consequently health care consumers. So the cycle of health paradigm-nursing theories continues as humans attempt to create theories that will restore wholeness.

\section{Paradigm Shifts}

Health paradigms come and go and will keep on shifting as long as health problems remain unsolved and the destination to complete wholeness is not reached. "As professions evolve, paradigms change, or in some cases shift abruptly to provide whole new ways for professionals to look at their world. A paradigm shift is a distinctly new way of looking at old problems" (Johnson, 1988, p. 1). New paradigms arise to address existing anomalies under the old paradigm and gain acceptance and popularity when they demonstrate a superior ability for problem solving than the ruling paradigm (Cody, 2000).

The conventional Western health care model with its focus on treating symptoms and disease has obviously not been a successful means of achieving health for all by the beginning of the new millennium. Conventional medicine has been good at crisis intervention but unsuccessful in prevention and maintenance (Wallis, 1991). This has opened the doors for the wholistic health model, which focuses on lifestyle changes to prevent illness rather than on the treatment to heal disease.

Not being static or universally accepted, health paradigms and nursing theories are under continuous scrutiny. In an age when each individual constructs his or her own value system and iruths, and the ultimate value and only absolute truth is tolerance (McDowell \& Hostetler, 1998), it is not easy to identify what criteria should be used for evaluating health paradigms and nursing theories. Whose worldview will be an adequate filter for analyzing and evaluating a human-made theory? 
It is specious to disparage theories as flawed, value-laden, presumptuous, and as presenting static narratives about people's lives. Theories, research measures, and people for that matter, are all value-laden and merely propose patterns of phenomena that are destined to be viewed differently over time. (Reed, 1998, p. 418)

Consequently, it is understandable why health professionals and specifically nursing theorists with such diverse worldviews have distinct ideas regarding holism, "wholistic" care, and spirituality.

\section{Holistic Paradigm in Nursing}

Most nurse theorists agree that individuals are holistic beings and advocate a holistic approach to nursing care (Parker, 2001). However, there is a discrepancy among them as to the meaning of holism and whether or not the concept includes spirituality (Hancock, 2000) and components of larger systems than the human body itself (Narayanasamy, 1999). Patterson (1998) posits holism is a very individualistic concept that depends on each person's view of reality and belief of where the "whole" begins and/or ends.

Nursing literature reveals that the beliefs and activities associated with the term holistic vary all the way from a traditional humanistic Western approach to health care, to alternative therapies such as acupressure, herbal teas, and yoga (Sarkis \& Skoner, 1987). How did two different ideologies like traditional Western health care and alternative therapies rooted in ancient Eastern philosophies become associated with the holistic paradigm in nursing? Sarkis and Skoner suggest this happened when "the issues and attitudes of the time were woven into the fabric of emerging nursing models" (p. 67).

Thomton and Gold (2000) do just that as they interweave old and emerging science into their interdisciplinary model of whole-person caring. Related concepts in 
their model include environment, health, whole-person caring, and spirituality. The key concept in their model, however, is the sacredness of being. People, they believe, are essentially spiritual, and spirituality is the process that integrates all other facets of life.

Meaning of holistic nursing

In their effort to provide greater insight into the holistic approach to nursing, Bishop and Scudder (1997) explain that the word meaning has at least two connotations. One use of the word is to seek the definition or significance of something as when we ask what a certain word means. Another use is to seek to know the worth of something as when we ask if life has meaning. This second use gives the term a spiritual connotation.

A holistic approach to nursing combines the two senses of meaning - the meaning of being a nurse in the everyday sense of meaning and the spiritual meaning that concerns the worth and significance of being a nurse. In holistic care, care for the patients and the worth of that care become one. (p. 106)

Principles of holistic nursing

Do expert holistic health nurse practitioners have consensus regarding the principles of holistic health? Which holistic health princıples do expert holistic health nurse practitioners believe provide guidance in healing interventions? What do expert holistic health nurse practitioners identify as care goals originating from identified principles of holistic heaith? These were the questions addressed by Estby and Freel (1994) in their survey study using three Delphi rounds. The expert respondents in this study consisted of 14 experienced holistic health nurse practitioners who use a wide range of healing techniques and modalities in their practices. The group consensus indicator used was the Fehring ratio (FR). During the first two rounds, all items with an FR $>.50$ were advanced to the next level. The 17 principles that received an FR of at 
least .80 on the first and third research questions and were accepted as basic principles of holistic nursing practice are the following:

1. Human beings are energy fields.

2. There is unity and interdependence within the mind, body, and spirit.

3. Health involves a sense of unity (connectedness or oneness) with the self and cosmos.

4. Health is a process which may include disease.

5. Health is the dynamic evolution (continuous process of emergence) toward balanced integration.

6. Healing, when viewed holistically, is not predictable in terms of time frame, cause, or outcome.

7. Energy fields are constantly interacting.

8. The Source is experienced or known through joy, beauty, love, light, peace, power, and life.

9. Changes in health can occur though experiential learning.

10. Spiritual health is necessary for physical, mental and emotional well-being.

11. The human spirit is the core of the person.

12. Energy fields can become unbalanced as a response to stress in any one of the three domains of body, mind and spirit.

13. Healing involves a transformational (second order) change that encompasses the whole person; it requires the involvement of the spiritual, emotional, and intellectual domains as well as the physical body.

14. Wellness encompasses increasing openness (acceptance of diversity) and increasing harmony (coherent, high frequency energy fields).

15. The client-practitioner relationship is one of equal partnership with differing responsibilities.

16. One's health and disease are manifested in one's lifestyle, habits, and conscious awareness as well as the body's physical being and energy.

17. Each health system should be respected for the resources and the tools that it offers while being challenged to prove its credibility. (pp. 402-412)

Based on their research findings, Estby and Freel (1994) conclude that "in

addition to reaffirming principles related to unity, irterdependence, evolution, and

energy, the AHNA nurse practitioner experts added a strong emphasis to the spiritual

dimension of the client and holistic practice" (p. 412).

However, as discussed previously, much diversity exists regarding the meaning of spirituality and consequently how to care for the spiritual dimension, especially between 
those holding a biblical worldview and those accepting New Age ideologies based on Eastern philosophies.

Holistic model versus traditional model

In contrast with the traditional health care model, the holistic paradigm in nursing focuses "on health rather than disease, on wholeness rather than fragments" explains Johnson (1988, p. 52). To answer her research question, "What are the concepts and activities that represent the holistic paradigm in nursing?" Johnson asked 40 nurses who belonged to the American Holistic Nursing Association or the Nurse Healers Professional Associates to identify out of a list of 153 words which ones represented the holistic paradigm in nursing the most. The top 10 selected with the corresponding percentage of respondents were the following: (1) therapeutic touch, $71 \%$; (2) healing/healer, $62 \%$; (3) self care, 57\%; (4) energy, 57\%; (5) touch, 52\%; (6) massage, 52\%; (7) imagery, $52 \%$; (8) wholeness, $48 \%$; (9) wellness, $48 \%$; and (10) spirituality, $48 \%$.

Johnson (1988) outlines the major differences between the traditional scientific medical paradigm and the holistic paradigm of health in regard to (1) context, beliefs, and values, (2) client role, (3) health care professional role, and (4) professional activities. Where disease was perceived as a "thing" in the traditional approach, it is seen as a "process" in the holistic model. Prevention traditionally consisted of vitamins, rest, exercise, immunizations, and not smoking. Holistically speaking, it consists of balance in work, relationships, goals, body-mind-spirit integration, as well as diet, exercise, and other health habits. In the traditional model the client was dependent, mind and body were considered separate, and mind was a secondary factor in illness. In the holistic model, the client is autonomous and responsible for his or her own care; mind, body, and 
spirit are interconnected; and the mind is a coequal factor in all illness. Health care professionals in the traditional model had an authoritative role whereas in the holistic model their role is of a therapeutic partner

\section{Critical-Holistic model}

As an alternative paradigm to the health-disease continuum and the patient-obeyphysician paradigm, which assigns an inadequately passive role to the health care client, Wright (2000) presents a critical-holistic model. Instead of encouraging dependence upon the health care giver or system, this model works toward increasing people's level of awareness regarding their problems and the societal cause as well as the remedies available. Depicting the interaction between three constructs-human being, society, and environment - and the need for integration and balance among these, the model portrays three overlapping circles that represent each of these concepts respectively. Development is placed at the center, where the three circles overlap, demonstrating the interconnectedness necessary for holistic development to occur. Wright explains that, "in the critical-holistic paradigm, health promotion is the process of conscientization of the individual and community through formal and liberating education. The individual must transform him- or her-self before the community and society can be transformed" ( $p$. 812)

\section{Spiritual Caregiving}

Although the history of nursing reveals its strong spiritual roots (Narayanasamy \& Owens, 2001), "the link between these two elements had become less obvious when modern medicine began to make its impact on health care at the turn of the $19^{\text {th }}$ century" 
(p. 447). Over the last 20 years, however, the renewed interest in spirituality and spiritual caregiving has been notorious (Narayanasamy, 1999). Spirituality is now becoming a visible factor in health care (Levin, 2001).

\section{Meaning of Spirituality}

The ontological significance of life as referred to by Frankl (1963), the cherished beliefs and values, the experience and appreciation of a dimension beyond the self, the relationships with self, others, and a higher power, and the sense of who one is and how one knows are aspects associated with spirituality found in nursing literature (Martsolf \& Mickley, 1998). The terms transcendence, connectedness (Hungelmann, Kenkel-Rossi, Klassen, \& Stollenwerk, 1996; Jones, 2001; O’Neill \& Kenny, 1998) and empowerment (Jones \& Meleis, 1993) are associated with the increasing interest in the spiritual dimension as a component of wholeness.

In spite of the growing acceptance that spirituality is important to holistic care, Martsolf and Mickley (1998) state there is uncertainty as to exactly what aspects of human nature may be considered spiritual. Hancock's (2000) review of the literature on the subject revealed no single definition of spirituality. Narayanasamy and Owens's (2001) critical incident study of nurses' responses to the spiritual needs of their patients also revealed confusion over the concept of spirituality and spiritual caregiving. There is consensus among both nursing and non-nursing authors that the contemporary understanding of spirituality is not equated to religion or religiosity, although it may be related to it (Carroll, 2001; Fitzgerald, 1999: Kendrick \& Robinson, 2000; Taylor, 2002). Attempts to define and clarify the concept of spirituality are found in nursing literature. Stoll's definition of spirituality as cited by Taylor (2002) emphasizes 
relationship with God and with others. "Spirituality ... reflects and fleshes out the supreme experiences of one's relationship with God through one's beliefs, values, lifestyle, quality of life, and interactions with self, others, and nature" (p. 5). Taylor believes the spiritual dimension has a powerful influence on every aspect of life and that all humans, because they possess a spiritual dimension, will express their spirituality to nurses, who in turn need to know how to respond.

Like Taylor, Carroll (2001) places spirituality as a central element in "wholistic" care and explains that this dimension is not isolated from other aspects of care:

While spirituality cannot be separated from religion, it is not synonymous with religion. Spirituality infiltrates all aspects of what it means to be human; it is part of the whoie

This view of spirituality makes it impossible to separate spirituality from the pychosocial and physical aspects of being-in-the-world-with-others. This means that every problem we humans encounter is fundamentally spiritual, or at least has a spiritual component. Each and every one of us. whether nurse, doctor or patient, will interpret spirituality according to our own culture, beliefs, experiences and social background. . . . The ability to recognize spiritual needs is an important aspect of holistic nursing care. (pp. 89-90)

Just as spirituality infiltrates all aspects of a person's Being, spiritual care infiltrates all aspects of nursing care. (p. 94)

Narayanasamy (1999) conducted a literature review of spirituality in

nursing and found that it usually was associated with a holistic approach and grounded in the Christian theological tradition. She suggests, however, that spirituality has evolved because it has biological value and believes the spiritual dimension is rooted in the biological makeup of humankind rather than the psychosocial dimension

Piles (1990) argues that nurses must differentiate between the psychosocial and spiritual dimensions, and understand that spirituality is that part of the person that seeks 
for a higher power outside of oneself that controls and sustains one through the good times, but especially through periods of need and crisis.

\section{Christian spirituality}

"Christian spirituality is the theory and practice of Christian living, believed to be under the inspiration of the Holy Spirit" (McGrath, 1993, p. 627). For the Christian nurse with a biblical worldview, an understanding of spirituality as the relationship with God through Jesus Christ is vital (Shelly \& Miller, 1999). Modern spirituality, even among Christians, believe Carney and Long (1997), has mostly focused on the development of the "inner life." Carney and Long do not deny that the "inner life" is an important part of spirituality, however, they contend that the development of the "outer life" of faith and the life in society is a part of spirituality that has been neglected.

Sadly, spirituality has been misunderstood and misused by many Christians who in their frantic search for something they cannot name "have gone shopping for their own brand of spirituality in the Pentecostal and New Age marketplaces" (Johnson \& Dreitcer, 2001, p. vii). What they are really looking for, claims Peterson (1994), is a "recovery of what was lost in the Fall" (p. ix). By "fall" Peterson is referring to the entrance of sin into this world.

Living the Christian life and knowledge of the true God are both essential elements in Christian spirituality, and neglect of the latter, explains Bloesch (1992), can lead to New Age mentality with its counterfeit spirituality. The Bible as God's expression of His will to humankind is the Christian's primary or supreme source of understanding (Erickson, 1985). The record of faithful people's spiritual experiences in 
the Bible offers the paradigm for Christian spirituality based on an encounter with God (Johnson \& Dreitcer, 2001).

Jesus himself stated, "I am the way and the truth and the life. No one comes to the Father except through me" (John 14:6 NIV). Schaeffer (1971) explains that just like all humans, whether rich or poor, sophisticated or simple, come into the physical world the same way, all must enter the spiritual realm the same way-by accepting Christ as their savior. The new birth (John $3: 1-8 \mathrm{NIV}$ ) is the door to spiritual birth, but it is only the beginning of spiritual life. After physical birth there must be growth and development in order to stay alive and have physical health. This is also true after spiritual birth. True spirituality, continues Schaeffer, involves a desire for a deeper life, a positive inward reality that has positive outward results, and experiential freedom from the bonds of sin.

Spiritual growth, explain Johnson and Dreitcer (2001), is a five dimensional journey that involves: (1) naming the desire, (2) naming God, (3) naming the relationship with God, (4) waiting, and (5) receiving.

The spiritual life begins with desire-a desire for God and for the expression of God in our lives and the world in forms like compassion, healing, justice. understanding, and love. Our desire for God flows from God's desire for us. At first the experience of the desire may be a vague feeling that all is not right. Or it may be misplaced desire-a hunger for material things, for instance, that fail to satisfy us. But if we notice the awakening of our desire and pay attention to it, the path into the Divine Mystery will begin to open before us. Yes, God knows our deepest longings, but God also wants us to know them. And God wants us to be specific about our desire. Only then can we make progress on our spiritual journey. (p. 89)

After identifying our deepest longing, we begin to realize that God is the answer to this core desire, and thus the second dimension of the spiritual journey emergesnaming God. In this dimension, glimpses of the nature of God are obtained through seeing how He satisfies our most pressing need, explain Johnson and Dreitcer. If we are 
in the need of guidance we might name God Wonderful Counselor. If in the need of comfor and security, God is our Shepherd.

As this need is satisfied by God's presence in our life, we are ready to move into the third dimension-naming our relationship with God. We begin to realize that God is greater and above our initial desire and that the name we gave God does not fully describe Him. Our spiritual journey then moves into this deeper dimension where God is more than one who meets our desires (Johnson \& Dreitcer, 2001).

The fourth dimension of the Christian's spiritual journey, explain Johnson and Dreitcer, is waiting for God. Being aware of our deepest longings and naming them do not automatically fulfill our needs. We must wait for God to fill our lives and transform us into His likeness. We also wait for God to do that to those we love, work with, and pray for.

Receiving God, according to Johnson and Dreitcer, is the deepest dimension of Christian spirituality. This can be accomplished when God speaks to us through His Word, when our lives are shaken by a severe crisis, or when God sends someone into our lives to deliver the good news and healing balm. Christian nurses who understand this process of spiritual growth are in a position where they can be that someone in the life of a patient. Shelly and Miller (1999) summarize what the Christian nurse's view of spiritual care should be:

Spiritual care is not a set of techniques, although we have many resources at our disposal. Spiritual care is a way of life that involves walking together with the Lord. Sometimes it is merely a listening ear or a gentle touch. At other times it requires confrontation. The basic resources we have to offer are prayer, the Word of God and the Christian community; however, the most important resource is God himself. The ultimate aim of our spiritual care is to bring people into dynamic personal relationship with Jesus Christ and the fellowship of his people. (p. 243) 
Although living in a secular world of pragmatic thinkers, the Christian nurse needs to have a Christian mind that sees beyond this life to another one and that is concerned for the salvation of people (Blamires, 1963).

\section{Nursing Theories and Models That Support Spiritual Care}

"There is a resurgence and inclusion of concepts of spirituality in current nursing practice, and a delineation of nursing's caring base that began in essence with the nursing life of Florence Nightingale" (Dunphy, 2001, p. 49). Since Nightingale's time, numerous nursing conceptual theories and models have been created. Depending on each theorist's worldview, spirituality may or may not be a central component of that particular nursing theory.

Martsolf and Mickley (1998) examined present modern nurse theorists' ideas on spirituality to determine the extent of focus on spiritual caregiving within each model or theory. They divided the models and theories into three categories: (1) those that said little or nothing about spiritual care include Peplau, Orlando, King, and Orem; (2) those that have spiritual care embedded in the theory include Levine, Roy, Leininger, and Rogers; and (3) those in which spirituality is a major concept include Neuman, Newman, Parse, and Watson. Taylor (2002) also mentions that among the nursing theorists who promote spiritual caregiving as an important aspect of "wholistic" nursing care are Virginia Avenel Henderson, Jean Watson, and Betty Neuman

Three models in which spirituality is a major concept will be discussed: Betty Neuman’s Systems Model, Margaret Newman's Health as Expanding Consciousness. and Jean Watson's Theory of Human Caring. 


\section{Neuman Systems Model}

Betty Neuman's conceptual model provides a way of looking at the relationships between the four basic concepts in the nursing metaparadigm: humans, environment. health, and nursing (Parker, 2001). In her model, Neuman uses the term client-client system in place of the word human to emphasize the collaborative relationship and the formation of a unit between the client and the caregiver (Aylward, 2001, p. 331).

The structure of the client-client system consists of the flexible line of defense, the normal line of defense, lines of resistance, and the basic structure energy resources. In the schematic presentation of the model, the basic structure energy resources are at the core of concentric circles that represent the lines of resistance, the normal line of defense, and the flexible line of defense, which is the outermost circle. The flexible line of defense acts like a buffer system to protect the normal line of defense. When this outermost flexible line moves away from the normal line of defense, the client has more protection from stressors and vice versa. Stressor penetration is more likely when the flexible line of defense is close to the normal line of defense (Neuman, 1995)

The next circle working inward, normal line of defense, represents the client's usual state of wellness, which Neuman believes has the dynamic capacity of expanding or contracting over time. The lines of resistance that follow are a series of concentric circles that surround the basic structure. When stressors pass the flexible line of defense and penetrate the normal line of defense, the lines of resistance are activated. These later lines contain known and unknown internal and external resource factors that support the client's basic structure and protect the integrity of the system. When the lines of resistance are effective, signs and symptoms decrease or a reversal to the reaction of the 
stressors can be observed. However, when the lines of resistance are ineffective, wellbeing cannot be maintained, ending in sickness and death (Neuman, 1995).

The basic structure consists of common factors to all organisms such as normal temperature range, genetic structure, response pattern, organ strength or weakness, and ego structure to mention a few. Within the entire client system are five interrelated variables that comprise the wholeness concept of care: physiological, psychological, socio-cultural, developmental, and spiritual. In the Neuman model the spiritual variable is considered an innate elemental of the basic structure whether or not it is accepted or developed by the client or client system (Martsolf \& Mickley, 1998).

To describe the spiritual component, Neuman (1995) uses the analogy of the human spirit as a seed with tremendous potential for growth and development. "This seed . . lies on a continuum of dormant, unacceptable or undeveloped to recognition, development, and positive system influence" (p. 48).

Spiritual awareness can occur at any point along the life cycle. A combination of human spirit, Holy Spirit from God, and life events 'catalyze' this 'seed' so that spiritual energy becomes recognizable as thought processes in the person. An assumption of this model is that ... 'spiritual development in varying degrees empowers the client system toward well-being by positively directing spiritual energy for use first by the mind and then by the body.' (Martsolf \& Mickley, 1998, p. 298)

Neuman (1995) maintains that attention to the spiritual dimension is necessary for a truly holistic perspective of nursing care.

\section{Health as Expanding Consciousness}

Strongly influenced by Martha Rogers's idea of humans as energy fields and by her personal experience in caring for her mother, who had a degenerative neurological disease, Margaret A. Newman developed the Theory of Health as Expanding 
Consciousness. The nurse's responsibility, believes Newman, "is not to make people well, or to prevent their getting sick, but to assist people to recognize the power that is within them to move to higher levels of consciousness" (as cited in Pharris, 2001, p. 266). To Newman (1994), the process of life involves moving towards higher levels of consciousness where consciousness is the capacity of the human being to interact with the environment

The underlying pattern of the person-environment is reflected in the individual's state of health, and represents an evolving pattern of the whole (Martsolf \& Mickley, 1998). The person-environment dimensions include: exchanging, communicating, relating, valuing, choosing, moving, perceiving, feeling, and knowing

To Newman (1994), spirituality is broadly equated with human interactions. The responsibility of nursing is to assist the individual towards expanded consciousness, which transcends physical boundaries and reaches a spiritual dimension. To accomplish this, nurses must first of all get in touch with their own patterns of interaction with the environment to be able to touch the patterns of others and then subsequently help clients identify their patterns of interaction with the environment (Martsolf \& Mickley, 1998).

Newman's nursing theory is appealing to health care professionals who desire to help their patients discover meaning and wholeness in their lives (Pharris, 2001).

\section{Theory of Human Caring}

Jean Waton's Theory of Human Caring is "based on spiritual-existential, and phenomenological orientations that draw on Eastern philosophies" (Martsolf \& Mickley, 1998, p. 300). Her theory is centered on a caring nurse-patient relationship that requires the personal, social, moral, and spiritual engagement of the nurse. 
To Watson (1985), heath is the unity and harmony of body, mind, and spirit. The goal of nursing is to help the client achieve a higher degree of harmony within the mind, body, and soul, which in turn will generate self-knowledge, self-reverence, self-healing, and self-care processes. This goal is accomplished through the "clinical caritas processes" which include:

(1) practice of loving kindness and equanimity ... (2) enabling and sustaining the deep belief system and subjective life world of self and one-being-cared-for ... (3) cultivation of one's own spiritual practices and transpersonal self . developing and sustaining a helping-trusting, authentic caring relationship being present to, and supportive of, the expression of positive and negative feelings as a connection with deeper spirit of self and the one-being-cared-for (6) creative use of self and all ways of knowing as part of the caring process (7) engaging in genuine teaching-learning experience that attends to unity of being and meaning ... (8) creating healing environment at all levels (physical as well as non-physical, subtle environment of energy and consciousness whereby wholeness, beauty, comfort, dignity, and peace are potentiated) . . (9) assisting with basic needs, with an intentional caring consciousness, administering 'human care essentials'... (10) opening and attending to spiritual-mysterious, and existential dimensions of one's own life-death; soul care for self and one-beingcared-for. (Watson, 2001, p. 347)

The act of caring is considered by Watson highly spiritual (Taylor, 2002).

Watson (2001) advocates that to truly grasp the meaning of her caring model it is necessary to experience it personally before it can be successfully implemented.

\section{Implementation of Spiritual Care}

Shelly and Miller (1999) believe that "spiritual care means putting people in touch with God through compassionate presence, active listening, witness, prayer, Bible reading, and partnering with the body of Christ" (p. 229). They clarify that spiritual care is appropriate for both Christians and non-Christians in a variety of settings and is an integral part of caring for the whole person. Although there are many techniques and resources available for implementing spiritual care, Shelly and Miller believe that 
spiritual caregiving goes beyond and "involves walking together with the Lord. . . The ultimate aim of our spiritual care is to bring people into a dynamic relationship with Jesus Christ and the fellowship of his people" (p. 243)

Approaches to spiritual caregiving

Using a critical incident technique, Narayanasamy and Owens (2001) conducted a qualitative study to (1) explore how nurses implement spiritual care, (2) typify their involvement in spiritual caregiving, and (3) describe the effects of their spiritual interventions. Based on their findings they identified four different approaches to spiritual care used by the nurses participating in the study: (1) personal approach, (2) procedural approach, (3) cultural approach, and (4) evangelical approach. The authors explain that nurses who view spirituality in a nonreligious manner used the personal approach to help clients meet their spiritual needs. Personal involvement, partnership, mutuality, and counseling were some of the elements used in this approach

On the other hand, nurses in the study who tend to equate spiritual needs with religious beliefs and practices used the procedural approach. Carrying out impersonal procedural and religious routines and referring patients to the chaplain were the measures most often used in this approach.

A few nurses in the study made an effort to understand their patients' cultural and religious identity and took special measures to accommodate to their needs and requests This group used the cultural interactionist approach to spiritual caregiving.

The evangelical approach was used by nurses who shared a similar religious background with their clients. The re-affirmation of the patient's faith and the sharing of personal values were used by the nurses in this approach. 
Therapeutic effects of the nurses' interventions regardless of the approach used were noticeable. Following spiritual care interventions patients were reported to appear "peaceful, relaxed, and calm, and grateful. . . Many families expressed gratitude and feelings of being comforted and happy as a result of the spiritual care interventions" ( $p$. 453). Even the nurses manifested that giving spiritual assistance to their clients proved to be a rewarding experience.

Of the four approaches to spiritual caregiving identified in their study, Narayanasamy and Owens (2001) suggest that the personal and cultural approaches offer prospects for developing a model of spiritual care that should be piloted and tested for validation. The procedural approach they claim is too impersonal while the evangelical approach can be perceived as unethical.

Spiritual needs and nursing interventions

Doenges and Moorhouse (1996) define spiritual need as "a disruption in the life principle which pervades a person's entire being and that integrates and transcends one's biological and psychosocial nature" (p. 445).

In a study using two discussion groups consisting of patients with psychiatric disorders who had been hospitalized and their family members, the following two questions were discussed: (1) "What does spirituality/religion mean to you" and (2) "What do you need from your pastor/spiritual resource during an inpatient hospitalization?" (Moller, 1999). From the responses obtained in the discussion groups, Moller arranged the specific spiritual needs into four themes: comfort, companionship, conversation, and consolation. Practical suggestions for meeting these spiritual needs were summarized into 11 major points: 


\section{Comfort}

1. Let me know you care.

2. Provide reassurance.

3. Accept me.

\section{Companionship}

4. Visit me.

5. Stay in touch.

Conversation

6. Listen to me

7. Be concrete.

8. Be real, not authoritative.

\section{Consolation}

9. Come prepared.

10. Do not express pity.

11. No sermons. (Moller, 1999, p. 8)

These practical suggestions are beneficial to all health care providers when caring for the spiritual dimension.

Sheldon (2000) also offers similar suggestions for meeting clients' spiritual needs and adds interventions such as: (1) providing privacy if appropriate, (2) conducting a spiritual life review or taking a faith history, (3) encouraging storytelling of one's spiritual life, (4) suggesting client keep a journal, and (5) providing spiritual reading or videos as requested.

Using Reed's Spiritual Perspective Scale and a modified version of the Nurses' Spiritual Care Perspectives Scale developed by Taylor et al. (1994), Stranahan (2001) studied the relationships among spiritual perception, attitudes about spiritual care, and spiritual care practices in nurse practitioners. The spiritual interventions most frequently practiced by the respondents were those that did not require direct involvement such as praying privately for a client and referring a patient to the chaplain. Stranahan observed that interventions that required a high degree of visibility were rarely used. Of the 102 participants in Stranahan's study, only 5 cited physical touching as a spiritual 
intervention, 4 used silent meditation, 2 mentioned listening, and only once were encouraging families to pray, singing with patients, being silently present, and asking others to pray for the client listed as interventions used.

Stranahan (2001) found statistically significant positive correlations between the respondents' perception of personal spirituality in 9 of the 12 spiritual care practices, as well as positive correlations between the participants' perception of personal spirituality in 8 of the 13 items describing attitude toward providing spiritual care. She concludes that the "current practice of spiritual care by nurse practitioners is not so positive. The implications for graduate nursing education involve designing specific courses in spiritual care to aid students in identifying spiritual needs and designing appropriate interventions" (p. 103).

To reach the goal of total well-being Summer (1998) urges that the spirit must be restored to its rightful place and states that nurses can promote the restoration of the spirit by providing spiritual support to clients. Summer suggests facilitating the process of finding meaning and purpose in life by encouraging a life review process and actively listening. Helping patients get in touch with their spiritual self by linking, connecting, and associating the experiences of illness wellness is also a means of spiritual support.

\section{Organizational Climate}

Personal identity, personality characteristics, and behavioral outcomes are important constructs in the study of human growth and development (Berger, 1994; Santrock, 1999). In their desire to achieve wholeness, normal human beings are constantly seeking for a balance and integration of identity, personality, and behavior (Weiten \& Lloyd, 1999). Likewise, educational institutions, being social-systems, 
develop an organizational identity, and demonstrate personality characteristics and behavioral outcomes (Hoy \& Miskel, 2001; Webb \& Norton, 1999). These organizational constructs also need to be balanced and integrated to provide an environment conducive to "wholism."

The interest in organizational behavior birthed the concept of organizational climate. Drawing from theories in cognitive psychology, social psychology, and sociology, organizational theorists have attempted to identify concepts that will help create theories about the behavior of people in organizations. Thus emerged the concept of organizational climate (Hughes, 1993).

\section{Evolution of Organizational Climate}

"Constructs are abstractions that cannot be observed directly; they are invented to explain behavior" (Gay \& Airasian, 2000, p. 147) and must be operationally defined before they can be measured. To become a construct, the concept of organizational climate passed through several stages of development, which Schneider (1990) describes by using his three-stage model of the evolution of constructs.

The first stage, termed introduction and elaboration, which occurs when a concept is created, discovered, or borrowed from another field, began in 1939 with the research of Lewin, Lippitt, and White (as cited in Schneider, 1990). They studied the relationship between leadership style and climate. The research on organizational climate conducted during this period by Argyris in 1958, Campbell, Dunnette, Lawler, and Weick in 1970, Fleishman in 1953, Litwin and Stringer in 1968, and McGregor in 1960 (as cited in Schneider, 1990) attempted to present data to educate readers and legitimize the existence of the construct. 
The second stage, evaluation and augmentation, began in 1972 with Schneider's study on "Organizational Climate: Individual Preferences and Organizational Realities." During the decade that this stage lasted, organizational climate researchers focused on faulty conceptualization, inadequate operationalization, and equivocal empirical results that led to a reconceptualization of the construct, which led to the third stage.

Consolidation and accommodation is the third stage of the concept development. This final stage began in 1982 with the work of Joyce and Slocum who explored the relationship between climate discrepancy and other outcomes (Schneider, 1990).

Because his focus is primarily business management, Schneider did not include studies on school organizational climates in his description of the development of the climate concept. Halpin and Croft's (1962) pioneering study on organizational climates in elementary schools would fit into the introduction and elaboration stage of Schneider's model of the evolution of constructs.

\section{Definition of Organizational Climate}

Organizational climate has been widely defined as the shared perceptions of employees about a given work environment, as the organization's personality, or as the feel of the workplace (Field \& Abelson, 1982; Hoy \& Miskel, 2001; Owens, 1998; Webb $\&$ Norton, 1999). The reflection of members' perceptions of and attitudes toward the important dimensions of organizational life is White's, Spencer's, and Peterson's (1993) definition of the concept. Lin (1999) perceives organizational climate as a mediating variable between organizational system and motivation. Gunnarson and Niles-Jolly (1994) also relate the motivational aspects of hehavior to climate when attempting to explain the concept: 
Climate-the "feeling in the air" one gets from walking around a company-may be difficult to define. But this doesn't make it any less real. Climate is the atmosphere that employees perceive is created in their organizations by practices, procedures, and rewards. These perceptions are developed on a day-to-day basis. They are not based on what management, the company newsletter, or the annual repon proclaim - rather, the perceptions are based on executives' behavior and the actions they reward. (p. 17)

Webb and Norton (1999) refer to organizational climate as "the collective personality" (p. 81) or syntality of an educational institution-the school atmosphere as characterized by the social and professional interactions within it. Both the internal and external environments of the school system influence the school climate, state Webb and Norton.

To Hoy and Miskel (2001) school climate is closely associated with behavior. The school climate affects the behavior of its members, and at the same time is based on their collective perceptions of the behaviors in the school. Consequently, the behavior of the members of an organization is both a contributing factor to the creation of its climate and is also affected by the existing climate

Schneider and Brief (1996) identify four climate dimensions that are helpful in conceptualizing organizational climate. Three dimensions that relate to function are (1) nature of interpersonal relationships, (2) nature of the hierarchy, and (3) nature of work. The fourth dimension is related to goals and has to do with the focus of support and rewards. Organizational climate spans across many organizational activities, as is the case with school climate. There is a difference however between the organizational goals of an educational institution and an organization whose main objective is not education. The overall mission of any educational institution, regardless of its educational philosophy, is learning. "A school's climate is its atmosphere for learning. It includes 
the feelings people have about school and whether it is a place where learning can occur" (Howard, Howell, \& Brainard, 1987, p. 5). Edgert (1994) describes campus climate as a collage of "interpersonal and group dynamics that comprise the experience of participants in a collegiate setting" (p. 53).

\section{School Climate Assessment Instruments}

Although it is difficult to concretely define, observe, and therefore assess organizational climate, Johnson and Johnson (1992) point out three generalizations regarding climate assessment that are widely accepted

1. Organizations undertake a core of activities "to achieve their objectives, to maintain their internal environment, and to adapt to and maintain control over the 'relevant' external environment" (p. 635).

2. Organizations are dynamic and operate in the historical context.

3. For organizational change to occur, "valid information on the current status of the organization is necessary" (p. 635).

Because schools are organizations that need to implement specific actions to control to some extent the internal and external environments so that learning can take place, and because they are places where the historical perspective of the institution will have an effect on its mission (Martin, Samels, \& Associates, 1997), the generalizations related to climate assessment are applicable to educational institutions as well.

School climate assessment tools that have been used and cited in the research and school climate literature are abundant: (1) Halpin's and Croft's Organizational Climate Description Questionnaire and its revisions, (2) Litwin's and Stringer's Climate Questionnaire, (3) Likert Profile of a School Questionnaire, (4) Stern's Activities Index 
and College Characteristics Index that became the Organizational Climate Index, (5) Brookover Elementary School Social Climate Questionnaire, (6) the CFK: Ltd. Profile (Johnson \& Johnson, 1992), and (7) Johnson et al. 's (1999) University Version of the Charles F. Kettering Climate Scale. Other instruments that have been used for measuring school climate include the Effective School Battery, the Comprehensive Assessment of School Environments (Witcher, 1993), the High School Characteristics Index, the Purdue Teacher Opinionaire, and the Organizational Health Inventory (Webb \& Norton, 1999). Kelley (1980) also mentions the School District Climate Profile and the Syracuse Indexes among others.

Shenkle, Snyder, and Bauer (1998) present an extensive list of campus climate measures useful for administrators in higher education who are interested in assessing campus climate factors. A listing of the instruments accompanied by a brief description of each and where they can be obtained is offered. A total of 59 different tools for measuring specific factors of campus life are presented in the following categories: (1) alumni surveys; (2) current student experiences, outcomes, and satisfaction; (3) diversity (general); (4) employee satisfaction and perceptions of campus climate; (5) former or withdrawing students; (6) substance abuse; and (7) miscellaneous. Nine web sites where additional information on assessing campus climate can be obtained are listed as well. The extensive number of instruments and web sites related to measuring campus climate is an indication of the growing interest and concern among institutions of higher education regarding campus life and its effects on learning (Shenkle et al., 1998)

The benefits of institutional self-assessment of campus climate outlined by Edgert (1994) include: (1) better understanding of the influence that campus climate has on 
institutional diversity goals; (2) attainment of information helpful in student flow measures such as retention and graduation; (3) target institutional strengths and weaknesses; (4) provide information on effectiveness of specific planned interventions; and (5) alert administrators of possible coming crisis.

Several campus climate studies are found in the literature. Mohammadi, Shaffer, and Farris (1995) conducted a campus climate study of Patrick Henry Community College in Virginia. They surveyed the faculty and staff's perceptions of job satisfaction, organizational communication, management, and work environment. Mattice (1994) assessed students' experiences, attitudes about diversity issues, and suggestions for improving the climate for diversity at College of the Canyons in California. Luan (1995) surveyed students enrolled in Cabrillo College in California to determine their perceptions of instruction, the availability of classes, student services, and the general climate of the college.

\section{Organizational Climate Description Questionnaire}

The conceptualization and measurement of organizational climate in schools began in 1962 with the studies conducted by Andrew W. Halpin and Don B. Croft. With the purpose of identifying important aspects of teacher-teacher and teacher-principal interactions, they developed a descriptive questionnaire of 64 items called the Organizational Climate Description Questionnaire (OCDQ). Through factor analysis, Halpin and Croft (1962) discovered six clusters of profiles, which they identified as the six basic school climates: open, autonomous, controlled, familiar, paternal, and closed. 
Although widely used to measure school climate, the OCDQ has its limitations. The forced designation of discrete types of climate based on the designers' profile of elementary schools in their original study is its main criticism (Hoy \& Miskel, 2001).

Consequently, this first tool for measuring the organizational climate of elementary schools was revised by Hoy and Clover (1986) into a 42-item instrument (OCDQ-RE) that identifies four instead of six types of school climates. A factor analysis of this revised version revealed two underlying factors of the conceptualization and measurement of school climate. The first factor identifies teachers' interactions as disengaged, intimate, and collegial, characterized by interactions that are meaningful and tolerant (low disengagement), friendly, close and supportive (high intimacy), enthusiastic, accepting, and mutually respectful (high collegial relations), respectively. This first factor was labeled "openness in faculty relations" while the second factor, which identifies the principal's behavior as restrictive, directive, and supportive, was labeled "openness in principal behavior" (Hoy \& Miskel, 2001).

Being that the two general factors of the OCDQ-RE scales, teacher interactions and teacher-principal relationships, are independent, four contrasting prototypes of school climate are theoretically possible: open, engaged, disengaged, and closed. When both factors are open there is congruence between the principal's and teachers' behavior producing an open school climate. On the other extreme, if both factors are closed, naturally a closed climate will prevail. If, however, the principal is open with the faculty but the teachers are closed with each other, the climate will be identified as disengaged. An engaged climate, on the other hand, will be characterized by the principal's closed 
relationship with the teachers while among themselves the teachers are open (Hoy $\&$ Miskel, 2001)

A further revision of the OCDQ scales by Kottkamp and Hoy (1987) produced the OCDQ-RS, a 34-item questionnaire that measures five dimensions of secondary school climates. Two of these dimensions refer to principal behavior (supportive and directive) and three to teacher behaviors (engaged, frustrated, and intimate). The OCDQ-RS assesses the faculty's perceptions of adult interactions as well as teacher behaviors and attitudes toward students (Witcher, 1993).

Because middle schools with their unique characteristics have replaced many junior high schools, a special climate instrument, the OCDQ-RM, was designed specifically for middle schools (Hoy \& Miskel, 2001).

Early studies on school climate that have used the OCDQ scales have revealed some research findings that are significant for creating environments conducive to the "wholistic" development of students. Students in schools with open climates have less sense of alienation toward the school and its personnel than those in closed climates (Hartley \& Hoy, 1972).

Kreitner (1995) identified four characteristics of an open climate: (1) interaction with the environment, (2) synergy, (3) dynamic equilibrium, and (4) equifinality. An open system interacts with the environment and depends on the environment for survival. Being more than the sum of its parts, all of an open system's components must be working harmoniously to achieve synergism. In order to maintain the internal balance necessary for "wholism." a dynamic equilibrium that utilizes resources from the 
environment is necessary. Kreitner's fourth characteristic, equifinality, means that open systems can achieve the same results by different means

Closed systems, on the other hand, are characterized by low staff morale, inadequate communication, limited socialization, and static equilibrium (Webb \& Norton, 1999)

\section{Other School Climate Assessment Instruments}

The High School Characteristics Index ( $\mathrm{HSCl}$ ) was developed at the Syracuse University Psychological Research Center and consists of 30 scales that measure factors of school climate such as group life, personal dignity, and achievement standards (Webb \& Nonton, 1999). This instrument, which is administered to the students, rather than faculty, as is the OCDQ, is used for assessing the students' perception of school climate.

The Purdue Research Foundation developed the Purdue Teacher Opinionaire (PTO) that assesses climate factors that include teacher rapport with the principal, rapport among teachers, teacher status, community support of education. and community pressures. Another instrument developed by this Foundation, the Purdue Evaluation Scale, completed by students, evaluates climate factors such as the ability to motivate students. students-teacher communication, and fairness of the teacher (Webb \& Norton, 1999)

The Organizational Health Inventory $(\mathrm{OHI})$, completed by teachers, is used to assess institutional integrity, principal influence, consideration, initiating structure, resource support, morale, and academic emphasis (Webb \& Norton, 1999)

An instrument that can be administered to teachers, students, and parents that assesses general. program. process, and material determinants of school climate is the 
Charles F. Kettering School Climate Profile (Witcher, 1993). Developed in the early 1970s under the direction of R. S. Fox, the test items were evaluated by more than 200 educators throughout the United States for content validity. The general climate factors section of the instrument consists of eight subscales containing 40 items that assess respect, trust, high morale, opportunity for input, school renewal, cohesiveness, continuous growth, and caring. Using a scale from 1 to 4 where $1=$ almost never; $2=$ occasionally; $3=$ frequently; and $4=$ almost always, participants are asked to rate their perception of "What Is" on one column and "What Should Be" on another (Johnson et al., 1999).

\section{University Version of Charles F. Kettering Climate Scale}

A university version of the Charles F. Kettering Climate Scale was developed by Johnson et al. (1999) to assess the psychological dimensions of a university climate. The revision consisted of replacing the words school with university and principal with teachers. The same eight subscales of the General Climate Factors section of the original instrument were maintained along with the scaling technique and 4-point column descriptors for the "What Is" and the "What Should Be" columns. The revised instrument was applied to 707 university students. The composite alpha for the 40 "What Is" item scores was 94 and for the "What Should Be" item scores was .93 . A more detailed description of the University Version of the Charles Kettering Scale can be found in chapter 3 . 


\section{Research on Organizational Climate}

Although "climate scholars do not agree on a theory and a related methodology to study climate" (Fink \& Chen, 1995, p. 494), and the operational definition is based on individual perceptions rather than objective observation, this has not been an impediment to conduct research in this area. As organizational concepts and theories evolve, organizational climate research accompanies the process and contributes to it.

A shift from the focus on technical aspects of work in fostering productivity to an emphasis on building and maintaining dynamic and harmonious human relationships began as early as 1924 with Mary Parker Follet questioning Taylor's task system (Webb \& Norton, 1999). During the following three decades, organizational concepts in the areas of democratic leadership, informal group influences, the school as a social system, and other organizational characteristics now related to school climate were greatly discussed and studied. The contemporary concept of organizational climate of schools had its beginnings in the 1960s with the work of Haplin and Croft. Since then, numerous climate studies have been conducted on (1) the characteristics found in schools with positive climates, (2) the impact of school climate on student achievement, (3) the impact of school climate on the behavior of personnel, and (4) the impact of school climate on school program innovation and change (Webb \& Norton, 1999).

Webb and Norton (1999) mention that these studies tend to agree that schools with positive climates present the following conditions: (1) provide opportunities for active student learning. (2) place emphasis on individualized performance, (3) have school programs that promote the intellectual, social, and physical development of students. (4) have school policies and regulations that have been jointly developed. 
precisely written, and extensively disseminated, (5) have "reward systems that place an emphasis on positive student reinforcement rather than punishment" (p. 121), (6) have leaders who strive to improve communication and personal relationships with teachers, staff, and students, and (7) "have developed a viable set of shared goals with expanding implications for the future" (p. 121).

\section{Structure and Climate in Schools of Nursing}

Two studies that look at climate and structure of nursing schools are Grigsby's (1991) and Lubbert's (1995).

Lubbert (1995) conducted a descriptive study to explore the relationship between dimensions of structure such as (centralization, formalization, and complexity) and climate in schools of nursing. To measure climate she used a modification by Grigsby of Moos's Work Environment Scale (WES) containing the following subscales:

Involvement, Peer Cohesion, Administrative Support, Autonomy, Task Orientation, Work Pressure, Clarity, Control, and Innovation. Alpha coefficients for the WES range from .65 to .86 (Grisgsby, 1991 ).

Lubbert's (1995) findings reveal a significant relationship between structure and climate in nursing schools. A more favorable climate was related to dispersion of influence throughout the school, whereas a less favorable climate was related to a higher degree of supervision by supervisors suggesting a relationship between structure and climate. Since climate is closely associated with behavior (Hoy \& Miskel, 2001), this supports Martin's (1998) statement that "the structural form of an organization shapes to a considerable degree the behaviour of the individuals within it" (p. 293). 
To explore the relationship between organizational structure and climate in schools of nursing, Grisgsby (1991) conducted a comparative study of two schools of nursing that differed in their structural characteristic of centralization and formalization. A purposive sampling procedure was utilized for choosing the two organizations. The faculty and administrators of the two schools were asked to complete a demographic questionnaire and the Work Environment Scale. Characteristics of both the bureaucratic and professional models of organizational structure where observed in the two schools. The school with a structural organization most resembling the professional model, however, had significantly higher scores on administrative support and autonomy, suggesting a relationship between structure and climate. Although the conclusions of this research are specific to the two schools studied, Grisgsby believes the findings have implications for administrators and faculty in other nursing schools and suggests that further studies be conducted to "develop an understanding of the impact of organizational factors on the individual functioning within the school and the resulting effect of an individual's productivity and satisfaction on the education of nursing students and the advancement of nursing knowledge" (p. 87).

\section{Organizational Climate and Employee Involvement}

Shadur and Kienzle (1999) studied three dimensions of organizational climate (bureaucracy, innovation, and support) and how these related to participation in decision making, teamwork, and communications among employees. Their findings suggest that a supportive organizational climate is a constant significant predictor of the three involvement variables studied. The investigators believe that it is likely that a supportive 
climate will enhance teamwork and communication by creating an atmosphere of cooperation and openness. Administrators need to understand the impact that organizational climate has on employee perceptions of involvement and their affective attitudes.

The conclusions of this research lead one to consider that a supportive organizational climate at a school of nursing may have a positive effect on decision making, teamwork, and communications among the nursing faculty which in turn would have a positive influence on the attitudes of the nursing students

\section{Organizational Climate and Health Behavior}

The possible moderating effects of school organizational climate on outcomes of a teacher health behavior change program in elementary schools were assessed by Cullen and Baranowski (1999). The researchers' premise is that since behavior is influenced by the interaction among the environment, personal factors, and behavior, organizational climate and teacher job satisfaction are characteristics of school environments that may influence teacher behavior, teacher receptiveness to change and, thereby, the success of both student and health promotion programs. The results of this research demonstrate that schools with high organizational climate scores reported more positive changes in health behaviors than schools with lower organizational climate scores.

"A healthy school," claim Cullen and Baranowski (1999), "successfully copes with disruptive external forces and directs its energies toward its mission" (p. 376). 


\section{School Climate and Organizational Health}

Health is a metaphor for examining the organizational climate (Hoy \& Hannum,

1997). These authors believe a healthy organization survives its environment and continuously develops and expands its coping abilities. They emphasize the importance of a healthy environment in education. Hoy and Hannum cite the work of Parsons, Bales, and Shils (1953), who describe that all social systems, including educational institutions, must solve the following four basic issues if they are to survive and prosper: "accommodate to its environment, set and implement its goals, maintain a cohesive system, and create and preserve a distinctive culture" (as cited in Hoy \& hannum, 1997, p. 292). To solve these issues, Parsons explains that schools have three levels of control. The first is the technical level, which is concerned with teaching and learning, the primary mission of the school. The second is the managerial level, which controls the internal coordination of the school. At this level the educational administrator must allocate resources, coordinate the work effort, develop teacher loyalty, trust, commitment, and motivation. The third level, the institutional level, connects the school and the community.

Using Parsons et al.'s work as the theoretical framework for their research, Hoy and Hannum (1997) pose the following question. Does school climate improve student achievement or does high student achievement produce a better school climate? The researchers posit the two are mutually dependent. After analyzing their findings, they conclude that a healthy school is a place where teachers like the school, the students, and each other and are enthusiastic about their work (high teacher affiliation). Teachers see the administrator as friendly, open, and respectful and as their ally in improvement of 
instruction (strong collegial leadership). Teachers see the students as serious and diligent in their learning (high academic emphasis). A healthy institutional environment also includes high principal influence, high resource support, and high institutional integrity. The researchers found that academic achievement in mathematics, reading, and writing is related to healthy interpersonal dynamics of schools.

A healthy environment, which enhances learning in general, is more likely to promote the conceptualization of wholeness. Pelletier (1977) compared "holistic" development in education to the medical model of health:

If the prevention of pathology is the ultimate goal, then health practitioners and lay men need to begin to consider the whole person. An individual needs to be considered physically, psychologically, and spiritually with the intent of gaining as much understanding as possible about his relationship with his total environment. This environment includes his family, peers, job situation, living situation, his concept of himself and his role in society, as well as his childhood background. ... Holistic medicine recognizes the inextricable interaction between the person and his psychosocial environment. Mind and body function as an integrated unit, and health exists when they are in harmony, while illness results when stress and conflict disrupt this process. (pp. 11-12)

\section{Leadership and School Climate}

Recognizing that leadership is considered an essential element in determining organizational climate and productivity (Ramsden, 1998; Schneider, 1983) and on the other hand that organizational climate is considered an important determinant of leadership effectiveness (Franklin, 1975), Griffith (1999) examined the relationship between leadership and school climate. In his study Griffith contrasted the organizational configuration of schools having principal changes to schools not having principal changes assuming that principal changes were mainly due to ineffective management 
He found that schools with principal changes had less internal control, less external focus, and less emphasis on end product.

An implication from Griffith's study would be that educational institutions that promote the "wholistic" development of students require internal control, outward focus. and emphasis on the end product, which in turn requires effective management.

\section{Management Practice, Organizational Climate, and Performance}

Schuster and Morden (1997) conducted an exploratory study to evaluate the effect over a 5-year period of implementing a structured, seven-step strategy to obtain improved organization performance through employee-centered management. The strategy used consisted of the following seven steps: (1) determine the baseline condition of the organization, (2) identify and act on key opportunities for improvement (communication, compensation program), (3) change executive evaluation and reward practices, (4) remove artificial barriers to participation, communication, and contribution, (5) report to employees what has been done to change management assumptions and practices, (6) measure again the condition of the organization, and (7) measure the correlation between the HRI data and hard criteria of organization performance.

This study's findings support the conclusion that improved motivation, morale, and commitment of an organization lead to improved organizational performance. The researchers found that interventions to implement employee-centered management have the potential to create significant improvement in organizational climate

This study also signals a relationship between organizational climate and organizational practices as well as the effect that climate has on the behaviors and 
attitudes of its members. A climate where nursing faculty feel motivated, committed, and supported in fulfilling the mission of the institution will be more conducive to students' "wholistic" development.

\section{Organizational Climate and Perception of Caring}

Caring is a core value for nursing practice (Tanner, 1990) that can be learned through interaction with others but not taught in a formal classroom (Hughes, 1993). Through their interaction with faculty, students are socialized to values and attitudes about caring. However, continues Hughes, certain organizational characteristics of schools of nursing "may create barriers to the experiential learning that is needed to develop caring practitioners" (p. 3). These organizational characteristics, such as size, faculty characteristics, structure of clinical experiences, affluence, complexity, and parent institution, contribute to the creation of a school climate

Hughes (1993) studied the relationships among characteristics of baccalaureate schools of nursing and the student-perceived organizational climate for caring. To measure these constructs she developed the Organizational Climate for Caring Questionnaire (OCCQ) which includes items that describe caring faculty behaviors, teachers' and students' sharing of ideas, teachers' ability to help students enact the caring role, and teachers' ability to affirm the students. A total of 365 junior students from 73 different baccalaureate nursing programs participated. Some of the characteristics of the schools that were described as having the most caring organizational climate were: (1) they were affiliated with a liberal arts college or parent institution, (2) they had a high percentage of full-time students, and (3) they had limited graduate emphasis. 
The findings of the above-mentioned studies suggest that a positive organizational climate: (1) fosters dispersion of influence throughout the school (Lubbert, 1995), (2) enhances teamwork and communication by creating an atmosphere of cooperation and openness (Shadur \& Kienzle, 1999), (3) helps organization members cope with disruptive external forces and direct their energy toward the mission of the organization (Cullen \& Baranowski, 1999), (4) enhances learning (Hoy \& Hannum, 1997), (5) is related to effective management (Griffith, 1999), and (6) improves organization performance by enhancing motivation, morale, and commitment of employees (Schuster \& Morden, 1997).

Assuming that a positive organizational climate in a nursing school would have similar effects to the ones observed in the studies mentioned, it is reasonable to consider these factors as possible promoters of spiritual care. Nursing educators who hold a biblical worldview face the challenge of promoting an environment conducive to spiritual development and caregiving.

\section{Chapter Summary}

Studies on organization climate suggest that a positive climate: (1) fosters dispersion of influence throughout the school (Lubbert, 1995), (2) enhances teamwork and communication by creating an atmosphere of cooperation and openness (Shadur \& Kienzle, 1999), (3) helps organization members cope with disruptive external forces and direct their energy toward the mission of the organization (Cullen \& Baranowski, 1999), (4) enhances learning (Hoy \& Hannum, 1997), (5) is related to effective management (Griffith, 1999), and (6) improves organization performance by enhancing motivation, morale, and commitment of employees (Schuster \& Morden, 1997). 
Caring is a core value for nursing practice (Tanner, 1990) that can be learned through interaction with others but not taught in a formal classroom (Hughes, 1993) Through their interaction with faculty, students are socialized to values and attitudes about caring. However, certain organizational characteristics of schools of nursing "may create barriers to the experiential learning that is needed to develop caring practitioners" (Hughes, 1993, p. 3). These organizational characteristics such as size, faculty characteristics, structure of clinical experiences, affluence, complexity, and parent institution characteristics contribute to the creation of a school climate.

Lubbert's (1995) and Grigsby's (1991) studies on climate and structure in schools of nursing reveal a significant relationship between the two constructs. Grigsby suggests that further studies be conducted to "develop an understanding of the impact of organizational factors on the individual functioning within the school and the resulting effect of an individual's productivity and satisfaction on the education of nursing students and the advancement of nursing knowledge" (p. 87).

The Seventh-day Adventist Church has a "wholistic" mission (Jemison, 1955) that combines a balanced, harmonious education (White, 1952) with a "wholistic" health message (Dysinger, 1997; White, 1905, 1912) that has as its ultimate aim to restore humankınd to the image of its Creator. In contrast, "the goal of New Age holistic health philosophy is to transform man to a new paradigm of seeing himself as a demi-god and as a body-mind self-healer" (Vazquez, 1996, p. 31). Vazquez warns of the physical and spiritual danger of alternative New Age holistic health therapies based on nonbiblical worldviews. The purpose of spiritual care in holistic health based on Eastern philosophies and postmodern ideologies is strengthening inner spirituality and connecting 
with supernatural entities and not spirituality from a biblical standpoint. The essence of "wholistic" heaith based upon a biblical worldview is to have a growing relationship with the Person who is the epitome of wholeness-Jesus Christ. To the Christian nurse, spiritual caregiving involves putting the client "in touch with God through compassionate presence, active listening, witness, prayer. Bible reading, and partnering with the body of Christ" (Shelly \& Miller, 1999, p. 229). If school climate has an impact on spiritual caregiving, or vice versa, it is important that nursing programs that uphold a Christian worldview be aware of the relationship and work towards providing an environment that promotes the "caring connection" as described by Jones (2001). 


\section{CHAPTER 3}

\section{METHODOLOGY}

\section{Introduction}

This chapter describes the population and sample, the instruments used for data collection, the research design, research procedures, and statistical analysis of the null hypotheses.

The purpose of this study was to explore the interrelationships between the perspectives of spiritual care held by students and faculty in Seventh-day Adventist baccalaureate nursing programs and their perception of the program's organizational climate. This study also allowed for comparisons of perspectives of spiritual care and organizational climate between faculty and students, Seventy-day Adventists and non Seventh-day Adventists, as well as between males and females.

The Seventh-day Adventist Church has a "wholistic" mission of which spiritual weil-being is a central part. In order to accomplish this mission, a positive attitude toward spiritual care is needed. The concept of spiritual care is not acquired in a void. The environment in which nursing students develop professionally contributes to defining the extent to which they incorporate this concept into their own lives and in their practice as health care professionals. If the organizational climate in nursing programs affects the transmission of this important concept, it is consequential that this be known. 


\section{Population and Sample}

The target population for this study was upper division students and faculty of Seventh-day Adventist NLN-accredited baccalaureate nursing programs in North America. There are a total of 10 programs that meet these specifications.

Because the entire population is less than 600 , the sample consisted of all upper division students and faculty of the qualifying programs that agreed to participate in the study. Directors of nine of the nursing programs agreed to have their program participate. Confidentiality of the nursing programs was maintained by not requesting demographic characteristics of the schools on the questionnaire and not identifying the names of the participating nursing programs in the report of the findings. Table 1 shows the Seventh-day Adventist NLN-accredited Baccalaureate Nursing Programs in North America.

Table 1

Seventh-day Adventist NLN Accredited Baccalaureate Nursing Programs in North America in 2001

\begin{tabular}{ll}
\hline Nursing Program & Location \\
\hline Andrews University Department of Nursing & Berrien Springs. MI \\
Atlantic Union College Department of Nursing & South Lancaster. MD \\
Columbia Union College Department of Nursing & Takoma Park. MD \\
Florida Hospital College of Health Sciences. Dept. of Nursing & Orlando, FL \\
Loma Linda University. School of Nursing & Loma Linda. CA \\
Pacific Union College Department of Nursing & Angwin. CA \\
Southem Adventist University School of Nursing & Collegedale. TN \\
Southwestern Adventist University Department of Nursing & Keene. TX \\
Union College Division of Health Sciences, Nursing Program & Lincoln, NE \\
Walla Walla College School of Nursing & College Place. WA \\
\hline
\end{tabular}

Note. From Seventh-day Adventist Schools of Nursing, by Office of International Nursing at Loma Linda University School of Nursing and the Department of Health Ministries of the General Conference of Seventh-day Adventists. 2000, Loma Linda. CA: Loma Linda University. 


\section{Statement of Null Hypotheses}

Null hypothesis 1: There is no significant relationship between each organizational climate subscale and total score and nursing students' perspectives of spiritual care.

Null hypothesis 2. There is no significant relationship between each organizational climate subscale and total score and the faculty's perspectives of spiritual care

Null hypothesis 3: There is no significant difference in perception of organizational climate between nursing programs

Null hypothesis 4: There is no significant difference in perspectives of spiritual care between nursing programs.

Null hypothesis 5: There is no significant difference in each organizational climate subscale and total score between faculty and students

Null hypothesis 6: There is no significant difference in each organizational climate subscale and total score between Seventh-day Adventist and non Seventh-day Adventist faculty.

Null hypothesis 7 : There is no significant difference in each organizational climate subscale and total score between Seventh-day Adventist and non Seventh-day Adventist students.

Null hypothesis 8: There is no significant difference in each organizational climate subscale and total score between male and female students

Null hypothesis 9: There is no significant difference in perspectives of spiritual care between students and faculty. 
Null hypothesis 10: There is no significant difference in perspectives of spiritual care between Seventh-day Adventist and non Seventh-day Adventist faculty.

Null hypothesis 1/: There is no significant difference in perspectives of spiritual care between Seventh-day Adventist and non Seventh-day Adventist students.

Null hypothesis 12: There is no significant difference in perspectives of spiritual care between male and female students.

\section{Instrumentation}

In order to assess both variables, organizational climate of the nursing program and perspectives of spiritual care, two instruments were chosen: The University Version of the Charles F. Kettering Climate Scale (UCFK) (Johnson et al., 1999) and the Spiritual Care Perspectives Scale (SCPS) (Taylor et al., 1999) (Appendix A). Permission to use these two scales in this study was obtained from the authors of both instruments (Appendix B).

The University Version of the Charles F. Kettering School Climate Scale

In this study, the organizational climate of a nursing program was considered to be the set of internal environmental characteristics of that particular program as perceived by its members (students and faculty), and which influence each member's behavior. To measure this construct the University Version of the Charles F. Kettering School Climate (UCFK) was used. Developed and analyzed by Johnson et al. (1999), the UCFK is a modification of a previously accepted climate assessment tool used to measure the psychological dimensions of school climate, the Charles F. Kettering (CFK) School Climate Profile (Johnson \& Johnson, 1992). 
The content validity of the original CFK was assessed by more than 200 educators throughout the United States who were requested to evaluate the instrument items. The original test developers did not publish reliability and validity data scores for the first CFK. However, Johnson et al.'s (1999) study and analysis of the revised Charles F. Kettering Climate Scale provide information on the instrument's reliability as described below.

The UCFK climate scale consists of 40 items divided into eight subscales containing five items each: (a) respect, (b) trust, (c) high morale, (d) opportunity for input, (e) continuous academic and social growth, (f) cohesiveness, (g) school renewal, and $(\mathrm{h})$ caring. Each item is answered using the following scale: $1=$ almost never, $2=$ occasionally, 3 = frequently, and $4=$ almost always. There are two discrepancy format columns where the respondents must place their answer to each item. The "What Is" column is the perceived actual condition, whereas the "What Should Be" column contains the perceived desired condition.

With the data obtained from 707 university students who responded to the UCFK, Johnson et al. (1999) performed a multivariate analysis of the instrument. A first-order principal components analysis was performed for each discrepancy column. Using the eigenvalues greater than 1 , the analysis for the "What Is" column yielded seven factors and the "What Should Be" column eight factors. To reduce the overriding factor with additional factors, the researchers performed an oblique rotation using the promax method. A second-order factor analysis was performed by the researchers in which two "What Is" factors and three "What Should Be" factors were identified from the interfactor correlation matrices and rotated to the varimax criterion. To avoid 
"interpretations of interpretations" the researchers postmultiplied "the first-order factor pattern matrix times the orthogonally rotated second-order factor pattern matrix" (p. 34l). The product matrices were then rotated to the varimax criterion. After performing this extensive analysis, Johnson et al. conclude that their results confirm that the CFK subscales do cluster generally as hypothesized by the original test developers.

To evaluate score reliability Johnson et al. (1999) used the Kuder-Richardson reliability formula for coefficient alpha and obtained a composite alpha score of .94 for all 40 "What Is" items and .93 for all 40 "What Should Be" items on their revised version, the UCFK. Cronbach alphas obtained on each individual subscale of the UCFK in the Johnson et al. analysis of the instrument were the following: "What Is" item scores: Respect, .65; Trust, .79; High Moral, .68; Opportunity for Input, .79; Academic and Social Growth, .73; Cohesiveness, .73; School Renewal, .78; and Caring, .82; and "What Should Be" item scores: Respect, .51; Trust, .66; High Moral, .67; Opportunity for Input, .76; Academic and Social Growth, 63; Cohesiveness, .64; School Renewal, .70; and Caring, 80

To compute the climate score as rated by each respondent, the totals for the "What Is" column were subtracted from the totals of the "What Should Be" column for each individual category of the climate scale (respect, trust, high moral, opportunity for input, continuous academic and social growth, cohesiveness, school renewal, and caring) thus obtaining a score for each category. Since there are five items in each of the eight categories, theoretically the scores for each category could range from 15 , indicating an extremely unfavorable climate in that particular area, to minus 15 , indicating a climate that is way better than desired. If the individual perceives that the actual climate 
corresponds to the desired climate, the score will be zero. The scores of the eight categories were then added to obtain the overall climate score as perceived by that respondent. Here again, theoretically, the total climate score can range from 120 to minus 120 .

The Spiritual Care Perspectives Scale

Perspectives of spiritual care refers to the nurses' (students' and faculty's) attitudes about the importance of including spiritual care in nursing caregiving. For measuring this construct, a subscale of the Spiritual Care Perspectives Scale (SCPS) developed by Taylor, Amenta, and Highfield (1995) was used. This scale consists of 13 items in two subscales that quantify the respondent's attitude regarding the importance of including spiritual care in nursing caregiving and how he or she should relate to patient spirituality. Only the seven items that pertain to the Role of Spiritual Care in Nursing Subscale were incorporated into the instrument used in this study.

The participants scored each of the seven items using a scale from 1-5. The sum of the scores of the seven items theoretically ranges from 7 to 35 . A high score indicates a positive attitude towards spiritual care, whereas a low score indicates a negative attitude (Taylor et al., 1999).

"Content validity of the SCPS was determined by a panel of experts, two expert nurse researchers and four doctorally prepared nurses who are experts in spiritual care" (Taylor et al., 1999, p. 32). The Cronbach's alpha reliability coefficient was 0.75 . An instrument with a higher reliability coefficient would have been preferred: however, the SCPS is favored over an instrument that has not been used before. 


\section{Research Design}

A correlational, causal-comparative study was conducted using survey research methodology. Pinsonneault and Ktaemer (1993) describe the characteristics of survey research as follows:

Surveys conducted for research purposes have three distinct characteristics. First, the purpose of the survey is to produce quantitative descriptions of some aspects of the studied population. Survey analysis may be primarily concerned either with relationships between variables, or with projecting findings descriptively to a predefined population. Survey research is a quantitative method, requiring standardized information from and/or about the subjects being studied. The subjects studied might be individuals, groups, organizations, or communities; they also might be projects, applications, or systems. Second, the main way of collecting information is by asking people structured and predefined questions. Their answers, which might refer to themselves or to some other unit of analysis, constitute the data to be analyzed. Third, information is generally collected about a fraction of the study population--a sample--but it is collected in such a way as to be able to generalize the findings to the population. (p. 75)

Quantitative descriptions of perceptions of organizational climate in schools of nursing and attitude toward spiritual care were collected in this study to analyze the relationship between these two constructs. Structured and predefined questions taken from two assessment tools that have been previously used in research studies, the UCFK and the SCPS, were used for collecting the data that were analyzed. Because the target population is relatively small, sampling was not necessary and the entire population was included in the study.

An experimental design for this study would not have been suitable because control of the variables organizational climate and spiritual care is inappropriate. Furthermore, the phenomena of interest must be studied in their natural setting. However, a comparative study that attempts to identify differences where a comparison is made between two or more groups that are already formed and are already different on the independent variable is appropriate (Gay \& Airasian, 2000). In this study the 
grouping into faculty and students and into the different participating nursing programs is already formed and cannot be manipulated. The effect of the status of the respondent (faculty or student), the religious preference, gender, and belonging to a specific nursing program on the perception of school climate and perspectives of spiritual care was explored by using a comparative design.

\section{Procedures}

A letter of invitation to participate in the study and an abstract of the dissertation proposal (Appendix C) were sent to the program director of each one of the 10 Baccalaureate Nursing Programs that fulfilled the specifications for participation in this study (Table 1). Between two to six contacts were made with each program director via telephone and e-mail to request they consider participating in the study and to answer questions and concerns they might have regarding the research study.

The nine program directors who agreed to participate in the study were requested to arrange a meeting with all upper division students enrolled in the baccalaureate nursing program and all full-time and part-time nursing faculty to apply the survey questionnaire in one sitting. Several program directors stated they were unable to take class or assembly time for participants to answer the questionnaire. Therefore, the program directors were given the option of placing the survey questionnaires in the students' and faculty's mail boxes for them to answer on their own time and return directly to me in the pre-addressed, stamped envelope provided. One program chose to have participants place the sealed envelope containing the answered questionnaire in a designated box and send the box to me. The program that actually followed the original procedure was the program with the highest return rate. 
A package containing the number of survey questionnaires specified by each program director, along with pre-addressed stamped envelopes for each participant (or blank envelopes for each participant for the programs that chose to return the answered questionnaires all at once) was sent to each program director who agreed to participate The questionnaires were colored coded so I could identify which program they were from. Between two to eight follow-up messages were sent and/or phone calls were made, as necessary, to the program directors requesting they remind participants to return the answered questionnaires.

Of the 515 questionnaires that were sent to the nine participating programs, 208 were returned answered representing a $40.4 \%$ overall response rate. The faculty response rate was $58.3 \%$, while the student response rate was $36.9 \%$.

The Statistical Package for the Social Sciences (SPSS) 10.0 for Windows was used for recording and analyzing the data. The participating programs were randomly assigned numbers for identification purposes.

\section{Statistical Analysis of the Null Hypotheses}

All hypotheses were tested at the .05 level of significance. Hypotheses 1 and 2 employed Pearson correlation to determine if there was a significant relationship between each organizational climate subscale and total score and perspectives of spiritual care. Hypotheses 3 and 4 were submitted to simple analysis of variance to determine whether there was a significant relationship between belonging to a particular nursing program and the members' perception of the school's organizational climate and perspectives of spiritual care. Hypotheses 5 through 8 were submitted to t-tests for independent samples to determine if there was a significant difference in each organizational climate subscale 
and total score between faculty and students, Seventh-day Adventists and non Seventhday Adventists, and males and females. Hypotheses 9 through 12 were submitted to $t$ tests for independent samples to determine if there was a significant difference in perspectives of spiritual care between faculty and students, Seventh-day Adventists and non-Seventh-day Adventists, and males and females

\section{Chapter Summary}

Program directors of the 10 Seventh-day Adventist NLN accredited baccalaureate nursing programs in North America were invited to participate in a descriptive, correlational, comparative study using survey research methodology. The University Version of the Charles Kettering Scale and a subscale of the Spiritual Care Perspectives Scales were sent to nine program directors who distributed the questionnaires to faculty and upper division students. Questionnaires were returned to me in sealed envelopes. The data were entered into the SPSS 10.0 for Windows.

The statistical analysis of the hypotheses that were tested at the .05 level of significance included Pearson correlation for hypotheses 1 and 2, simple analysis of variance for hypotheses 3 and 4 , and $t$ test for independent samples for hypotheses 5 through 12 .

Chapter 4 contains a description of the participants, a description of the characteristics of the variables in the study, and the results of the statistical analysis performed to test the hypotheses. 


\section{CHAPTER 4}

\section{ANALYSIS OF THE DATA}

\section{Introduction}

As described in the previous chapter, a descriptive, correlational, comparative study using survey research methodology was conducted to explore the relationship between perspectives of spiritual care and organizational climate in baccalaureate nursing programs. The units of observation were the upper division students and the faculty members of Seventh-day Adventist baccalaureate nursing programs in Norh America. To assess organizational climate and perspectives of spiritual care, the University Version of the Charles Kettering Climate Scale and the Role of Spiritual Care in Nursing Subscale of the Spiritual Care Perspectives Scale were used (Appendix A).

This chapter describes the characteristics of the participants and the characteristics of the variables in the study and presents the results of the statistical analysis of the data.

\section{Description of the Participants}

A total of 208 members (49 faculty and 159 upper division students) from nine different Seventh-day Adventist, National League for Nursing accredited baccalaureate nursing programs participated in the study. Their ages ranged from 20 to 68 with a mean age of 34 . Among the participants, $186(90 \%)$ were females, $19(9 \%)$ were males, and 3 ( $1 \%)$ did not identify their gender. As to religious preference, $122(59 \%)$ indicated Seventh-day Adventist, $83(40 \%)$ mentioned other denominations such as Baptist, Four 
Square, Lutheran, Protestant, Christian, or non-religious, and $3(1 \%)$ did not answer that question.

Table 2 presents the percentage of faculty and students who participated in the study from each nursing program and the percentage of participants who were Seventhday Adventists, non-Seventh-day Adventists, females, and males.

Table 2

Percentage of Faculty and Students From Each Program Who Participated in the Siudy and Percentage of Participants Who Were SDA, non-SDA. Female, and Male

\begin{tabular}{lrccrrrr}
\hline $\begin{array}{l}\text { Program } \\
\text { ID }\end{array}$ & $N$ & \multicolumn{7}{c}{ PER C E N T A G E } \\
\cline { 3 - 8 } Number & & Faculty $^{\text {a }}$ & Students $^{\mathbf{2}}$ & \multicolumn{1}{c}{ SDA } & Non-SDA & Female & Male \\
\hline 1 & 27 & 20.0 & 29.4 & 29.6 & 70.4 & $\mathbf{8 8 . 8}$ & 11.1 \\
2 & 13 & 66.7 & 64.3 & 100.0 & 0.0 & 76.9 & 23.1 \\
3 & 18 & 100.0 & 85.7 & 83.3 & 16.7 & 94.4 & 5.6 \\
4 & 42 & 100.0 & 56.3 & 42.9 & 57.1 & 95.2 & 4.8 \\
5 & 7 & 83.3 & 10.0 & 100.0 & 0.0 & 100.0 & 0.0 \\
6 & 26 & 45.5 & 7.3 & 73.1 & 26.9 & 96.2 & 3.8 \\
7 & 27 & 100.0 & 64.7 & 37.0 & 63.0 & $\mathbf{8 8 . 9}$ & 11.1 \\
8 & 41 & 100.0 & 97.3 & 73.2 & 19.5 & 80.5 & 12.2 \\
9 & 7 & 14.3 & 46.2 & 28.6 & 71.4 & 85.7 & 14.3 \\
Overall & 208 & 58.3 & 36.9 & 58.7 & 39.9 & $\mathbf{8 9 . 4}$ & 9.1 \\
\hline
\end{tabular}

${ }^{a}$ Only the percentage of faculty and students of each program who participated in the study are given. The number of faculty and students in each program is not given in order to protect the program's identity. $N$ refers to the total participants from each program.

\section{Characteristics of the Faculty}

The age range of the participating faculty members was 25 to 68 years with a mean and median of 50 . Of the 49 faculty members who participated, $45(92 \%)$ were female, $1(2 \%)$ was male, and $3(6 \%)$ did not identify their gender. As their religious preference, 42 (86\%) specified Seventh-day Adventist, 4 (8\%) mentioned other 
denominations, and $3(6 \%)$ did not answer that question. A total of $43(88 \%)$ were fulltime faculty, $3(6 \%)$ were part-time, and $3(6 \%)$ did not specify workload. Doctorate degrees were held by $17(35 \%)$ of the faculty, master's degrees by $26(53 \%)$, and bachelor's deg:ees by $2(4 \%)$. While $2(4 \%)$ mentioned holding other degrees (education specialist), another $2(4 \%)$ did not answer that question. The total time faculty had worked in that particular baccalaureate nursing program varied from 5 to 330 months, the mean being 110 months.

\section{Characteristics of the Students}

The age range of the upper division students who participated was 20 to 57 years with a mean of 29 and a median of 25 . Of the 159 students in the study, $141(89 \%)$ were females and $18(11 \%)$ were males. Seventh-day Adventist was given as the religious preference by $80(50 \%)$ of the students while the other $79(50 \%)$ indicated other preferences. When entering the baccalaureate nursing program, $59(37 \%)$ came directly from high school, $73(46 \%)$ had previously completed an A.S. degree in nursing, 21 $(13 \%)$ held associate or bachelor degrees in other areas, and $6(4 \%)$ did not answer the question peraining to highest degree obtained before entering the B.S. nursing program The total amount of time the students had been in the current program varied from 1 to 84 months with a mean of 18 months. The total number of credits completed at the time of answering the survey varied from zero to 260 with a mean of 62 credits. 


\section{Description of the Characteristics of the Variables}

\section{Organizational Climate}

In this study, the organizational climate of a nursing program was considered to be the set of internal environmental characteristics of that particular program as perceived by its members (students and faculty), and which influence each member's behavior. To measure this construct the University Version of the Charles F. Kettering School Climate (UCFK) was used. The UCFK climate scale consists of 40 items divided into eight subscales containing five items each: (a) Respect, items 1-5, (b) Trust, items 6-10, (c) High Morale, items 11-15, (d) Opportunity for Input, items 16-20, (e) Continuous Academic and Social Growth, items 21-25, (f) Cohesiveness, items 26-30, (g) School Renewal, items 31-35, and (h) Caring, items 36-40. Each of these subscales measures the climate factor its name indicates. In this study, when referring to the climate subscale, the term will be capitalized. When referring to the climate factor, quotation marks will be used.

There are two discrepancy format columns on the UCFK where the respondents placed their answer to each item. In the "What Is" column the respondents indicated the perceived actual condition, whereas in the "What Should Be" column they indicated the perceived desired condition. Each item was answered using the following scale for both columns: 1 = almost never, 2 = occasionally, 3 = frequently, and $4=$ almost always.

The scores for each subscale could range from 15, indicating an extremely unfavorable climate in that particular area, to minus 15 , indicating a climate that is way better than desired. These scores were obtained by subtracting the number on the "What Is" column from the number on the "What Should Be" column for each item in that 
particular subscale. If the individual perceived that the actual climate corresponded to the desired climate for each item in that subscale, the score would be zero for that subscale. If the numbers on the "What Should Be" column were larger than the numbers on the "What Is" column, the score would be a positive number indicating that the actual climate was not up to par with the desired climate. However, if the numbers on the "What Is" column were larger, the score would be a negative number indicating that the actual climate was even better than desired. The scores of the eight subscales were then added to obtain the overall organizational climate score as perceived by that respondent. Theoretically, the total climate score could range from 120 to minus 120 .

A mean of 20.51 , median of 17.00 , and mode of 20.00 were obtained for organizational climate. Figure 1 shows the frequencies of the organizational climate scores and Table 3 presents the overall mean, standard deviation, and range of organizational climate and subscales scores obtained in this study.

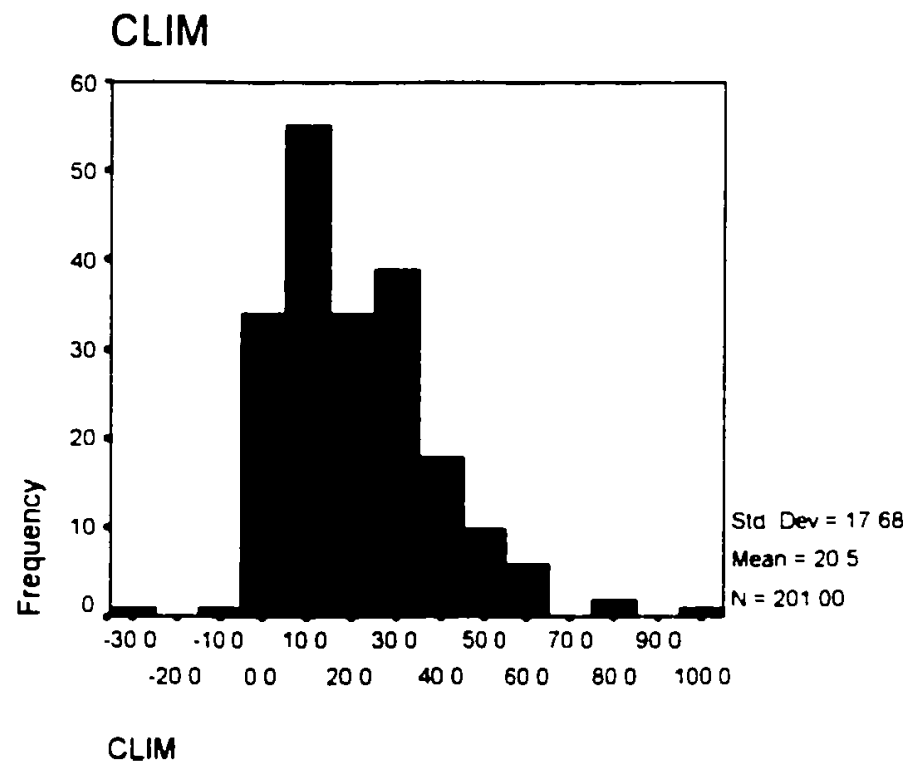

Figure 1. Organizational climate scores. 
Table 4 presents the organizational climate mean score, standard deviation, and skewness for each participating nursing program.

Table 3

Overall Mean, Standard Deviation, and Range of Organizational Climate and Subscales Scores $(N=208)$

\begin{tabular}{lrrlll}
\hline Variable & Mean & $S D$ & Skewness & Minimum & Maximum \\
\hline Organizational Climate & 20.51 & 17.68 & 1.04 & -27 & 95 \\
Caring & 1.89 & 2.68 & 1.50 & -4 & 12 \\
Respect & 1.91 & 1.91 & 1.11 & -2 & 11 \\
Trust & 3.25 & 3.04 & 1.06 & -4 & 14 \\
Cohesive & 2.08 & 2.54 & 1.10 & -4 & 13 \\
Morale & 2.14 & 2.25 & .90 & -3 & 10 \\
Input & 3.65 & 3.64 & .76 & -8 & 15 \\
Growth & 2.87 & 2.73 & 1.18 & -2 & 15 \\
Renewal & 2.99 & 2.96 & 1.10 & -2 & 14 \\
\hline
\end{tabular}

Table 4

Organizational Climate Mean Score, Standard Deviation, and Skewness of Nursing Programs $(N=208)$

\begin{tabular}{llrc}
\hline Program & Climate mean & \multicolumn{1}{c}{$S D$} & Skewness \\
\hline 1 & 27.82 & 24.52 & 0.29 \\
2 & 23.77 & 9.99 & -0.33 \\
3 & 20.33 & 19.08 & 0.85 \\
4 & 14.02 & 13.56 & 0.77 \\
5 & 13.29 & 16.09 & 1.52 \\
6 & 29.04 & 15.29 & 0.51 \\
7 & 24.35 & 21.23 & 1.70 \\
8 & 14.73 & 12.84 & 1.30 \\
9 & 20.00 & 11.30 & -0.61 \\
\hline
\end{tabular}

\section{Spiritual Care}

Perspectives of spiritual care refers to the nurses' (students' and faculty's) attitudes about the importance of including spiritual care in nursing caregiving. For 
measuring this construct, the Role of Spiritual Care in Nursing Subscale of the Spiritual Care Perspectives Scale was used.

The participants scored each of the seven items of this section of the instrument using a scale from 1-5. The sum of the scores of the seven items theoretically range from 7 to 35 . A high score indicates a positive attitude towards spiritual care whereas a low score indicates a negative attitude.

A mean score of 29.43 , median of 30.00 , and mode of 32 were obtained for perspectives of spiritual care. The minimum score was 17 and the maximum 35 . The standard deviation was 3.49 and the skewness -7.30 .

Figure 2 shows the frequencies of the perspectives of spiritual care scores obtained in this study.

Table 5 presents the mean, standard deviation, and skewness of the perspectives of spiritual care scores of the nine paricipating nursing programs. Table 6 shows the mean and standard deviation for each of the seven items on the Role of Spiritual Care in Nursing Subscale.

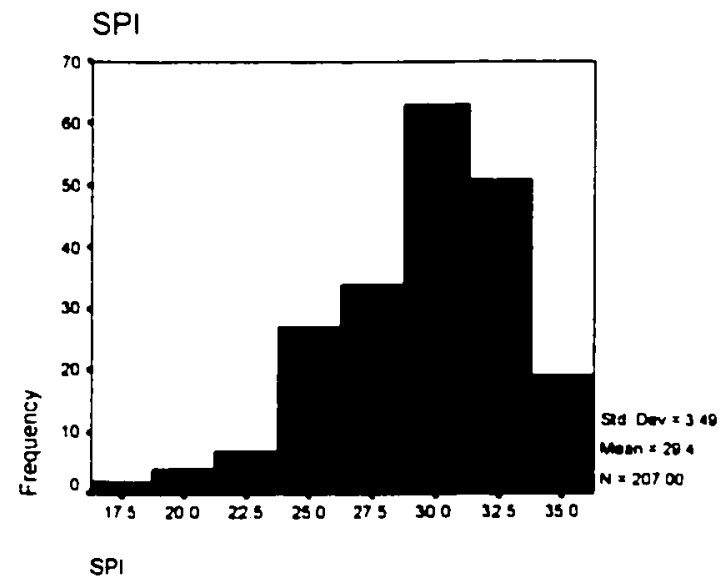

Figure 2. Perspectives of spiritual care scores. 
Table 5

Perspectives of Spiritual Care Mean Score, Standard

Deviation, and Skewness of Nursing Programs $(N=208)$

\begin{tabular}{llll}
\hline Program & Spiritual Care Mean & $S D$ & Skewness \\
\hline 1 & 28.04 & 4.37 & -0.53 \\
2 & 30.54 & 2.30 & -1.23 \\
3 & 30.67 & 3.05 & -0.50 \\
4 & 29.71 & 3.93 & -1.15 \\
5 & 29.86 & 2.91 & 0.76 \\
6 & 30.77 & 3.08 & 0.66 \\
7 & 29.22 & 3.32 & -0.57 \\
8 & 28.25 & 3.04 & -0.16 \\
9 & 30.00 & 1.83 & 0.00 \\
\hline
\end{tabular}

Table 6

Overall, Faculty, and Student Mean and Standard Deviation of Items on the Role of Spiritual Care in Nursing Subscale ( $N=208$ participants: 49 faculty and 159 students)

\begin{tabular}{lcccccc}
\hline Item & Mean & SD & $F$ Mean & $S D$ & $S$ mean & $S D$ \\
\hline Spiritual care is a significant part of nursing. & 4.18 & .77 & 4.43 & .76 & 4.11 & .76 \\
My patients have much spiritual need. & 3.65 & .74 & 3.96 & .61 & 3.55 & .75 \\
Nursing practice does include spiritual care. & 4.14 & .89 & 4.55 & .77 & 4.01 & .90 \\
Spiritual care is only for religious persons. & 4.57 & .73 & 4.92 & .28 & 4.46 & .79 \\
A patient's spiritual concerns are my business. & 4.21 & .87 & 4.53 & .68 & 4.11 & .90 \\
$\begin{array}{l}\text { Only clergy should help patients with religious } \\
\quad\end{array}$ & 4.28 & .88 & 4.51 & .77 & 4.21 & .90 \\
$\begin{array}{l}\text { Thetivities. } \\
\quad \text { spiritual resources to cope with illness. }\end{array}$ & 4.41 & .83 & 4.50 & .46 & 4.29 & .89 \\
Perspectives of Spiritual Care Mean & 29.43 & 3.49 & 31.69 & 2.29 & 28.73 & 3.51 \\
\hline
\end{tabular}

\section{Testing of the Null Hypotheses}

The Relationship Between Organizational Climate and

Perspectives of Spiritual Care

Null hypotheses 1 and 2 tested the relationship between perspectives of

spiritual care and organizational climate subscales total scores for nursing students and faculty respectively. 


\section{Null Hypothesis 1}

Null hypothesis lstated: There is no significant relationship between nursing students' perspectives of spiritual care and each organizational climate subscale and total score.

This hypothesis was subdivided for testing purposes. Pearson $r$ was employed for testing the relationship between nursing students' perspectives of spiritual care and organizational climate as well as each climate subscale (Caring. Cohesiveness.

Growth, High Morale, Opportunity for Input. Respect, School Renewal, and Trust).

The correlation coefficient and probability values of students' perspectives of spiritual care and organizational climate and climate subscales are presented in Table 7

Appendix D shows the SPSS output of the descriptive statistics and the correlations calculated for the subhypotheses.

\section{Table 7}

Pearson Correlation of Students' Perspectives of Spiritual Care and Organizational Climate Scale and Subscales

\begin{tabular}{lll}
\hline $\begin{array}{l}\text { Climate Scale and } \\
\text { Subscales }\end{array}$ & $r$ & $p$ \\
\hline Organizational Climate & -.1552 & .056 \\
Caring & -.1859 & $.021^{*}$ \\
Cohesiveness & -.0172 & .833 \\
Growth & -.1338 & .098 \\
High Morale & -.1321 & .102 \\
Opportunity for Input & -.1400 & .083 \\
Respect & -.1702 & $.035^{*}$ \\
School Renewal & -.1619 & $.045^{*}$ \\
Trust & -.1254 & .121 \\
\hline * Correlation is significant at the 0.05 level (2-tailed)
\end{tabular}


1a. There is no significant relationship between nursing students' perspectives of spiritual care and organizational climate. Null hypothesis la was retained $(r=-.1552, p=.056)$

1b. There is no significant relationship between nursing students' perspectives of spiritual care and the climate subscale Caring. Null hypothesis $1 \mathrm{~b}$ was rejected $(r=-.1859, p=.021)$

1c. There is no significant relationship between nursing students' perspectives of spiritual care and the climate subscale Cohesiveness. Null hypothesis lc was retained $(r=-.0172, p=.833)$.

ld. There is no significant relationship between nursing students' perspectives of spiritual care and the climate subscale Growth. Null hypothesis Id was retained $(r=-.1338, p=.098)$

le. There is no significant relationship between nursing students' perspectives of spiritual care and the climate subscale Opportunity for Input. Null hypothesis le was retained $(r=-.1400, p=.083)$

If. There is no significant relationship between nursing students perspectives of spiritual care and the climate subscale High Morale. Null hypothesis If was retained $(r=-.1321, p=.102)$.

lg. There is no significant relationship between nursing students' perspectives of spiritual care and the climate subscale Respect. Null hypothesis $1 \mathrm{~g}$ was rejected $(r=-.1702, p=.035)$ 
Th. There is no significant relationship between nursing students' perspectives of spiritual care and the climate subscale School Renewal. Null hypothesis $1 \mathrm{~h}$ was rejected $(r=-.1619, p=.045)$.

li. There is no significant relationship between nursing students' perspectives of spiritual care and the climate subscale Trust. Null hypothesis li was retained $(r=$ $-.1254, p=.121)$

\section{Null Hypothesis 2}

Null hypothesis 2 stated: There is no significant relationship between the faculty's perspectives of spiritual care and each organizational climate subscale and total score

This hypothesis was subdivided for testing purposes. Pearson $r$ was employed for testing the relationship between the faculty's perspectives of spiritual care and organizational climate as well as each climate subscale (Caring, Cohesiveness, Growth, High Morale, Opportunity for Input, Respect, School Renewal, and Trust). The correlation coefficient and probability values of faculty's perspectives of spiritual care and organizational climate and the climate subscales are presented in Table 8 Appendix D shows SPSS output of descriptive statistics and correlations.

2a. There is no significant relationship between the faculty's perspective of spiritual care and organizational climate. Null hypothesis 2 a was retained $(r=-0765$. $p=.605)$

2b. There is no significant relationship between the faculty's perspective of spiritual care and the climate subscale Caring. Null hypothesis $2 \mathrm{~b}$ was retained 
$(r=-.0125, p=.933)$

Table 8

Pearson Correlation of Faculty's Perspectives of Spiritual Care and Organizational Climate Scale and Subscales

\begin{tabular}{lll}
\hline Climate Scale and & $r$ & $p$ \\
Subscales & & .605 \\
\hline Organizational Climate & -.0765 & .933 \\
Caring & -.0125 & .449 \\
Cohesiveness & -.1119 & .487 \\
Growth & -.1027 & .229 \\
High Morale & -.1770 & .957 \\
Opportunity for Input & .0081 & .775 \\
Respect & -.0423 & .781 \\
School Renewal & -.0411 & .832 \\
Trust & -.0314 & \\
\hline
\end{tabular}

2c. There is no significant relationship between the faculty's perspective of spiritual care and the climate subscale Cohesiveness. Null hypothesis $2 \mathrm{c}$ was retained $(r=-.1119, p=.449)$

$2 \mathrm{~d}$. There is no significant relationship between the faculty's perspective of spiritual care and the climate subscale Growth. Null hypothesis $2 \mathrm{~d}$ was retained $(r=-.1027, p=487)$.

2e. There is no significant relationship between the faculty's perspective of spiritual care and the climate subscale Opportunity for Input. Null hypothesis 2e was retained $(r=-.0081, p=.957)$

2f. There is no significant relationship between the faculty's perspective of spiritual care and the climate subscale High Morale. Null hypothesis $2 \mathrm{f}$ was retained 
$(r=-.1770, p=.229)$

$2 \mathrm{~g}$. There is no significant relationship between the faculty's perspective of spiritual care and the climate subscale Respect. Null hypothesis $2 \mathrm{~g}$ was retained $(r=-.0423, p=.775)$

$2 \mathrm{~h}$. There is no significant relationship between the faculty's perspective of spiritual care and the climate subscale School Renewal. Null hypothesis $2 \mathrm{~h}$ was retained $(r=-.0411, p=.781)$.

$2 \mathrm{i}$. There is no significant relationship between the faculty's perspective of spiritual care and the climate subscale Trust. Null hypothesis $2 \mathrm{i}$ was retained $(r=-.0314, p=.832)$

\section{Difference in Organizational Climate and Perspectives of Spiritual Care Between Nursing Programs}

Null hypotheses 3 and 4 tested for differences in perception of organizational climate and perspectives of spiritual care between the nursing programs.

\section{Null Hypothesis 3}

Null hypothesis 3 stated: There is no significant difference in perception of organizational climate between nursing programs.

Only the nursing programs with at least a $50 \%$ response rate from both faculty and students were included in the analysis of this hypothesis. Table 2 shows the percentage of faculty and students who responded from each program.

One-way ANOVA was used to compare the means of the school climate scores of nursing programs number $2,3,4,7$, and 8 . Table 9 reveals the values obtained. 
Although a significant $F$ ratio was obtained $(F=2.688, p=.034)$, the assumption of equality of variances of groups was not reached as evidenced by Levene's test of homogeneity of variances (Appendix D).

Utilizing Games-Howell post hoc test for unequal variances, no group was significantly different from the others. Appendix D shows SPSS output of one-way ANOVA and Games-Howell post hoc test. A boxplot of organizational climate and nursing programs showed one outlier in program 7 and two outliers in program 8 . One-way ANOVA was repeated after withdrawing the three extreme cases, obtaining the same results as before removing the extreme cases.

Table 9

ANOVA of Organizational Climate Scores of Selected Nursing Programs

\begin{tabular}{lccccc}
\hline Source & $\begin{array}{l}\text { Sum of } \\
\text { Squares }\end{array}$ & $d f$ & $\begin{array}{l}\text { Mean } \\
\text { Squares }\end{array}$ & F ratio & Sig. \\
\hline Between Groups & 2637.269 & 4 & 659.317 & 2.6880 & .0340 \\
Within Groups & 32132.466 & 131 & 245.286 & & \\
Total & 34769.735 & 135 & & & \\
\hline
\end{tabular}

Therefore, because Games-Howell post hoc test revealed no group was significantly differ ent from the others, null hypothesis 3 was retained.

\section{Null Hypothesis 4}

Nuli hypothesis $\mathbf{4}$ stated: There is no significant difference in perspectives of spiritual care between nursing programs. 
Only the nursing programs with at least a $50 \%$ response rate from both faculty and students were included in the testing of this hypothesis. Table 2 shows the percentage of faculty and students who responded from each program. One-way ANOVA was used to compare the means of the perspectives of spiritual care scores of nursing programs number $2,3,4,7$, and 8 . Table 10 presents the values obtained $(F=$ $2.329, d f=4, p=.059)$. No two groups were significantly different at the .05 level. Therefore, null hypothesis 4 was retained.

Table 10

ANOI'A of Perspectives of Spiritual Care Scores of Selected Nursing Programs

\begin{tabular}{lcclcl}
\hline Source & $\begin{array}{l}\text { Sum of } \\
\text { Squares }\end{array}$ & $d f$ & $\begin{array}{l}\text { Mean } \\
\text { Squares }\end{array}$ & F ratio & Sig. \\
\hline Between Groups & 103.631 & 4 & 25.908 & 2.329 & .059 \\
Within Groups & 1501.969 & 131 & 11.126 & & \\
Total & 1605.600 & 135 & & & \\
\hline
\end{tabular}

Difference in Organizational Climate Subscale and Total Climate Score Between Different Participant Categories

Null hypotheses 5 through 8 tested differences in each organizational climate subscale score (Caring, Cohesiveness, Growth, High Morale, Opportunity for Input, Respect, School Renewal, and Trust) and total climate score between the different participant categories. 


\section{Null Hypothesis 5}

Null hypothesis 5 stated: There is no significant difference in each organizational climate subscale and total score between faculty and students.

This hypothesis was subdivided for testing purposes. A / test for independent samples was performed on the total organizational climate score and on each climate subscale score (Caring, Cohesiveness, Growth, High Morale, Opportunity for Input, Respect, School Renewal, and Trust). Table 11 presents the mean and standard deviation of organizational climate and subscales scores of faculty and students. Table 12 shows the values obtained on the $t$ tests performed. Appendix D shows SPSS output of $t$ tests for independent samples.

5a. There is no significant difference in the organizational climate score between faculty and students. Null hypothesis 5a was retained $(t=-1.67, d f=199, p$ $=.097)$

5b. There is no significant difference in the climate subscale Caring between faculty and students. Null hypothesis $5 b$ was retained $(t=-1.58, d f=201, p=.116)$.

5c. There is no significant difference in the climate subscale Cohesiveness between faculty and students. Null hypothesis $5 \mathrm{c}$ was retained $(t=-1.17, d f=200, p$ $=.244)$.

5d. There is no significant difference in the climate subscale Growth between faculty and students. Null hypothesis $5 d$ was retained $(t=-.29, d f=201, p=.770)$. 
Table 11

Mean and Standard Deviation of Organizational Climate and Subscales Scores of Faculty and Students $(N=208$ : faculty 49 and students 159$)$

\begin{tabular}{lrrrrr}
\hline Variable & $\begin{array}{l}\text { Faculty } \\
\text { Mean }\end{array}$ & $S D$ & $\begin{array}{l}\text { Student } \\
\text { Mean }\end{array}$ & $S D$ & $\begin{array}{l}\text { Mean } \\
\text { Difference }\end{array}$ \\
\hline Climate & 16.81 & 13.68 & 21.67 & 18.65 & -4.86 \\
Caring & 1.35 & 2.50 & 2.05 & 2.72 & -0.70 \\
Respect & 1.18 & 1.21 & 2.12 & 2.03 & -0.94 \\
Trust & 2.45 & 2.07 & 3.49 & 3.25 & -1.04 \\
Cohesiveness & 2.45 & 2.39 & 1.96 & 2.58 & 0.49 \\
High Morale & 1.95 & 1.74 & 2.19 & 2.37 & -0.24 \\
Input & 2.20 & 3.10 & 4.09 & 3.69 & -1.89 \\
Growth & 2.77 & 2.42 & 2.90 & 2.81 & -0.13 \\
Renewal & 2.41 & 2.37 & 3.16 & 3.09 & -0.75 \\
\hline
\end{tabular}

Table 12

t Test Values for Organizational Climate and Subscale Scores Between Faculty and Students

\begin{tabular}{|c|c|c|c|c|c|c|}
\hline \multirow[t]{2}{*}{ Scale } & \multicolumn{2}{|c|}{ Levene's test } & \multirow[t]{2}{*}{ Variances } & \multirow[t]{2}{*}{$t$} & \multirow[t]{2}{*}{$d f$} & \multirow{2}{*}{$\begin{array}{l}\text { 2-tail } \\
\text { sig. }\end{array}$} \\
\hline & $T$ & $P$ & & & & \\
\hline Climate & 3.058 & .082 & Equal & -1.67 & 199 & .097 \\
\hline Caring & 815 & .368 & Equal & -1.58 & 201 & .116 \\
\hline Cohesiveness & .108 & .743 & Equal & 1.17 & 200 & .244 \\
\hline Growth & .430 & .513 & Equal & -.29 & 201 & .770 \\
\hline Input & 1.588 & .209 & Equal & -3.21 & 201 & $.002^{* *}$ \\
\hline High Morale & 6.234 & .013 & Unequal & -.74 & 106 & .459 \\
\hline Renewal & 4.025 & .046 & Unequal & -1.77 & 101 & .079 \\
\hline Respect & 10.172 & .002 & Unequal & -3.93 & 134 & $.000 * * *$ \\
\hline Trust & 11.007 & .001 & Unequal & -2.60 & 124 & $.010^{* *}$ \\
\hline
\end{tabular}

** Difference is significant at the 0.01 level (2-tailed).

*** Difference is significant at the 0.001 level (2-tailed). 
5e. There is no significant difference in the climate subscale High Morale between faculty and students. Null hypothesis se was retained $(t=-.74$, $d f=106, p=$ 459).

5f. There is no significant difference in the climate subscale Opportunity for Input between faculty and students. Null hypothesis $5 f$ was rejected $(t=-3.21$, $d f=201, p=.002)$

5g. There is no significant difference in the climate subscale Respect between facuity and students. Null hypothesis $5 \mathrm{~g}$ was rejected $(t=-3.93, d f=134, p=.000)$.

5h. There is no significant difference in the climate subscale School Renewal between faculty and students. Null hypothesis $5 \mathrm{~h}$ was retained $(t=-1.77, d f=101, p$ $=.079)$

5i. There is no significant difference in the climate subscale Trust between faculty and students. Null hypothesis 5i was rejected $(t=-2.60, d f=124, p=.010)$.

\section{Null Hypothesis 6}

Null hypothesis 6 stated: There is no significant difference in each organizational climate subscale and total score between Seventh-day Adventist and non-Seventh-day Adventist faculty.

This hypothesis was subdivided for testing purposes. A $t$ test for independent samples was performed on each subscale (Caring, Cohesiveness, Growth, High Morale. Opportunity for Input, Respect, School Renewal, and Trust) and on the total climate score. Table 13 shows the values obtained. 
Table 13

t Test Values for Organizational Climate and Subscale Scores Betw'een SDA and Non-SDA Faculty

\begin{tabular}{|c|c|c|c|c|c|c|}
\hline \multirow[t]{2}{*}{ Scale } & \multicolumn{2}{|c|}{ Levene's test } & \multirow[t]{2}{*}{ Variances } & \multirow[t]{2}{*}{$t$} & \multirow[t]{2}{*}{$d f$} & \multirow{2}{*}{$\begin{array}{l}\text { 2-tail } \\
\text { sig. }\end{array}$} \\
\hline & $F$ & $P$ & & & & \\
\hline Climate & 1.718 & 197 & Equal & 1.08 & 43 & 285 \\
\hline Caring & 3.371 & .073 & Equal & 98 & 43 & 335 \\
\hline Cohesiveness & .936 & .339 & Equal & 1.21 & 43 & 232 \\
\hline Growth & .641 & .428 & Equal & .71 & 43 & .480 \\
\hline High Morale & .873 & .355 & Equal & .64 & 43 & .526 \\
\hline Input & 4.651 & .037 & Unequal & 4.05 & 35 & $.000 * * *$ \\
\hline Renewal & 2.709 & .107 & Equal & .73 & 43 & .470 \\
\hline Respect & 2.515 & .120 & Equal & 37 & 43 & .712 \\
\hline Trust & .046 & .832 & Equal & 01 & 43 & .991 \\
\hline
\end{tabular}

*** Difference is significant at the 0.001 level (2-tailed).

6a. There is no significant difference in the organizational climate score between Seventh-day Adventist and non-Seventh-day Adventist faculty. Null hypothesis $6 \mathrm{a}$ was retained $(t=1.08, d f=43, p=.285)$.

6b. There is no significant difference in the climate subscale Caring between Seventh-day Adventist and non-Seventh-day Adventist faculty. Null hypothesis 6b was retained $(t=.98, d f=43, p=.335)$.

6c. There is no significant difference in the climate subscale Cohesiveness between Seventh-day Adventist and non-Seventh-day Adventist faculty. Null hypothesis $6 c$ was retained $(l=1.21, d f=43, p=.232)$.

$6 \mathrm{~d}$. There is no significant difference in the climate subscale Growth between Seventh-day Adventist and non-Seventh-day Adventist faculty. Null hypothesis $6 \mathrm{~d}$ was retained $(t=.71, d f=43, p=.480)$. 
6e. There is no significant difference in the climate subscale High Morale between Seventh-day Adventist and non-Seventh-day Adventist faculty. Null hypothesis $6 \mathrm{e}$ was retained $(t=.64, d f=43, p=.526)$

6f. There is no significant difference in the climate subscale Opportunity for Input between Seventh-day Adventist and non-Seventh-day Adventist faculty. Null hypothesis $6 f$ was rejected $(t=4.05, d f=35, p=.000)$.

6g. There is no significant difference in the climate subscale Respect between Seventh-day Adventist and non-Seventh-day Adventist faculty. Null hypothesis $6 \mathrm{~g}$ was retained $(t=.37, d f=43, p=.712)$

6h. There is no significant difference in the climate subscale School Renewal between Seventh-day Adventist and non-Seventh-day Adventist faculty. Null hypothesis $6 \mathrm{~h}$ was retained $(t=.73, d f=43, p=.470)$.

6i. There is no significant difference in the climate subscale Trust between Seventh-day Adventist and non-Seventh-day Adventist faculty. Null hypothesis $6 \mathrm{i}$ was retained $(t=.01, d f=43, p=.991)$.

\section{Null Hypothesis 7}

Null hypothesis 7 stated: There is no significant difference in each organizational climate subscale and total score between Seventh-day Adventist and non-Seventh-day Adventist students.

This hypothesis was subdivided for testing purposes. A $/$ test for independent samples was performed on each subscale (Caring, Cohesiveness, Growth, High 
Morale, and Opportunity for Input, Respect, School Renewal, and Trust) and on the total climate score. Table 14 shows the values obtained

Table 14

t Test Values for Organizational Climate and Subscale Scores Between SDA and Non-SDA Students

\begin{tabular}{|c|c|c|c|c|c|c|}
\hline \multirow[t]{2}{*}{$\overline{\text { Scale }}$} & \multicolumn{2}{|c|}{ Levene's test } & \multirow[t]{2}{*}{ Variances } & \multirow[t]{2}{*}{$t$} & \multirow[t]{2}{*}{$d f$} & \multirow{2}{*}{$\begin{array}{l}\text { 2-tail } \\
\text { sig. }\end{array}$} \\
\hline & $F$ & $P$ & & & & \\
\hline Climate & 8.249 & .005 & Unequal & 72 & 135 & .473 \\
\hline Caring & .466 & .496 & Equal & .59 & 153 & 554 \\
\hline Cohesiveness & 3.359 & .069 & Equal & .09 & 152 & .929 \\
\hline Growth & 1.268 & .262 & Equal & 1.45 & 153 & .149 \\
\hline Input & 3.729 & .055 & Equal & -.45 & 153 & .654 \\
\hline Morale & 5.376 & .022 & Unequal & .49 & 144 & .622 \\
\hline Renewal & 2.406 & .123 & Equal & 89 & 153 & .373 \\
\hline Respect & 5.151 & .025 & Unequal & 1.45 & 139 & .150 \\
\hline Trust & .822 & .366 & Equal & 1.93 & 153 & .055 \\
\hline
\end{tabular}

7a. There is no significant difference in the organizational climate score between Seventh-day Adventist and non-Seventh-day Adventist students. Null hypothesis 7 a was retained $(l=.72, d f=135, p=.473)$.

7b. There is no significant difference in the climate subscale Caring between Seventh-day Adventist and non-Seventh-day Adventist faculty. Null hypothesis $7 \mathrm{~b}$ was retained $(t=.59, d f=153, p=.554)$.

7c. There is no significant difference in the climate subscale Cohesiveness between Seventh-day Adventist and non-Seventh-day Adventist faculty. Null hypothesis $7 \mathrm{c}$ was retained $(t=.09, d f=152, p=.929)$. 
7d. There is no significant difference in the climate subscale Growth between Seventh-day Adventist and non-Seventh-day Adventist faculty. Null hypothesis $7 d$ was retained $(t=1.45, d f=153, p=.149)$.

7e. There is no significant difference in the climate subscale High Morale between Seventh-day Adventist and non-Seventh-day Adventist faculty. Null hypothesis $7 \mathrm{e}$ was retained $(t=.49, d f=144, p=.622)$.

7f. There is no significant difference in the climate subscale Opportunity for Input between Seventh-day Adventist and non-Seventh-day Adventist faculty. Null hypothesis $7 \mathrm{f}$ was retained $(l=-.45, d f=153, p=.654)$.

7g. There is no significant difference in the climate subscale Respect between Seventh-day Adventist and non-Seventh-day Adventist faculty. Null hypothesis $7 \mathbf{g}$ was retained $(t=1.45, d f=139, p=.150)$.

7h. There is no significant difference in the climate subscale School Renewal between Seventh-day Adventist and non-Seventh-day Adventist faculty. Null hypothesis 7 w was retained $(t=.89, d f=153, p=.373)$.

7i. There is no significant difference in the climate subscale Trust between Seventh-day Adventist and non-Seventh-day Adventist faculty. Null hypothesis 7i was retained $(t=1.93, d f=153, p=.055)$

\section{Null Hypothesis 8}

Null hypothesis 8 stated: There is no significant difference in each organizational climate subscale and total score between male and female students 
This hypothesis was subdivided for testing purposes. A $l$ test for independent samples was performed on each subscale (Caring, Cohesiveness. Growth, High Morale, Opponunity for Input. Respect. School Renewal, and Trust) and on the total climate score. Table 15 shows the values obtained.

Table 15

t Test lalues for Organizational Climate and Subscale Scores Berueen Male and Female Students

\begin{tabular}{|c|c|c|c|c|c|c|}
\hline \multirow[t]{2}{*}{ Scale } & \multicolumn{2}{|c|}{ Levene's test } & \multirow[t]{2}{*}{ Variance } & \multirow[t]{2}{*}{$I$} & \multirow[t]{2}{*}{$d f$} & \multirow{2}{*}{$\begin{array}{l}\text { 2-tail } \\
\text { sig. }\end{array}$} \\
\hline & $F$ & $P$ & & & & \\
\hline Climate & 1.891 & 171 & Equal & -.13 & 151 & .895 \\
\hline Caring & .066 & .798 & Equal & 45 & 153 & 651 \\
\hline Cohesiveness & .001 & .982 & Equal & -.74 & 152 & .463 \\
\hline Growth & 427 & .514 & Equal & -.69 & 153 & 493 \\
\hline High Morale & 10.154 & .002 & Unequal & 1.18 & 32 & 247 \\
\hline Input & 1.851 & .176 & Equal & 1.48 & 153 & 140 \\
\hline Renewal & $1.06 !$ & .305 & Equal & -.24 & 153 & .810 \\
\hline Respect & .057 & .811 & Equal & -.57 & 152 & 567 \\
\hline Trust & 1.005 & .318 & Equal & -1.17 & 153 & .243 \\
\hline
\end{tabular}

8a. There is no significant difference in the organizational climate score between male and female students. Null hypothesis $8 \mathrm{a}$ was retained $(t=.-13$, df $=$ $151, p=895)$.

$8 \mathrm{~b}$. There is no significant difference in the climate subscale Caring between male and female students. Null hypothesis $8 \mathrm{~b}$ was retained $(t=45, d f=153, p=$ $651)$ 
8c. There is no significant difference in the climate subscale Cohesiveness between male and female students. Null hypothesis $8 \mathrm{c}$ was retained $(t=.74, d f=152$, $p=.463)$

8d. There is no significant difference in the climate subscale Growth between male and female students. Null hypothesis $8 \mathrm{~d}$ was retained $(t=69 . \mathrm{df}=153, p=$ 493).

8e. There is no significant difference in the climate subscale High Morale between male and female students. Null hypothesis $8 \mathrm{e}$ was retained $(t=1.18, d f=32$. $p=.247)$

8f. There is no significant difference in the climate subscale Opportunity for Input between male and female students. Null hypothesis $8 \mathrm{f}$ was retained $(t=1.48, d f$ $=153, p=.140)$

8g. There is no significant difference in the climate subscale Respect between male and female students. Null hypothesis $8 \mathrm{~g}$ was retained $(t=-.57, d f=152, p=$ $.567)$.

8h. There is no significant difference in the climate subscale School Renewal between male and female students. Null hypothesis $8 \mathrm{~h}$ was retained $(\mathrm{t}$-value $=-.24, \mathrm{df}$ $=153, p=.810)$

8i. There is no significant difference in the climate subscale Trust between male and female students. Null hypothesis $8 \mathrm{i}$ was retained $(t=-1.17, d f=153, p=$ $.243)$ 
Difference in Perspectives of Spiritual Care Between the Different Participant Categories

Null hypotheses 9 through 12 tested for significant differences in perspectives of spiritual care between students and faculty, Seventh-day Adventist and nonSeventh-day Adventist faculty, Seventh-day Adventist and non-Seventh-day Adventist students, and male and female students.

Table 16 shows the mean, standard deviation, and range of perspectives of spiritual care scores for the different participant categories.

Table 16

Mean, Standard Deviation, and Range of Perspectives of Spiritual Care Scores for the Different Participant Categories

\begin{tabular}{llllll}
\hline Variable & Mean & SD & Skewness & Minimum & Maximum \\
\hline Overall & 29.43 & 3.49 & -.73 & 17 & 35 \\
Faculty & 31.69 & 2.29 & -.54 & 26 & 35 \\
Student & 28.73 & 3.51 & -.63 & 17 & 35 \\
SDA & 30.07 & 3.05 & -.51 & 21 & 35 \\
Non SDA & 28.42 & 3.90 & -.64 & 17 & 35 \\
Female & 29.44 & 3.54 & -.74 & 17 & 35 \\
Male & 29.00 & 3.20 & -.62 & 23 & 33 \\
\hline
\end{tabular}

Note. $N=208$ participants: 49 faculty and 159 students; 122 SDA and 83 non SDA; 186 females and 19 males.

Table 17 presents the results of the $t$ tests for comparing students with faculty, Seventh-day Adventist with non-Seventh-day Adventist faculty, Seventh-day Adventist with non-Seventh-day Adventist students, and males with female students. 
Table 17

t Test Values for Perspectives of Spiritual Care Scores Between Differemt Participamt Categories

\begin{tabular}{lrrlrrl}
\hline Variable & \multicolumn{2}{c}{ Levene's test } & Variance & $t$ & $d f$ & sig. \\
\cline { 2 - 7 } & $F$ & $P$ & & & & \\
\hline Students and faculty & 7.443 & .007 & Unequal & 6.89 & 123 & $.000^{* * *}$ \\
SDA and non-SDA faculty & 2.224 & .143 & Equal & .64 & 44 & .525 \\
SDA and non-SDA students & 4.799 & .030 & Unequal & 1.58 & 143 & .116 \\
Male and female students & .043 & .835 & Equal & .21 & 156 & .837 \\
\hline
\end{tabular}

Note. $N=208$ participants: 49 faculty and 159 students; 42 SDA and 4 non-SDA faculty; 80 SDA and 78 non-SDA students; 140 female and 18 male students.

*** Difference significant at the 0.001 level (2-tailed).

\section{Null Hypothesis 9}

Null hypothesis 9 stated: There is no significant difference in perspectives of spiritual care between students and faculty.

To test this hypothesis a $t$ test for independent samples was performed. Null hypothesis 9 was rejected $(t=6.89, d f=123, p=.000)$.

\section{Null Hypothesis 10}

Null hypothesis 10 stated: There is no significant difference in perspectives of spiritual care between Seventh-day Adventist and non-Seventh-day Adventist faculty.

To test this hypothesis a $t$ test for independent samples was performed. Null hypothesis 10 was retained $(t=.64, d f=44, p=.525)$. 


\section{Null Hypothesis 11}

Null hypothesis 11 stated: There is no significant difference in perspectives of spiritual care between Seventh-day Adventist and non-Seventh-day Adventist students.

To test this hypothesis a $t$ test for independent samples was performed. Null hypothesis 11 was retained $(t=1.58, d f=143, p=.116)$

\section{Null Hypothesis 12}

Null hypothesis 12 stated: There is no significant difference in perspectives of spiritual care between male and female students.

To test this hypothesis a $l$ test for independent samples was performed. Null hypothesis 12 was retained $(t=-.21, d f=156, p=.837)$

\section{Summary}

A total of 49 faculty and 159 upper division students of nine Seventh-day Adventist Baccalaureate Nursing Programs answered the University Version of the Charles Kettering Climate Scale and the Role of Spiritual Care in Nursing Subscale of the Spiritual Care Perspectives Scale. This represents a return rate of $40.4 \%$ overall, $58.3 \%$ faculty, and $36.9 \%$ student.

Of the 12 null hypotheses in this study 8 were retained and 4 were rejected. Null hypotheses 1,2 , and 5 through 8 were subdivided into nine sub-hypotheses each for testing purposes. 
The results of the data analysis suggest that there is weak relationship between students' perspectives of spiritual care and their perception of climate subscales Caring, Respect, and School Renewal. No significant relationship was found between students' perspectives of spiritual care and the total organizational climate score or between faculty's perspectives of spiritual care and the total organizational climate score.

Significant differences were not found in perception of organizational climate or perspectives of spiritual care between nursing programs.

Significant differences were found in the climate subscales Opportunity for Input and Trust between faculty and students. A significant difference was also found in the climate subscale Opportunity for Input between Seventh-day Adventist and nonSeventh-day Adventist faculty. A significant difference was found in perspectives of spiritual care between students and faculty.

Significant differences were not found in any of the organizational climate subscales or total climate score between Seventh-day Adventist and non-Seventh-day Adventist students or between male and female students. No significant differences were found in perspectives of spiritual care between Seventh-day Adventist and nonSeventh-day Adventist students or between male and female students.

Chapter 5 presents a summary of the study, a discussion of the findings, the conclusions and implications of the findings, and the recommendations for further research. 


\section{CHAPTER 5}

\section{SUMMARY, DISCUSSION, CONCLUSIONS,}

\section{AND RECOMMENDATIONS}

This final chapter presents a summary of the study, a discussion of the findings, the conclusions and implications, along with the recommendations for further study.

\section{Summary}

This summary includes the statement of the problem, the purpose of the study, a brief overview of the literature, a review of the methodology used, and an outline of the findings.

\section{Statement of the Problem}

In accordance with the philosophy of Seventh-day Adventist education, spiritual development is an essential aspect of a balanced education. Consequently, spiritual caregiving should have an integral and fundamental place in the official curriculum of Seventh-day Adventist nursing programs. Indeed, a look at whether the hidden curriculum, as transmitted through selected school climate factors, relates to perspectives of spiritual care becomes important.

The impact of school climate on primary and secondary education has been widely studied (Freiberg et al.,1987; Hoy \& Hannum, 1997; Webb \& Norton, 1999). Not as much work has been done however on organizational climate in higher education (Johnson et al., 1999). "In spite of the emphasis in the literature concerning the 
importance of climate research, climate in nursing education settings rarely has been investigated" (Lubbert, 1995, p. 317)

Hughes (1993) revealed the need for further investigation in this area. She recommends investigating the relationship "between the organizational climate for caring and the ability of students to enact in the nursing role as one caring" (p. 341). This research study focused on a specific component of the total caring package-spiritual care

\section{Purpose of the Study}

The purpose of this study was to explore the interrelationships between the perspectives of spiritual care held by students and faculty in Seventh-day Adventist baccalaureate nursing programs and their perception of the program's organizational climate. This study also allowed for comparison of perspectives and spiritual care and perception of organizational climate between faculty and students, Seventh-day Adventists and non-Seventh-day Adventists, and between males and females, as well as between nursing programs.

\section{Overview of the Literature}

The literature reviewed for this study was related to spiritual care and organizational climate. The first part of the review addressed wholistic care, spirituality, nursing theories, and models that support wholism and spiritual caregiving, and the implementation of spiritual care. 


\section{Overview of Spiritual Care}

There is an increasing interest in spirituality and spiritual caregiving among health care professionals (Narayanasamy, 2001). However, in spite of the growing acceptance that spirituality is important to holistic care (Martsolf \& Mickley, 1998), uncertainty prevails as to exactly what aspects of human nature may be considered spiritual. Hancock's (2000) review of the literature on the subject revealed no single definition of spirituality. Narayanasamy and Owens's (2001) critical incident study of nurses' responses to the spiritual needs of their patients also revealed confusion over the concept of spirituality and spiritual caregiving.

Lack of clarity regarding the differences and similitude between the terms holistic and wholistic, of which the spiritual dimension is an important part, adds to the confusion. While Schubert (1989) uses von Bertalanffy's System Theory to differentiate wholistic from holism, Estby and Freel (1994) use the same theory for describing the basic tenets that it shares with holism.

Although both terms wholistic (Jones, 2001; Piles, 1990; Schuster, 1997) and holistic (Alster, 1984; Bishop \& Scudder, 1997; Dossey, 1998; Estby \& Freel, 1994; Johnson, 1988; Laffrey \& Kulbok, 1999; Plawecki, 1996; Schubert, 1989; Simpson, 1999; Smuts, 1926; Springett, 1989; Wright, 2000) can be found in the literature, there is an increasingly marked preference for the omission of the "w."

Vazquez (1996) signals a difference in preference: "New Agers prefer to use 'holistic' spelled without the ' $w$ ' whereas Christians traditionally have used the term 'wholistic' spelled with a 'w' " (p. 5). A deeper study reveals definite differences in the conceptualization and the underlying ideologies of the users. The concept of holism, 
generally traced to the Greek philosopher Plato, and believed to have been coined by Jan Smuts in 1926, like wholism, acknowledges the integrated, inseparable human dimensions of mind, spirit, and body (Robins, 1999). However, the term has a different connotation to those who hold a biblical worldview than to the originators and postmodern advocates of holism (Vasquez, 1996). Regardless of the underlying philosophy, humans seek the restoration of wholeness even through reductionism if they could (Robins, 1999). The choice of the word holistic or wholistic, holism or wholism, itself, is not as significant to spiritual care and the restoration of wholeness as is each author's underlying worldview and conceptualization of spirituality.

Martsolf and Mickley (1998) examined present modern nurse theorists' ideas on spirituality to determine the extent of focus on spiritual caregiving within each model or theory. They divided the models and theories into three categories: (1) those that said little or nothing about spiritual care which include the models developed by Peplau, Orlando, King, and Orem; (2) those that have spiritual care embedded in the theory include the models of Levine, Roy, Leininger, and Rogers; and (3) those in which spirituality is a major concept include the models of Neuman, Newman, Parse, and Watson. Among the nursing theorists who promote spiritual caregiving as an important aspect of wholistic nursing care are Virginia Avenel Henderson, Jean Watson, and Betty Neuman (Taylor, 2002). Three models in which spirituality is a major concept are Neuman Systems Model (Neuman, 1995), Health as Expanding Consciousness (Newman, 1994), and Theory of Human Caring (Watson, 1985).

Taylor (2002) believes the spiritual dimension has a powerful influence on every aspect of life and that all humans, because they possess a spiritual dimension, will 
express their spirituality to nurses, who in turn need to know how to respond. For the

Christian nurse with a biblical worldview, an understanding of spirituality as the relationship with God through Jesus Christ is vital (Shelly \& Miller, 1999). Although living in a secular world of pragmatic thinkers, the Christian nurse needs to have a Christian mind that sees beyond this life to another one and that is concerned for the salvation of people (Blamires, 1963).

Both Soeken and Carson (1986) and Stranaham (2001) found a direct relationship between personal spiritual well-being and a positive attitude toward providing spiritual care. Taylor et al. (1999), in a comparative study of perspectives and practices of spiritual care between nurses in two subspecialties, found that what determined spiritual care perspectives and caregiving the most was the spirituality of the nurse. These authors stress the importance of further exploring how nurses' personal spirituality contributes to spiritual caregiving.

Jones (2001) suggests that the most basic spiritual caregiving involves providing a "caring connection" for the patient. Nurses who have experienced connectedness with themselves, and with a Higher Power, explains Jones, will be more prepared to promote "wholistic" health and spiritual well-being in their patients.

\section{Overview of Organizational Climate}

The concept of organizational climate, school climate, instruments used to assess climate, and research conducted in this field was addressed in the second part of the literature review.

Since Halpin and Croft's (1962) initial work on climate of schools, numerous climate studies have been conducted on (1) the characteristics found in schools with 
positive climates, (2) the impact of school climate on student achievement, (3) the impact of school climate on the behavior of personnel, and (4) the impact of school climate on school program innovation and change (Webb \& Norton, 1999).

The findings of research on organizational climate suggest that a positive and open climate: (1) fosters dispersion of influence throughout the school (Lubbert, 1995), (2) enhances teamwork and communication by creating an atmosphere of cooperation and openness (Shadur \& Kienzle, 1999), (3) helps organization members cope with disnuptive external forces and direct their energy toward the mission of the organization (Cullen \& Baranowski, 1999), (4) enhances learning (Hoy \& Hannum, 1997), (5) is related to effective management (Griffith, 1999), and (6) improves organization performance by enhancing motivation, morale, and commitment of employees (Schuster \& Morden, 1997).

No studies were found that link organizational climate to spiritual care. Hughes (1993) investigated the relationships among organizational characteristics of baccalaureate schools of nursing and the student-perceived organizational climate for caring. Caring is a core value for nursing practice (Tanner, 1990) that can be learned through interaction with others but not taught in a formal classroom, maintains Hughes (1993). Through their interaction with faculty, students are socialized to values and attitudes about caring. However, certain organizational characteristics of schools of nursing "may create barriers to the experiential learning that is needed to develop caring practitioners" (Hughes, 1993, p. 3). These organizational characteristics such as size, faculty characteristics, structure of clinical experiences, affluence, complexity, and parent institution characteristics contribute to the creation of a school climate. 
Lubbert (1995) and Grigsby's (1991) studies on climate and structure in schools of nursing reveal a significant relationship between the two constructs. Grigsby (1991) suggests that further studies be conducted to "develop an understanding of the impact of organizational factors on the individual functioning within the school and the resulting effect of an individual's productivity and satisfaction on the education of nursing students and the advancement of nursing knowledge" (p. 87).

\section{Methodology}

A descriptive, correlational, causal-comparative study using survey methodology was conducted to explore the relationship between faculty and students' perspectives of spiritual care and organizational climate in Seventh-day Adventist baccalaureate nursing programs.

Because the entire population was less than 600 , the sample consisted of all upper division students and faculty of the nine programs who agreed to participate in the study. Five hundred and fifteen survey questionnaires were sent to 9 of the 10 qualifying programs. A total of 208 members (49 faculty and 159 upper division students) from the nine different nursing programs answered the University Version of the Charles $F$ Kettering School Climate Scale and the Role of Spiritual Care in Nursing Subscale of the Spiritual Care Perspectives Scale.

Twelve hypotheses were generated from the research questions and tested at the .05 level of significance. The first 2 hypotheses addressed the relationship between perspectives of spiritual care and each organizational climate subscale and total climate score. Climate scores and spiritual care perspectives scores obtained from the answers to the University Version of the Charles F. Kettering School Climate Scale and the Role of 
Spiritual Care in Nursing Subscale were correlated. Pearson correlation was employed to test each climate subscale and total score of these two hypotheses

Hypotheses 3 and 4 addressed the difference in perception of organizational climate and spiritual care perspectives between nursing programs. To test these hypotheses, one-way ANOVA was employed.

Hypotheses 5 through 8 addressed the difference in each organizational climate subscale and total score between the different participant categories (students and faculty, Seventh-day Adventists and non-Seventh-day Adventists, males and females). A $t$ test for independent samples was performed to test differences in each climate subscale and total score between the pairs in the different participant categories.

Finally, hypotheses 9 through 12 addressed the difference in perspectives of spiritual care between the different participant categories. $t$ tests were performed to test these hypotheses.

\section{Summary of the Findings}

This section presents a summary of the results of the hypotheses testing.

\section{Hypothesis :}

There is no significant relationship between nursing students' perspectives of spiritual care and each organizational climate subscale and total score.

This hypothesis was subdivided for testing purposes. Null hypothesis $I$ was rejected for the climate subscales Caring, Respect, and School Renewal and retained for the climate subscales Cohesiveness, Growth, Opportunity for Input, High Morale, and Trust as well as total climate score. No statistically significant relationship was found 
between nursing students' perspectives of spiritual care and total organizational climate score. A significant relationship was found, however, between nursing students' perspectives of spiritual care and the climate subscales Caring, Respect, and School Renewal.

\section{Hypothesis 2}

There is no significant relationship between the faculty's perspectives of spiritual care and each organizational climate subscale and total score.

Null hypothesis 2 was retained because no statistically significant relationship was found between the faculty's perspectives of spiritual care and any of the organizational climate subscales or total climate score.

\section{Hypothesis 3}

There is no significant difference in perception of the school's organizational climate between nursing programs.

Null hypothesis 3 was retained. No significant difference was found in perception of school climate between nursing programs

\section{Hypothesis 4}

There is no significant difference in perspectives of spiritual care between nursing programs.

Null hypothesis 4 was retained as no significant difference was found in perspectives of spiritual care between nursing programs. 


\section{Hypothesis 5}

There is no significant difference in each organizational climate subscale and total score between faculty and students.

Null hypothesis 5 was rejected for climate subscales Opportunity for Input and Trust and retained for climate subscales Caring, Cohesiveness, Growth, High Morale, Respect, and School Renewal, as well as total climate score. A significant difference between faculty and students was found only in the climate subscales Opportunity for Input and Trust.

\section{Hypothesis 6}

There is no significant difference in each organizational climate subscale and total score between Seventh-day Adventist and non-Seventh-day Adventist faculty.

Null hypothesis 6 was rejected for climate subscale Opportunity for Input and retained for climate subscales Caring, Cohesiveness, Growth, High Morale, School Renewal. Respect, and Trust. A significant difference between Seventh-day Adventist and non-Seventh-day Adventist faculty was found only in the climate subscale Opportunity for Input.

\section{Hypothesis 7}

There is no significant difference in each organizational climate subscale and total score between Seventh-day Adventist and non-Seventh-day Adventist students

Null hypothesis 7 was retained as no significant difference was found in any of the organizational climate subscales or total climate score between Seventh-day Adventist and non-Seventh-day Adventist students. 


\section{Hypothesis 8}

There is no significant difference in each organizational climate subscale and total score between male and female students.

Null hypothesis $\mathbf{8}$ was retained as no significant difference was found in any of the organizational climate subscales or total climate score between male and female students.

\section{Hypothesis 9}

There is no significant difference in perspectives of spiritual care between students and faculty.

Null hypothesis 9 was rejected. A significant difference in perspectives of spiritual care was found between students and faculty.

\section{Hypothesis 10}

There is no significant difference in perspectives of spiritual care between Seventh-day Adventist and non-Seventh-day Adventist faculty.

Null hypothesis 10 was retained as no significant difference in perspectives of spiritual care was found between Seventh-day Adventist and non-Seventh-day Adventist faculty.

\section{Hypothesis 11}

There is no significant difference in perspectives of spiritual care between Seventh-day Adventist and non-Seventh-day Adventist students 
Null hypothesis 11 was retained as no significant difference in perspectives of spiritual care was found between Seventh-day Adventist and non-Seventh-day Adventist students.

\section{Hypothesis 12}

There is no significant difference in perspectives of spiritual care between male and female students

Null hypothesis 12 was retained as no significant difference in perspectives of spiritual care was found between male and female students.

\section{Discussion of the Findings}

\section{Relationship Between Perspectives of Spiritual Care and Organizational Climate}

The findings of this study showed no significant relationship between either students' or faculty's perspectives of spiritual care and their perception of the overall school climate. When analyzing the relationship between the faculty's perspectives of spiritual care and each school climate subscale (Caring, Cohesiveness, Growth, Opportunity for Input, High Morale, Respect, School Renewal, and Trust) separately, none of the climate subscales correlated with the faculty's perspectives of spiritual care. However, three climate subscales showed a statistically significant, although weak, correlation with students' perspectives of spiritual care: Caring, Respect, and School Renewal.

"One way to interpret correlation coefficients is: coefficient below plus or minus .35 , low or not related; coefficient between plus or minus .35 and .65 , moderately related, and coefficient higher than plus or minus 65 highly related (Gay \& Airasian, 2000, p. 
324). However, as Gay and Airasian explain, statistical significance depends on the sample size.

To be $95 \%$ confident that a correlation represents a true relationship (not a chance one), with a small sample of only 12 participants you would need a correlation of at least .58 in order to conclude the existence of a significant relationship. On the other had, using a sample of 102 participants you would need a correlation of only .19 to conclude that the relationship is significant. This concept makes sense if you consider the case when you could collect data on every member of a population. In this case, no inference would be needed because the whole population was in the sample. Thus regardless of how small the actual correlation coefficient was, it would represent the true degree of relationship between the variables for that population. Even if the coefficient were only .11, for example, it would still indicate the existence of a significant relationship. (pp. 326-327)

The entire population in this study consisted of less than 600 individuals and a total of 208 of these participated in the study. Considering the sample size and using Gay and Airasian's (2000) criteria for interpreting correlation coefficients, the coefficients for Caring, Respect, and School Renewal represent a significant relationship with students' perspectives of spiritual care. However, because of the effect size, the relationship may not be as meaningful.

Given that the purpose of this study was not to explore the more obvious factors that may relate to perspectives of spiritual care such as worldview and personal spirituality, but the factors that are subtler to perceive, even a weak relationship is consequential in this study.

When analyzing the instrument used for assessing the different climate factors, several of the items of the University Version of the Charles F. Kettering Climate Scale pertaining to the Respect and School Renewal subscales, and all of the items of the Caring subscale portray a caring attitude towards the student. For example, item 2, which is part of the Respect subscale, states, "Teachers treat students as persons." Item 33. 
which is part of the School Renewal subscale, states, "When a student comes along who has special problems, this nursing program works out a plan that helps that student."

Question items 36 to 40 , which assessed the "caring" climate factor, were:

36. There is someone in this nursing program on whom I can always count.

37. The teachers really care about the students.

38. I think people in this nursing program care about me as a person and are concerned about more that just how well I perform my role at the school.

39. The nursing school is a nice place to be because I feel wanted and needed there.

40. Most people at this nursing school are kind.

Students who felt better cared for, as revealed by their responses to the Respect,

School Renewal, and Caring subscales, tended to have slightly more positive perspectives of spiritual care. On the other hand, students who perceived a greater gap between the real "caring" school climate and the desired one scored lower on the Spiritual Care Perspectives Scale. This finding prompts conjecture that if students perceive a caring environment, they are more apt to project this caring attitude towards others, including their patients. This caring attitude can then be reflected in their perspectives of spiritual care.

The existence of an association between the perception of a caring environment and spiritual caregiving is not hard to conceive. A "caring connection" is linked to both experiencing a caring environment and to spiritual caregiving. Whether positive perspectives of spiritual care propitiate a caring environment, or a caring environment is more conducive to developing positive perspectives of spiritual care is not the issue in this study. The fact that they are related, however small that relationship may be, is meaningful to the philosophy and mission of Seventh-day Adventist "wholistic" education. Although the findings of this study reveal a very weak correlation between 
perspectives of spiritual care and a "caring" climate, these findings provide a lead to a climate factor that needs to be examined more carefully. Any effort to improve both the caring environment and the perspectives of spiritual care has the potential of producing a synergizing effect, thus potentially strengthening the correlation.

As each faculty member's commitment to God and to the mission of Seventh-day Adventist education strengthens, it is assumable that the "caring connection" would be fortified, hence narrowing the gap between the perceived and desired caring environment and propitiating spiritual caregiving

Whether considering the concept of caring as based on benevolence and social justice, obligation and duty, or love and affection, caring cannot be experienced in an abstract manner (Hughes, 1993). It must be experienced at the interpersonal level.

The goal of caring, explains Hughes. is directed toward "the enhancement of the human experience through either the maintenance or augmentation of the potentialities of another" (p. 76). The attributes of the one caring (in this case the nursing educator) as described by Hughes can be outlined in three points: (1) desire to act on behalf of the student; (2) personal knowledge of the student and perception of the student's reality; and (3) an enriched sense of self that enables the educator to invest emotional energy in the student. On the other hand, the one being cared for (the student) must feel the disposability and intentionality of the educator

Bush (1988) summarizes the characteristics of a caring nurse educator under six concepts: (1) sensitivity, (2) communion with the other. (3) organization of teachinglearning, (4) spirituality, (5) presence, and (6) mutual respect. The subconcepts mentioned by Bush under spirituality, which are characteristics of a caring teacher, 
include: "dynamic, enhances welfare of students, enthusiastic, joyful, knows self, positive self-concept, promotes student self-esteem, realistic, self-congruent, sincere, strong, and thoughtful" (p. 181). When teacher-student encounters have the characteristics of a caring relationship and a caring connection, it is more probable that students will have a better basis for the commitment needed to provide spiritual care to their patients

The fact that faculty's perspectives of spiritual care were not significantly related to any of the individual climate factors may reflect that their attitudes toward spiritual care are more rooted in their worldview and personal spirituality and less related to how they perceive the caring environment than the students' perspectives are.

Previous studies on spiritual care perspectives (Soeken \& Carson, 1986; Stranahan, 2001; Taylor et al., 1999) suggest a positive relationship between personal spirituality and perspectives of spiritual care. This supports the assumption that the participants' perspectives of spiritual care, especially the faculty's, were also related more to their sense of spirituality, their worldview, and their personal spiritual experience than to the organizational climate they were experiencing

Because no previous studies were found in which the concept of organizational climate or climate factors were linked to the perspectives of spiritual care. it was not possible to compare findings.

\section{Difference in Perspectives of Spiritual Care and Organizational Climate Between Nursing Programs}

No significant difference was found in perception of the school climate between nursing programs. The internal environmental characteristics of a particular nursing program which influence the behavior and attitudes of each member were perceived 
similarly by the members of the different participating nursing programs. Regardless of the nursing program they belonged to, all expressed experiencing a similar environmental reality in what relates to the combination of climate factors "respect," "trust," "high morale," "opportunities for input," "continuous academic and social growth," "cohesiveness," "school renewal," and "caring."

Possible limitations caused by a return rate of $40 \%$ or unequal representation from each program were considered. Although some programs had a relatively small representation of either faculty or students or both (as low as $14.3 \%$ faculty participation in one program and $7.3 \%$ student participation in another; see Table 2), five of the nine participating programs had a representation above $50 \%$ for both faculty and students. Even when only including the five programs with more than $50 \%$ member participation in the calculation, the difference in the overall school climate and perspectives of spiritual care between nursing programs remained insignificant

Both the perception of organizational climate and perspectives of spiritual care tended to be uniform across nursing programs rather than diverse. Because all nursing programs included in the study uphold a Christian worldview and Seventh-day Adventist philosophy of education, and supposedly foster the importance of spiritual well-being, this finding is not unexpected.

Although Hughes's (1993) findings suggest that organizational characteristics such as size, faculty characteristics, structure of clinical experiences, affluence, complexity, and parent institution characteristics contribute to the creation of a school climate, the existence of any unique nursing program characteristics that could be 
contributing to more positive perspectives of spiritual care and perception of organizational climate in its members are not implied by the findings of this study.

\section{Difference in Organizational Climate Between the Different Participant Categories}

When testing for differences between faculty's and students' perception of organizational climate and the individual school climate subscales (Respect, Trust, High Morale, Opponunity for Input, Continuous Academic Growth, Cohesiveness, School Renewal, and Caring), a significant difference was found in three of the eight climate subscales: Respect, Trust, and Opportunity for Input. The faculty's mean scores were closer to their desired climate than the students' in all climate factors except Cohesiveness and were significantly different from what pertains to the climate subscales Respect (items 1-5), Trust (items 6-10), and Opportunity for Input (items 16-20) on the survey questionnaire. Although it is not surprising and almost expected as well as desired that faculty would perceive greater opportunity for input than students, the difference in perception of the respect and trust climate is not as desirable.

The items on the UCFK that assessed "respect" and "trust" were the following

1. In this nursing program even low achieving students are respected.

2. Teachers treat students as persons.

3. Parents are considered by this nursing program as important collaborators.

4. Teachers from one subject area or grade level respect those from other subject areas.

5. Teachers in this nursing program are proud to be teachers.

6. Students feel that teachers are "on their side."

7. Although we do not always agree we can share our concerns with each other openly.

8. The teachers are good spokespersons for students' interests and needs.

9. Students can count on teachers to listen to their side of the story and to be fair.

10. Teachers trust students to use good judgment. 
Faculty members perceived a more respectful and trusting relationship among themselves and between themselves and the students than the students did. What faculty members think they are transmitting through the hidden curriculum, as assessed by the climate subscales Respect and Trust, might not be entirely captured by the students. Showing genuine respect and trust are important in developing a working relationship with students and helping them develop critical thinking skills (Rowles \& Brigham, 1998). "The teacher-student relationship must become a "working with' relationship" ( $p$ 249). Finke (1998) describes the knowledge, skills, and values vital to the teaching component of the nursing faculty role. Among these are the competencies related to relationships with students, which include:

Being an advocate for students; advising and counseling students; accepting student diversity; showing consideration for students; having a sense of humor; conveying a sense of caring to students; serving as mentor and role model; facilitating student development; and developing collaborative, collegial relationships with students characterized by mutual respect... (p. 12)

Several of these competencies were assessed in the 10 items related to respect and trust on the survey questionnaire. A closer look at the values and beliefs taught through the interaction with students may reveal some of the contents of the hidden curriculum, which has a much greater impact on the students than the written curriculum (Bevis \& Watson, 1989) and reasonably a greater effect on establishing a "caring connection" with the student.

When analyzing the difference in each organizational climate subscale and total score between Seventh-day Adventist and non-Seventh-day Adventist faculty, no difference was found in total climate score, and the only climate subscale that did show a significant difference was Opportunity for Input. 
Items number 16 through 20 on the survey questionnaire that assessed the climate factor "opportunity for input" were the following:

16. I feel that my ideas are listened to and used in this nursing program

17. When important decisions are made about the nursing program, 1 personally have heard about the plan beforehand and have been involved in some of the decisions.

18. Important decisions are made in this nursing program by a governing council with representation from students, faculty, and administration.

19. Although I cannot have a vote on every decision that is made in this nursing program that affects me, I do feel that I can have some important input into that decision.

20. When all is said and done, I feel that I count in this nursing program.

Of the 49 faculty who participated in the study, only 4 identified their religious preference as other than Seventh-day Adventist. Albeit they were full-time faculty, it is probable that because they do not completely share the beliefs and philosophy of the institution, they perceived less opportunity for input than their Seventh-day Adventist colleagues did. Nonetheless, in spite of their differences in religious beliefs, however great or small, all other climate factors were perceived similarly by Seventh-day Adventist and non-Seventh-day Adventist faculty alike.

Seventh-day Adventist and non-Seventh-day Adventist students also perceived the overall school climate, as well as each climate factor similarly. As far as the transmission of the hidden curriculum, as assessed through the climate subscales, both categories expressed uniformity in their perception of "care," "trust," "respect," "school renewal," "high morale," “opportunity for input," "growth," and "cohesiveness." This gives reason to believe that the students in either category, at least in what relates to these climate factors, did not perceive a difference in treatment

Differences in the perceived organizational climate and climate subscales between male and female students were not found. Because the role of caregiver has been 
considered in the past as mainly a female function, nursing has been, and still is, predominantly a female profession. The proportion of males to females in this study does not disclaim this. Nonetheless, the males who participated in this study perceived a similar caring environment, as did their female classmates. This might in par be due to the fact that, despite gender differences, males who choose the nursing profession have a similar sensitivity to the caring environment and "caring connection" as females who choose nursing.

\section{Difference in Perspectives of Spiritual Care Between Different Participant Categories}

Although no significant difference was observed between faculty and students' perception of the overall organizational climate, a significant difference was found between faculty's and students' perspectives of spiritual care. The faculty's perspectives of spiritual care were more positive than the students' perspectives. This is expected and desired assuming that the faculty members in Seventh-day Adventist nursing programs uphold the organization's philosophy and are conscientious of transmitting the importance of spiritual well-being. Furthermore, faculty are more experienced, and in most cases older than the students, placing them further along in their professional as well as developmental process.

Considering that $85.7 \%$ of the faculty members endorsed Seventh-day Adventist as their religious preference while only $50.3 \%$ of the students indicated this preference, the difference in perspectives at first sight could be ascribed to the higher percentage of Seventh-day Adventist among the nursing faculty than among the students. However, inasmuch as no significant difference was found in perspectives of spiritual care between 
Seventh-day Adventist and non-Seventh-day Adventist students or faculty, this argument does not stand

The fact that students scored significantly lower on the Spiritual Care Perspectives Scale than faculty, regardless of religious preference, has implications for Seventh-day Adventist nursing programs. Because Seventh-day Adventist educational institutions uphold the church's beliefs, practices, and worldview, they are committed to offer a "wholistic" education with a strong spiritual foundation (White, 1923, 1952). The mandate from God to "Therefore go and make disciples of all nations, baptizing them in the name of the Father and of the Son and of the Holy Spirit" (Matt 28.19, NIV) involves Seventh-day Adventist colleges and universities as well. The document (General Conference, 1996) voted at the Annual Council of the General Conference of Seventhday Adventists held in San Jose, Costa Rica, in the autumn of 1996, titled Total Commitment to God: A Declaration of Spiritual Accountability in the Family of Faith. outlines what Seventh-day Adventist colleges' and universities' involvement in the total commitment includes. Among the points mentioned are the following:

Developing a comprehensive spiritual master plan, proposed by the faculty and approved by the board, that identifies the spiritual truths and values, both cognitive and relational, which the institution is committed to share with its students and to comprehensively identify the opportunities through which those values will be communicated during a given period of time in campus life, maintaining a classroom and overall campus environment which ensures opportunities for both academic instruction and Gospel encounters that produce graduates who are recognized by both the academic and spiritual aspects of their lives; men and women who are well-balanced spiritually, mentally, physically, and socially. (p. 3)

Piles (1990) contends that nursing educators committed to "wholistic" caregiving must take seriously their responsibility of teaching and modeling the an of spiritual caregiving, which is hardly ever learned through intuition. To strengthen students' 
spiritual care perspectives, "spiritual care must occupy a more prominent place in nursing education at both levels to adequately prepare nurse generalists and advanced practice nurses to perform this role competently" (Stranahan, 2001, p. 102).

Using the same Spiritual Care Perspectives Scale used in this study, Stranahan studied spiritual perception and attitudes about spiritual care among nursing practitioners. When comparing the spiritual care perspectives mean score of nurse practitioners in Stranahan's study (after inverting the scores of the negatively stated items), the student mean score in this study was 2.37 points higher, while the faculty mean score was 5.04 points higher than in Stranahan's study. Nonetheless, because of the spiritual emphasis in Seventh-day Adventist nursing programs, it is expected that faculty and students in these institutions have more positive perspectives of spiritual care than the general nursing population. An even greater difference than was found in this study would have been desirable.

A comparison of the item means of the seven questions on the Role of Spiritual Care in Nursing Subscale used in Stranahan's study with this study reveals several similarities. Stranahan's highest item mean was also "spiritual care is only for religious persons" ( 1.68 or 4.32 , after adjusting the negative answer to positive), which is close to the overall mean of 4.57 and even closer to the student mean of 4.46 in this study (see Table 6 ). The item with the lowest mean in Stranahan's study (3.16) coincides with the item with the lowest overall mean (3.65), faculty mean (3.96), and student mean (3.55) in this study, "my patients have much spiritual need." All the overall item means in this study were 0.2 to 0.7 points higher than the item means in Stranahan's study. The item mean with the greatest 
discrepancy was "spiritual care is a significant part of nursing" while the item mean with the smallest discrepancy was "a patient's spiritual concerns are none of my business."

Taylor et al (1994) conducted a study to explore cancer nurse clinicians' spiritual care attitudes and beliefs, using the Oncology Nurse Spiritual Care Perspectives Survey they developed, which contains the Role of Spiritual Care in Nursing Subscale used in this study. Taylor et al.'s highest item mean was also "spiritual care is only for religious persons" (4.38). All student and faculty item means in this study were 0.02 to 0.72 points higher than Taylor's except for the students' mean score for "my patients have much spiritual need" (3.55 was students' mean score in this study compared to 3.84 in Taylor's study). Considering that Taylor et al. described their participants as "nurses who viewed themselves as rather religious and spiritual" (p. 485), it is understandable that these experienced and "rather spiritual" nurses would more readily perceive patient's spiritual needs than the students in this study.

Based on the highest and lowest score means of the seven items on the Role of Spiritual Care in Nursing Subscale in all three studies (this one, Stranaham's, and Taylor et al.'s), it is interesting to note that while many admitted that spiritual care is for everyone, many had difficulty in perceiving spiritual needs in their patients. Price et al., (1995) believe the difficulty in assessing spiritual needs is due to the vague understanding of spirituality in nursing practice. They advocate that nursing educators' responsibility for teaching spiritual care begins with assessing their own spiritual needs.

Spiritual caregiving assumes the presence of spiritual needs in both nurse and client . . . . Indeed, it is reasonable to assume that nurse educators themselves must become more comfortable in matters of spiritual health in order to convey appropriate sensitivities to their students. (pp. 6, 7) 
This suggests that for students to develop the ability of perceiving patients' spiritual needs, they must first perceive their own spiritual needs. Consequently, to teach students how to assess their spiritual needs so they can in turn identify spiritual needs in their patients, nursing educators should be in tune with their own spirituality.

Furthermore, according to the document on Total Commitment to God (General Conference of Seventh-day Adventists, 1996), Adventist educators must address the issue of accountability to God based on the Gospel Commission.

The family of God acknowledges that each person is individually accountable to God. At the same time, believers are admonished to examine themselves (see 2 Corinthians 13:5). A spiritual assessment process has its place in the personal life. Just as surely it has its place in organizational life. (p. I)

Nurse educators therefore have a double spiritual responsibility: personal accountability and organizational accountability to God. Assessment of one's spiritual needs involves connectedness within oneself Jones (2001) explains that "knowing ourselves, and accepting our strengths and weakness is essential to having connectedness within ourselves" (p. 8). Connection with self will facilitate connection with others and, most important of all, connection with God. Jones suggests that basic spiritual caregiving involves a "caring connection." Teachers who connect with God and with students will facilitate students' connection with God and with patients, thus propitiating patients' connection with God, which is the desired result in spiritual caregiving based on a Christian worldview.

As mentioned previously, no significant difference was found in perspectives of spiritual care between Seventh-day Adventist and non-Seventh-day Adventist faculty. The same faculty members, who perceived a lesser degree of opportunity for input than their Seventh-day Adventist colleagues, nonetheless shared similar perspectives of 
spiritual care with them. Assuming that nursing programs that uphold a Christian worldview and the Seventh-day Adventist philosophy of education are selective in choosing faculty that are at least supportive of the program's philosophy, whether or not they profess the Seventh-day Adventist beliefs, this finding is not surprising.

What is unexpected, however, is that no significant difference was found in perspectives of spiritual care between Seventh-day Adventist and non-Seventh-day Adventist students. In spite of the importance the Seventh-day Adventist church places on spiritual well-being and the gospel commission, Seventh-day Adventist students did not have more positive perspectives of spiritual care than their non-Adventist classmates. Factors other than stating preference to the Seventh-day Adventist church appear to be weighing more on perspectives of spiritual care. The difference between religion and spirituality is a factor that requires consideration in this case. Claim to a particular religious preference does not ensure personal spirituality.

As mentioned before, previous studies on spiritual care perspectives (Soeken \& Carson, 1986; Stranahan, 2001; Taylor et al., 1999) suggest a positive relationship between personal spirituality and perspectives of spiritual care. This may very well be the predominant factor in both facuity's and students' perspectives of spiritual care

No significant difference was found in perspectives of spiritual care between male and female students. Once again, personal spirituality rather than religion or gender may be a more relevant factor in determining perspectives of spiritual care.

\section{Conclusions}

The following conclusions about perception of organizational climate and perspectives of spiritual care among faculty and upper division students of Seventh-day 
Adventist baccalaureate nursing programs in North America can be drawn from the findings of this study:

1. The overall organizational climate is not related to perspectives of spiritual care.

2. Students' perspectives of spiritual care are weakly related to three of the eight school climate factors: "respect," "school renewal," and "caring."

3. Faculty's perspectives of spiritual care are not related to any of the climate factors.

4. Members of the different nursing programs do not differ in their perception of the organizational climate or perspectives of spiritual care.

5. Faculty members perceive the climate factors "opportunity for input," "trust," and "respect" closer to the desired climate in these three areas than students do.

6. Seventh-day Adventist faculty perceive more "opportunity for input" than non-Seventh-day Adventist faculty do.

7. There is no difference in the perception of overall organizational climate and the individual climate factors between Seventh-day Adventist and non-Seventh-day Adventist students.

8. There is no difference in the perception of overall organizational climate and the individual climate factors between male and female students.

9. Faculty's perspectives of spiritual care are more positive than students' perspectives.

10. There is no difference in perspectives of spiritual care between Seventh-day Adventist and non-Seventh-day Adventist faculty. 
11. There is no difference in perspectives of spiritual care between Seventh-day Adventist and non-Seventh-day Adventist students.

12. There is no difference in perspectives of spiritual care between male and female students.

\section{Implications}

Since caring is central to the educative process (Noddings, 1992), as well as to the nursing process (Shelly \& Miller, 1999), caring becomes twice as important in nursing education. The findings of this study suggest a relationship between students' perception of the caring climate factor of the school and their perspectives of spiritual care Although weak, this reiationship has implications for Seventh-day Adventist baccalaureate nursing programs desirous of graduating students with more positive perspectives of spiritual care. A specific implication is the fostering of the "caring connection" among the members of the nursing program. This does not necessarily require major changes in the present formal curriculum or in the teaching methodologies used. It does require a careful look at the hidden curriculum "that is taught through the ways in which faculty interact with students" (Hughes, 1993, p. 343).

This study also revealed a difference between the faculty's and students' perspectives of spiritual care. Because of the confusion regarding the meaning and importance of spirituality in "wholistic" health may be contributing to this difference, another implication would be the need for more clearly defining spirituality within a Christian frame of reference. Strengthening spiritual care role modeling together with fostering a "caring connection" could help students develop a more positive attitude towards spiritual caregiving. 
The development and implementation of a comprehensive spiritual master plan as recommended in the Total Commitment to God (General Conference, 1996) document, mentioned previously, would promote the "caring connection" by strengthening faculty's and students' connections with God and each other. A spiritual master plan that helps nursing students to be accountable for their personal spiritual growth and maturity and to become committed to the Gospel Commission would foster spiritual caregiving among faculty and students and consequently to patients.

\section{Recommendations}

Based on the findings, discussion, conclusions, implications, and evaluation of the methodology used, there are specific and general recommendations regarding perspectives of spiritual care, methodological aspects of the study, and the need for further research

\section{Relationship Between Perspectives of Spiritual Care and a Caring Environment}

Baccalaureate nursing programs desirous of graduating nurses with positive perspectives of spiritual care compatible with a Christian worldview are encouraged to

1. Define spirituality within a Christian frame of reference.

2. Assess students' concept of spirituality and spiritual caregiving. Taylor et al.'s (1994) Spiritual Care Perspectives Scale may be used for assessing attitudes towards spiritual care.

3. Assess the program's caring environment. Use the Organizational Climate for Caring Questionnaire or develop a similar instrument for assessing the caring environment. 
4. Provide spiritual-care role-modeling by nursing faculty.

5. Develop and implement a comprehensive spiritual master plan that would foster and strengthen faculty's and students' connections with God and with each other.

\section{Research Protocol}

Replications of this study with the following methodological changes are recommended. In order to obtain a greater response rate from both faculty and students, it is recommended that the researcher:

1. After obtaining consent for participation from the nursing program directors, the researcher should personally contact each nursing faculty member of all the participating programs to explain the purpose of the study and request their participation as well as encourage the participation of their students. The assumption was made that the program directors would give their faculty members information regarding the study; however, comments written on the returned questionnaires by a few faculty members revealed they were unaware of the purpose of the study and whom to contact in case of questions or comments regarding the study. In other words, the research protocol should be improved upon.

2. If financial constraints do not permit the researcher to personally apply the survey questionnaire at each participating nursing program, as was the case in this study, it can be suggested to the program directors that the responsibility of administering the questionnaires be delegated to a faculty member who has shown interest in the study. When contacting the faculty members, identifying the ones who show a particular interest in the study is crucial. Enthusiasm is contagious and they will be more likely to encourage their colleagues and students to participate. Maintaining close contact not only 
with the program directors but also with the persons responsible for distributing and administering the questionnaire throughout the data collection period is pivotal. In the programs where the responsibility was delegated, the return rate was higher.

3. Work with program directors to find ways of applying the questionnaire to as many students and faculty members as possible in one sitting. Several programs stated they were not able to take class or assembly time to answer the questionnaire. Therefore, explore other options than just handing out the questionnaires to the participants to answer and return on their own.

\section{Further Research}

1. Considering that the climate factor "caring" showed a correlation with students' perspectives of spiritual care, conduct a quantitative study to specifically assess the caring climate in Seventh-day Adventist baccalaureate nursing programs. The Organizational Climate for Caring Questionnaire developed and tested by Hughes (1993) could be used as the assessment tool in that study.

2. Conduct a qualitative study with at least two of the programs that had participated in the assessment of the caring climate study mentioned above, using a purposeful sample based on the maximum difference in the climate for caring scores. Search for characteristics of the environment that permit students to experience caring, and that foster caring behaviors.

3. Studies are needed to investigate the educational processes through which caring in general, and spiritual caregiving in specific, can be learned.

4. Studies are needed to develop, implement, and evaluate comprehensive spiritual master plans in Seventh-day Adventist nursing programs. 
5. Extending this research to include Christian non-Seventh-day Adventist baccalaureate nursing programs could provide data to corroborate if there are differences in the organizational climates and perspectives of spiritual care between the Seventh-day Adventist and non-Seventh-day Adventist programs

6. Extending this research to include all Seventh-day Adventist baccalaureate nursing programs around the world could provide cross-cultural comparisons and possibly greater variability. 
APPENDIX A

INSTRUMENTS

Reproduced with permission of the copyright owner. Further reproduction prohibited without permission. 


\section{ANDREWS UNIVERSITY \\ School of Education \\ Educational Administration and Leadership}

Dear Participant.

\section{SURVEY QUESTIONNAIRE}

As an important member of your nursing program. you have been selected to panicipate in a research study that seeks to explore the interrelationships between organizational climatc in Seventh-day Adventist Baccalaureate Nursing Programs and the students' and faculty's perspective of spiritual care. Your honest opinion and response to all the questions are very imporant in the data collection. Do not write your name on the questionnaire. This information will be processed confidentially. Upon completion. please place the questionnaire in the pre-addressed. stamped envelope provided and mail it. Thank you ven much. Your time and willingness to participate in this study are greatly appreciated as your contribution is of great value. Please answer all the items as one unanswered question invalidates the entire questionnaire. The return of the answered questionnaire is indication of your consent to participate.

Section I: Demographic Information

Age Gender Religious preference

If you are a facully nember antwor the questions th the tef box. If you are a student, answer the questions in the box to the right.

\section{FACULTY}

Place an $X$ in the box that applies to you

1. Status:

Full-time faculty 0 Part-time faculty 0

2. Highest academic or professional degree Bachelors Dasters D Doctorate $]$ Other $\square$ Spexify

3. Indicate length of time you have worked in this BS program years months

\section{STUDENT}

Answer questions 1 and 2 with $a$ number and 3 with an $\mathrm{X}$ in the appropriate box:

1. Total number of credits completed in present BS program: credits

2. Total length of time you have been studying in this BS program: months

3. Highest degree earned before entering BS nursing program: High School AS in nursing $こ \quad$ Other - specify

\section{Section II: Climate Scale}

This section gives you an opportunity to express your feelings about several aspects of the climate of your baccalaureate-nursing program. The items in this section were taken with permission from the authors of the University Version of the Charles F. Kettering Climate Scale: William Johnson. Antabel Johnson. Douglas Kranch. and Kurt Zimmerman.

Read each item thoughtfully and indicate a rating under both the "What Is" column and the "What Should Be" column. Please do not leave any items unanswered, as this would invalidate the entire questionnaire. Use the following scale to indicate your rating for each item in hoth columns:

1 - Almost Never

3 - Frequently

2 - Occasionally

$$
\text { 4-Almost Always }
$$

The following two items are only examples of possible ratings.

\begin{tabular}{|c|l|c|}
\hline WHAT IS & \multicolumn{1}{|c|}{ ITEM } & $\begin{array}{c}\text { WHAT } \\
\text { SHOULD BE }\end{array}$ \\
\hline 2 & i. & Students at this school help to decide learning objectives. \\
\hline 3 & $\begin{array}{l}\text { ii. } \\
\begin{array}{l}\text { The school's program encourages students to develop self-discipline and } \\
\text { initiative. }\end{array}\end{array}$ & $\mathbf{2}$ \\
\hline
\end{tabular}


Rating Scale:

1 - Almost Never

2-Occasionally
3- Frequently

4-Almost Always

\begin{tabular}{|c|c|c|}
\hline $\begin{array}{l}\text { WHAT } \\
\text { IS }\end{array}$ & ITEM & $\begin{array}{l}\text { WHAT } \\
\text { SHOULD BE }\end{array}$ \\
\hline & 1. In this nursing program even low achieving students are respected. & \\
\hline & 2. Teachers treat students as persons. & \\
\hline & 3. Parents are considered by this nursing program as important collaborators & \\
\hline & $\begin{array}{l}\text { 4. Teachers from one subject area or grade level respect those from other } \\
\text { subject areas. }\end{array}$ & \\
\hline & 5. Teachers in this nursing program are proud to be teachers. & \\
\hline & 6. Students feel that teachers are "on their side." & \\
\hline & $\begin{array}{l}\begin{array}{l}\text { Although we do not always agree we can share our concerns with each } \\
\text { other openly. }\end{array} \\
\end{array}$ & \\
\hline & 8. The teachers are good spokespersons for students' inierests and needs. & \\
\hline & $\begin{array}{l}\text { 9. Students can count on teachers to listen to their side of the ston and to be } \\
\text { fair. }\end{array}$ & \\
\hline & 10. Teachers tust students to use good judgment. & \\
\hline & 11. This nursing program makes students enthusiastic about learning. & \\
\hline & 12. Teachers feel pride in this nursing program and its students. & \\
\hline & 13. Altendance is good: students stay away only for urgent and good reasons. & \\
\hline & $\begin{array}{l}\text { 14. Parents. teachers, and students would rise to the defense of this nursing } \\
\text { program if it were challenged. }\end{array}$ & \\
\hline & 15. I like working/studving in this nursing program. & \\
\hline & 16. I feel that my ideas are listened to and used in this nursing program. & \\
\hline & $\begin{array}{l}\text { 17. When important decisions are made about the nursing program. I } \\
\text { personally, have heard about the plan beforehand and have been involved } \\
\text { in some of the decisions. }\end{array}$ & \\
\hline & $\begin{array}{l}\text { 18. Important decisions are made in this nursing program by a governing } \\
\text { council with representation from students. faculty, and administration. }\end{array}$ & \\
\hline & $\begin{array}{l}\text { 19. Although I cannot have a vote on every decision that is made in this nursing } \\
\text { program that affects me. I do feel that I can have some imponant input into } \\
\text { that decision. }\end{array}$ & \\
\hline & 20. When all is said and done. I fecl that I count in this nursing program. & \\
\hline & $\begin{array}{l}\text { 21. The teachers are "alive": they are interested in life around them: they are } \\
\text { doing interesting things outside of the nursing program. }\end{array}$ & \\
\hline & $\begin{array}{l}\text { 22. Teachers in this nursing program are "out in front" seeking better ways of } \\
\text { teaching and learning. }\end{array}$ & \\
\hline & $\begin{array}{l}\text { 23. Students feel that the nursing program is meaningful and relevant to their } \\
\text { present and future needs. }\end{array}$ & \\
\hline & 24. The teachers are growing and learning. too. They are seeking new ideas. & \\
\hline & $\begin{array}{l}\text { 25. The nursing program supports parent growth. Regular opportunities are } \\
\text { provided for parents to be involved in learning activities and in examining } \\
\text { new ideas. }\end{array}$ & \\
\hline & 26. Students would rather attend this nursing program than transfer to another. & \\
\hline & 27. There is a "we" spirit in this nursing program. & \\
\hline & $\begin{array}{l}\text { 28. Administration and teachers collaborate toward making the nursing } \\
\text { program run effectively: there is little administrator-teacher tension. }\end{array}$ & \\
\hline & $\begin{array}{l}\text { 29. Differences between individuals and groups (both among faculty and } \\
\text { students) are considered to contribute to the richness of the nursing } \\
\text { program. not as divisive infuences. }\end{array}$ & \\
\hline & $\begin{array}{l}\text { 30. New students and faculty members are made to feel welcome and pan of } \\
\text { the group. }\end{array}$ & \\
\hline
\end{tabular}




\begin{tabular}{|c|c|c|}
\hline $\begin{array}{l}\text { WHAT } \\
\text { IS }\end{array}$ & $\overline{\text { ITEM }}$ & $\begin{array}{l}\text { WHAT } \\
\text { SHOULD BE }\end{array}$ \\
\hline & $\begin{array}{l}\text { 31. When a problem comes up. this nursing program has procedures for working } \\
\text { on it: problems are seen as normal challenges, not as "rocking the boat." }\end{array}$ & \\
\hline & $\begin{array}{l}\text { 32. Teachers are encouraged to innovate in their classroom rather than to } \\
\text { conform. }\end{array}$ & \\
\hline & $\begin{array}{l}\text { 33. When a student comes along who has special problems, this nursing } \\
\text { program works out a plan that helps that student. }\end{array}$ & \\
\hline & 34. Students are encouraged to be creative rather than to conform. & \\
\hline & $\begin{array}{l}\text { 35. Careful effor is made when new programs are introduced to adapt them to } \\
\text { the paricular needs of this community and this nursing program. }\end{array}$ & \\
\hline & 36. There is someone in this nursing program on whom I can alwavs count. & \\
\hline & 37. The teachers really care about the students. & \\
\hline & $\begin{array}{l}\text { 38. I think people in this nursing program care about me as a person and are } \\
\text { concerned about more that just how well I perform my role at the school } \\
\text { (as student, teacher, parent etc) }\end{array}$ & \\
\hline & $\begin{array}{l}\text { 39. The nursing school is a nice place to be because I feel wanted and needed } \\
\text { there. }\end{array}$ & \\
\hline & lost people at this nursing school are kind. & \\
\hline
\end{tabular}

\section{Section III: Spiritual Care Perspectives Scale}

This section measures nurses' attitudes regarding the importance of including spiritual care in nursing caregiving. The items in this section were taken with permission from the authors of the Spiritual Care Perspectives Scale: Elizabeth Johnston Taylor, Martha Highfield, and Madalon Amenta.

Please circle the number that describes your view best. It is important that all items be answered.

The following two items are only examples of possible responses:

i. I believe that as a nurse I should:

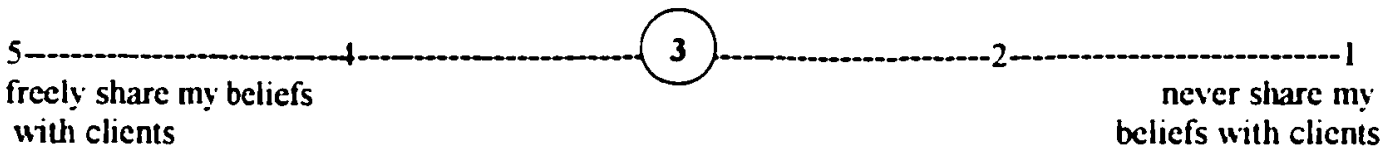

ii. Relationships with others are important to patients'spiritual health:

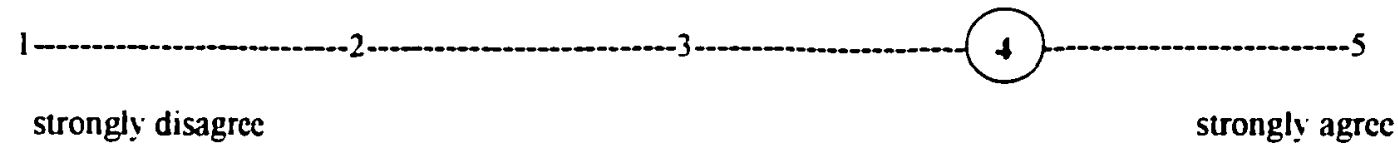


1. Spiritual care is:

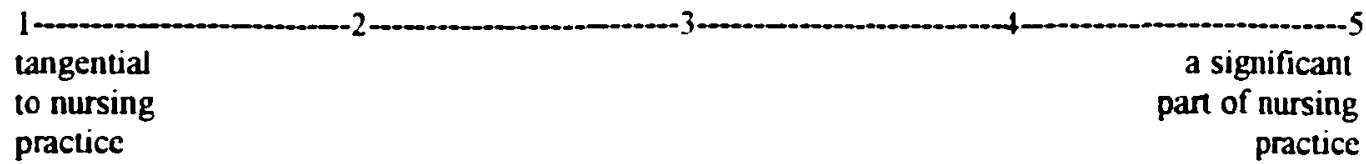

2. In general, my patients have:

much
spiritual
need

3. The domain of nursing practice:

$\begin{array}{ll}\text { does not include } & \begin{array}{l}\text { does include } \\ \text { spiritual care }\end{array}\end{array}$

4. "Spiritual care" is only for religious persons:

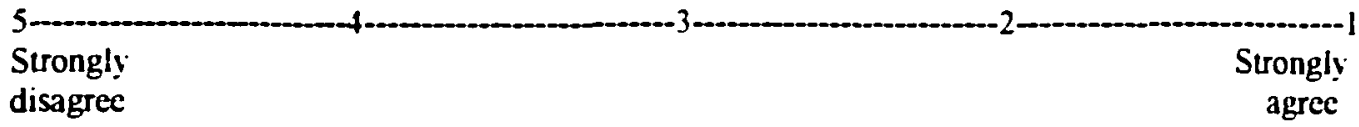

5. A patient's spiritual concerns are none of my business:

Strongly
agree

6. Only clergy should help patients with specifically religious activities:

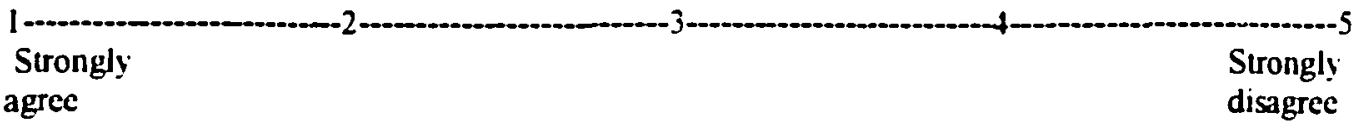

7. The nurse should assist a patient in using his/her religious or spiritual resources to cope with illness:

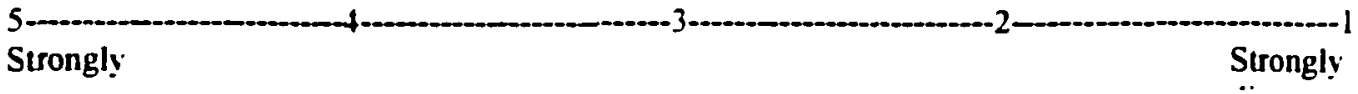

Thank you for taking time to complete this questionnairc. Please be sure you have answered all of the questions. Leaving just one item unanswered will invalidate the entire questionnaire. Thank you for placing it in the pre-addressed stamped envelope provided and mailing it. You have made a great contribution to the success of this research study! 
APPENDIX B

\section{PERMISSION LETTERS}

Reproduced with permission of the copyright owner. Further reproduction prohibited without permission. 


\section{Permission to use UCFK}

\section{6/29/01 Friday 5 p.m. CST}

Edelweiss,

You certainly have our approval to use the UCFK. We ask, however, that the EPM article (and authors) be cited whenever the material is used in the present or revised form. Also, if the form or your revision accrues any monetary proceeds, we ask to be advised of such for the appropriate negotiations. We would also request to be copied on published materials referencing the UCFK as the original document.

Best wishes in your work.

William L. Johnsonwljabj@aol.com

QED 


\section{Permission to use SCPS}

\section{Hi Edelweiss!}

Thanks for your sweet note. I'm sorry our time together was so distracted, but we did get to meet in person and that was nice. Attached is the full questionnaire we sent out to participants of the study, and then also the Spiritual Care Perspectives Scale (which is embedded within the questionnaire) with psychometric information. The best write up about how the tool was developed is found in the Applied Nursing Research article (1999 I think) on predictors of nurses' spiritual perspectives. Of course you have permission to use it. Just as we tell the others, please be sure to cite the authors (me and my colleagues) and send us a copy of your findings (eg, abstract from your dissertation). Actually, do let me know if indeed you do decide to use it. It'd be convenient if this worked for you. But it may not. I'd recommend a reference librarian might tell you how to locate instruments that are catalogued somewhere. I know there are books compiled of instruments, but I believe there is also a database accessible via CD-ROM or the web that häs nursing instruments. (I know I have the nurse editor for it call me and ask to have this tool placed there. and I didn't do so.) So I'd go searching via such a route for possible instruments. Sounds like this is the next step! Much "Luck" to you!

Beth

Elizabeth Johnston Taylor, PhD, RN

Associate Professor of Nursing

School of Nursing

Loma Linda University 


\section{APPENDIX C}

\section{COVER LETTER TO NURSING PROGRAM DIRECTORS}




\section{Consent to Participate in Survey Research}

\section{Dear Colleague:}

The purpose of this letter is to request your participation in a survey research project that seeks to explore the interrelationships between organizational climate in SDA BS nursing programs and students' perspective of spiritual care. This study is part of the requirements for the completion of a $\mathrm{Ph}$. $\mathrm{D}$. degree in Educational Administration and Leadership at Andrews University.

The Seventh-day Adventist Church has a wholistic mission. In order to accomplish this mission, health professionals need to have a clear perspective of spiritual care, as part of wholistic nursing. The environment in which nursing students develop contributes to defining the extent to which they incorporate wholism into their own lives and in their practice as health care professionals. If the organizational climate in schools of nursing affects the transmission of this important concept, it is consequential that we as nursing education administrators and nursing faculty know that.

A questionnaire containing 47 items taken from two previously tested assessment tools - the University Version of the Charles F. Kettering Climate Scale and the Spiritual Care Perspectives Scale-will be administered to BS nursing upperclassmen and to all nursing faculty. This questionnaire will take approximately 30 minutes to answer.

Please be assured that your participation is voluntary and will remain completely confidential as participants' names will not appear on the questionnaires. Neither you. your school, your faculty, nor your students will be identified in the report of the findings. There are no hazards or risks associated with answering the questionnaire and you may withdraw from participating in the study at any time, without prejudice.

Kindly indicate your consent to participate or not by emailing me at edel@um.edu.mx. Should you agree to participate, please send the name and email of the person who you choose to be responsible for applying the instrument and the number of students and faculty that fulfill the above stated requirements for participation. Upon receipt of your consent I will communicate with the person you have indicated and will mail him or her a package containing the instruments, instructions for administration and postage paid envelope/box to return the questionnaires in. Follow up emails will be sent if confirmation to participate or not has not been received. Collection of the data is projected for October and November 2001.

I deeply appreciate your cooperation. Should you desire more information about this project please contact me via email and I will be happy to respond with a call or email. You may also contact Dr. Hinsdale Bernard at (616) 471-6702 or hbemarda andrews.edu or Dr. Linda Thorman at (616) 471-3405 or lthormanâandreus.edu. Thank you for your assistance. A summary of the findings will be made available to you upon request.

Sincerely,

Edelweiss Ramal, RN, MS

Doctoral Candidate

3508 Warbler Ave

McAllen, TX 78504

(956) 661-1605
Hinsdale Bernard, Ph. D.

Dissertation Committee Chair

Educational Administration

and Leadership Chair 
ABSTRACT OF DISSERTATION PROPOSAL

\author{
Andrews University \\ School of Education \\ Educational Administration and Leadership
}

Title: THE RELATIONSHIP BETWEEN PERSPECTIVES OF SPIRITUAL CARE AND ORGANIZATIONAL CLIMATE IN SEVENTH-DAY ADVENTIST BACCALAUREATE NURSING PROGRAMS IN NORTH AMERICA

\author{
Researcher: $\quad$ Edelweiss Ramal \\ Committee Chair: Hinsdale Bernard, Ph.D. \\ Problem
}

The Seventh-day Adventist Church has a wholistic mission of which spiritual well being is a central part. In order to accomplish this mission, a positive attitude toward spiritual care is needed. The concept of spiritual care is not acquired in a void. The environment in which nursing students develop professionally contributes to defining the extent to which they incorporate this concept into their own lives and in their practice as health care professionals. If the organizational climate in nursing programs affects the transmission of this important concept it is consequential that it be known. The purpose of this study is to explore the interrelationships between perspectives of spiritual care held by students and faculty in Seventh-day Adventist baccalaureate nursing programs and their perception of the program's organizational climate.

\title{
Research Questions
}

1. Is there a relationship between each organizational climate subscale and total score and the nursing students' perspectives of spiritual care?

2. Is there a relationship between each organizational climate subscale and total score and the faculty's perspectives of spiritual care?

3. Is there a difference in perception of the school's organizational climate between nursing programs?

4. Is there a difference in perspectives of spiritual care between nursing programs?

5. Is there a difference in each organizational climate subscale and total score between faculty and students?

6. Is there a difference in each organizational climate subscale and total score between Seventh-day Adventist and non Seventh-day Adventist faculty?

7. Is there a difference in each organizational climate subscale and total score between Seventh-day Adventist and non Seventh-day Adventist students?

8. Is there a difference in each organizational climate subscale and total score between male and female students?

9. Is there a difference in perspectives of spiritual care between students and faculty?

10. Is there a difference in perspectives of spiritual care between Seventh-day Adventist and non Seventh-day Adventist faculty? 
11. Is there a difference in perspectives of spiritual care between Seventh-day Adventist and non Seventh-day Adventist students?

12. Is there a difference in perspectives of spiritual care between male and female students?

\section{Methodology}

A descriptive, correlational, comparative study will be conducted using survey research methodology. The unit of observation is the student and the faculty member, not the nursing program. To assess organizational climate and perspective of spiritual care, the University Version of the Charles Kettering Climate Scale developed by W. Johnson, A. Johnson, D. Kranch, and K. Zimmerman and the Role of Spiritual Care in Nursing Subscale of the Spiritual Care Perspectives Scale developed by E. J. Taylor, M. Highfield, and $M$. Amenta will be administered to the upperclassmen and nursing faculty of all the SDA, NLN accredited baccalaureate nursing programs in the US that agree to participate in the study. The questionnaire contains 47 items that can be answered in 30 minutes or less.

A letter of invitation to participate will be sent to the Dean, Chair, or Program Director of each one of the ten nursing schools that fulfill the specifications for participation in this study. Upon receiving consent from the nursing program director to participate, a package containing the questionnaires, instructions for application, and preaddressed, stamped envelopes for each respondent to return the answered questionnaire in will be sent to the program directors. Participation is voluntary and will remain completely confidential. Consent of each respondent to participate will be indicated by returning the answered questionnaire. Neither the nursing programs, program directors, faculty, nor students will be identified in the report of the findings. Demographic information about the participating nursing programs will not be requested or identified, because comparisons will not be made between the specific characteristics of the participating nursing programs.

The Statistical Package for the Social Sciences (SPSS) 10.0 for Windows will be used for recording and analyzing the data. All hypotheses will be tested at the .05 level of significance. Statistical analysis will include correlation, t-test and one-way ANOVA. 
APPENDIX D

SPSS OUTPUT

Reproduced with permission of the copyright owner. Further reproduction prohibited without permission. 


\section{Correlations Hypotheses 1 and 2}

status of participant $=$ faculty

\section{Descriptive Statistics}

\begin{tabular}{|l|r|r|r|}
\hline & \multicolumn{1}{|c|}{ Mean } & Std. Devration & N \\
\hline SPI & 31.69 & 2.29 & 49 \\
CLIM & 16.81 & 13.69 & 48 \\
RES & 1.19 & 1.21 & 48 \\
TRU & 2.46 & 2.07 & 48 \\
MOR & 1.96 & 1.75 & 48 \\
INP & 2.21 & 3.10 & 48 \\
GRO & 2.77 & 2.43 & 48 \\
COH & 2.46 & 2.40 & 48 \\
REN & 2.42 & 2.38 & 48 \\
CAR & 1.35 & 2.51 & 48 \\
\hline
\end{tabular}

a. status of participant $=$ faculty

Correlations

\begin{tabular}{|c|c|c|c|c|c|c|c|c|c|c|c|}
\hline & & SPI & CLIM & RES & TRU & MOR & INP & GRO & $\mathrm{COH}$ & $\overline{\text { REN }}$ & CAR \\
\hline \multirow[t]{3}{*}{ SPI } & Pearson Correlati & 9.000 & -.077 & -.042 & -.031 & -.177 & .008 & -.103 & -.112 & -.044 & -.013 \\
\hline & Sig. (2-tailed) & & .605 & .775 & .832 & .229 & .957 & .487 & 449 & .781 & .933 \\
\hline & $\mathbf{N}$ & 49 & 48 & 48 & 48 & 48 & 48 & 48 & 48 & 48 & 48 \\
\hline \multirow[t]{3}{*}{ CLIM } & Pearzon Correlati & .077 & 1.000 & $608^{\circ}$ & $805^{\circ}$ & $638^{\circ}$ & $872^{\circ}$ & $.743^{\circ}$ & $.752^{\circ}$ & $840^{\circ}$ & $741^{\circ}$ \\
\hline & Sig. (2-tailed) & 605 & & .000 &.$\infty 00$ & .000 & .000 & .000 &.$\infty 00$ & .000 &.$\infty 00$ \\
\hline & N & 48 & 48 & 48 & 48 & 48 & 48 & 48 & 48 & 48 & 48 \\
\hline \multirow[t]{3}{*}{ RES } & Pearson Correlati & .042 & $608^{\circ}$ & 1.000 & $616^{\circ}$ & $.334^{\circ}$ & $504^{\circ}$ & $405^{\circ}$ & 277 & $370^{\circ}$ & $460^{\circ}$ \\
\hline & Sig. (2-tailed) & .775 &.$\infty 00$ & &.$\infty 00$ & .020 & .000 & .004 & .057 & 010 & .001 \\
\hline & N & 48 & 48 & 48 & 48 & 48 & 48 & 48 & 48 & 48 & 48 \\
\hline \multirow[t]{3}{*}{ TRU } & Pearson Contelati & -.031 & $805^{\circ}$ & $616^{\circ}$ & 1.000 & $604^{\circ}$ & $.667^{\circ}$ & $563^{\circ}$ & $458^{\circ}$ & $604^{\circ}$ & $.468^{\circ}$ \\
\hline & Sig. (2-tailed) & 832 & .000 & .000 & . & .000 & .000 & .000 & .001 & .000 & .001 \\
\hline & N & 48 & 48 & 48 & 48 & 48 & 48 & 48 & 48 & 48 & 48 \\
\hline \multirow[t]{3}{*}{ MOR } & Pearson Correlati & -.177 & $638^{\circ}$ & $334^{\circ}$ & $604^{\circ}$ & 1.000 & $370^{\circ}$ & $524^{\circ}$ & $334^{\circ}$ & $541^{\circ}$ & $.329^{\circ}$ \\
\hline & Sig. (2-tailed) & 229 &.$\infty 0$ & .020 & .000 & & .010 &.$\infty 00$ & .020 & .000 & .023 \\
\hline & $\mathbf{N}$ & 48 & 48 & 48 & 48 & 48 & 48 & 48 & 48 & 48 & 48 \\
\hline \multirow[t]{3}{*}{ INP } & Pearson Correlati & .008 & $872^{\circ}$ & $504^{\circ}$ & $667^{\circ}$ & $370^{\circ}$ & 1.000 & $485^{\circ}$ & $640^{\circ}$ & $715^{\circ}$ & $.713^{\circ}$ \\
\hline & Sig. (2-tailed) & .957 &.$\infty 0$ & .000 &.$\infty 00$ & .010 & & .000 & .000 & $\infty$ & .000 \\
\hline & $\mathrm{N}$ & 48 & 48 & 48 & 48 & 48 & 48 & 48 & 48 & 48 & 48 \\
\hline \multirow[t]{3}{*}{ GRO } & Pearson Correlati & -.103 & $743^{\circ}$ & $405^{\circ}$ & $563^{\circ}$ & $.524^{\circ}$ & $485^{\circ}$ & 1000 & $527^{\circ}$ & $629^{\circ}$ & $360^{\circ}$ \\
\hline & Sig. (2-tailed) & 487 & .000 &.$\infty 4$ & .000 & .000 &.$\infty 0$ & & .000 & $\infty \infty$ & 012 \\
\hline & $N$ & 48 & 48 & 48 & 48 & 48 & 48 & 48 & 48 & 48 & 48 \\
\hline \multirow[t]{3}{*}{$\mathrm{COH}$} & Pearson Correkati & -.112 & $.752^{\circ}$ & 277 & $458^{\circ}$ & $334^{\circ}$ & $640^{\circ}$ & $.527^{\circ}$ & 1.000 & $612^{\circ}$ & $.522^{\circ}$ \\
\hline & Sig. (2-tailed) & 449 &.$\infty 00$ & .057 & .001 & .020 & .000 & .000 & &.$\infty 00$ & .000 \\
\hline & $N$ & 48 & 48 & 48 & 48 & 48 & 48 & 48 & 48 & 48 & 48 \\
\hline \multirow[t]{3}{*}{ REN } & Pearcon Correlati & .041 & $840^{\circ}$ & $.370^{\circ}$ & $604^{\circ}$ & $541^{\circ}$ & $.715^{\circ}$ & $.629^{\circ}$ & $.612^{\circ}$ & 1.000 & $.503^{\circ}$ \\
\hline & Sig. (2-tailed) & .781 & .000 & .010 &.$\infty 00$ & .000 & .000 & .000 & .000 & . & .000 \\
\hline & $\mathbf{N}$ & 48 & 48 & 48 & 48 & 48 & 48 & 48 & 48 & 48 & 48 \\
\hline \multirow[t]{3}{*}{ CAR } & Peareon Correlati & -.013 & $.741^{\circ}$ & $460^{\circ}$ & $468^{\circ}$ & $329^{\circ}$ & $713^{\circ}$ & $360^{\circ}$ & $522^{\circ}$ & $.503^{\circ}$ & 1.000 \\
\hline & Sig. (2-tailed) & .933 & .000 &.$\infty 1$ &.$\infty 1$ & .023 & .000 & .012 & .000 & .000 & \\
\hline & $\mathbf{N}$ & 48 & 48 & 48 & 48 & 48 & 48 & 48 & 48 & 48 & 48 \\
\hline
\end{tabular}

- Correlation is significant at the 0.01 level (2-tailed)

- Correlation is significant at the 0.05 level (2-tailed).

- status of participant = feculty 


\section{status of participant $=$ student}

Descriptive Statistics -

\begin{tabular}{|l|r|r|r|}
\hline & Mean & Sid. Deviution & $N$ \\
\hline SLI & 28.73 & 3.51 & 158 \\
RES & 21.67 & 18.65 & 153 \\
TRU & 2.13 & 2.03 & 154 \\
MOR & 3.49 & 3.25 & 155 \\
INP & 2.19 & 2.38 & 155 \\
GRO & 4.10 & 3.69 & 155 \\
COH & 2.90 & 2.82 & 155 \\
REN & 1.97 & 2.58 & 154 \\
CAR & 3.17 & 3.10 & 155 \\
\hline
\end{tabular}

a. status of participant $=$ student

Correlations

\begin{tabular}{|c|c|c|c|c|c|c|c|c|c|c|c|}
\hline & & SPI & CLIM & RES & TRU & MOR & INP & GRO & $\mathrm{COH}$ & REN & CAR \\
\hline \multirow[t]{3}{*}{ SPI } & Pear & 1.000 & -.155 & $-.170^{\circ}$ & -.125 & -.132 & -.140 & -.134 & -.017 & $-.162^{\circ}$ & $-.186^{\circ}$ \\
\hline & Sig. (2-tailed) & & .056 & .035 & .121 & .102 & .083 & .098 & .833 & .045 & .021 \\
\hline & $\mathbf{N}$ & 158 & 152 & 153 & 154 & 154 & 154 & 154 & 153 & 154 & 154 \\
\hline \multirow[t]{3}{*}{ CLIM } & Pearson Correl & -.155 & 1.000 & $807^{\circ}$ & $841^{\circ}$ & $.844^{\circ}$ & $.860^{\circ}$ & $.843^{\circ}$ & $.775^{\circ}$ & $903^{\circ}$ & $.805^{\circ}$ \\
\hline & Sig. $(2$ & .056 & & .000 & .000 & .000 & .000 & .000 & .000 & .000 & .000 \\
\hline & $N$ & 152 & 153 & 153 & 153 & 153 & 153 & 153 & 153 & 153 & 153 \\
\hline \multirow[t]{3}{*}{ RES } & Pearson Correl & $-.170^{\circ}$ & $.807^{\circ}$ & 1.000 & $.699^{\circ}$ & $.624^{\circ}$ & $.618^{\circ}$ & $690^{\circ}$ & $.546^{\circ}$ & $.739^{\circ}$ & $.626^{\circ}$ \\
\hline & Sig. (2-tailed) & .035 & .000 & & .000 & .000 & .000 & .000 & .000 & .000 & .000 \\
\hline & $\mathbf{N}$ & 153 & 153 & 154 & 154 & 154 & 154 & 154 & 153 & 154 & 154 \\
\hline \multirow[t]{3}{*}{ TRU } & Pearson Correl & -.125 & $.841^{\circ}$ & $699^{\circ}$ & 1.000 & $.695^{\circ}$ & $654^{\circ}$ & $684^{\circ}$ & $.555^{\circ}$ & $.725^{\circ}$ & $666^{\circ}$ \\
\hline & Sig. & 121 & .000 & .000 & & .000 & .000 & .000 & .000 & .000 & .000 \\
\hline & $N$ & 154 & 153 & 154 & 155 & 155 & 155 & 155 & 154 & 155 & 155 \\
\hline \multirow[t]{3}{*}{ MOR } & Pearson Correl & -.132 & $844^{\circ}$ & $624^{\circ}$ & $.695^{\circ}$ & 1.000 & $690^{\circ}$ & $677^{\circ}$ & $628^{\circ}$ & $.752^{\circ}$ & $.606^{\circ}$ \\
\hline & Sig. (2-tailed) & 102 & .000 & .000 & .000 & & .000 & .000 & .000 & .000 & .000 \\
\hline & $N$ & 154 & 153 & 154 & 155 & 155 & 155 & 155 & 154 & 155 & 155 \\
\hline \multirow[t]{3}{*}{ INP } & Pearson Correl & -.140 & $.860^{\circ}$ & $618^{\circ}$ & $.654^{\circ}$ & $690^{\circ}$ & 1.000 & $675^{\circ}$ & $.606^{\circ}$ & $.755^{\circ}$ & $.697^{\circ}$ \\
\hline & Sig. (2-tailed) & .083 & .000 & .000 & .000 & .000 & & .000 & .000 & .000 & .000 \\
\hline & $\mathbf{N}$ & 154 & 153 & 154 & 155 & 155 & 155 & 155 & 154 & 155 & 155 \\
\hline \multirow[t]{3}{*}{ GRO } & Pearson Correl & -134 & $843^{\circ}$ & $.690^{\circ}$ & $684^{\circ}$ & $677^{\circ}$ & $675^{\circ}$ & 1.000 & $.618^{\circ}$ & $.763^{\circ}$ & $.599^{\circ}$ \\
\hline & Sig. (2-tailed) & .098 & .000 & .000 & .000 & .000 & .000 & & .000 & .000 & .000 \\
\hline & $N$ & 154 & 153 & 154 & 155 & 155 & 155 & 155 & 154 & 155 & 155 \\
\hline \multirow[t]{3}{*}{$\mathrm{COH}$} & Pearson Correl & -.017 & $.775^{\circ}$ & $.546^{\circ}$ & $.555^{\circ}$ & $.628^{\circ}$ & $.606^{\circ}$ & $618^{\circ}$ & 1.000 & $.659^{\circ}$ & $.585^{\circ}$ \\
\hline & -tailed) & .833 & .000 & .000 & .000 & .000 & .000 & .000 & & .000 & .000 \\
\hline & $N$ & 153 & 153 & 153 & 154 & 154 & 154 & 154 & 154 & 154 & 154 \\
\hline \multirow[t]{3}{*}{ REN } & Pearson Correl & $-.162^{\circ}$ & $.903^{\circ}$ & $.739^{\circ}$ & $.725^{\circ}$ & $.752^{\circ}$ & $755^{\circ}$ & $.763^{\circ}$ & $659^{\circ}$ & 1.000 & $691^{\circ}$ \\
\hline & Sig. (2-tailed) & .045 & .000 & .000 & .000 & .000 & .000 & .000 & .000 & & .000 \\
\hline & $\mathrm{N}$ & 154 & 153 & 154 & 155 & 155 & 155 & 155 & 154 & 155 & 155 \\
\hline \multirow[t]{3}{*}{ CAR } & Pearson Correl & $-.186^{\circ}$ & $.805^{\circ}$ & $626^{\circ}$ & $666^{\circ}$ & $.606^{\circ}$ & $697^{\circ}$ & $.599^{\circ}$ & $.585^{\circ}$ & $691^{\circ}$ & 1.000 \\
\hline & ailed) & .021 & .000 & .000 & .000 & .000 & .000 & .000 & .000 & .000 & \\
\hline & $\mathbf{N}$ & 154 & 153 & 154 & 155 & 155 & 155 & 155 & 154 & 155 & 155 \\
\hline
\end{tabular}

.Correlation is significant at the 0.05 level (2-tailed)

*. Correlation is significant at the 0.01 level (2-tailed).

a.status of participant $=$ student 


\section{Hypotheses 3 and 4}

\section{One-way ANOVA}

\section{Games-Howell Post Hoc Test}

\section{One-way}

Test of Homogeneity of Variances

\begin{tabular}{|l|r|r|r|r|}
\hline & $\begin{array}{c}\text { Levene } \\
\text { Statistic }\end{array}$ & \multicolumn{1}{|c|}{ df1 } & \multicolumn{1}{c|}{ df2 } & \multicolumn{1}{c|}{ Sig. } \\
\hline CLIM & 2.927 & 4 & 131 & .023 \\
SPI & 1.129 & 4 & 135 & .346 \\
\hline
\end{tabular}

ANOVA

\begin{tabular}{|ll|r|r|r|r|r|}
\hline & $\begin{array}{r}\text { Sum of } \\
\text { Squares }\end{array}$ & df & Mean Square & \multicolumn{1}{|c|}{$F$} & Sig. \\
\hline CLIM & Between Groups & 2637.269 & 4 & 659.317 & 2.688 & .034 \\
& Within Groups & 32132.466 & 131 & 245.286 & & \\
& Total & 34769.735 & 135 & & & \\
\hline SPI & Between Groups & 103.631 & 4 & 25.908 & 2.329 & .059 \\
& Within Groups & 1501.969 & 135 & 11.125 & & \\
& Total & 1605.600 & 139 & & & \\
\hline
\end{tabular}




\section{Post Hoc Tests}

\section{Mutdple Comparisons}

Games-Howell

\begin{tabular}{|c|c|c|c|c|c|c|c|}
\hline \multirow[b]{2}{*}{ Dependent Variabl } & \multirow[b]{2}{*}{ (1) NEWPR } & \multirow[b]{2}{*}{ (J) NEWPR } & \multirow{2}{*}{$\begin{array}{c}\text { Mean } \\
\text { Difference } \\
(1-J)\end{array}$} & \multirow[b]{2}{*}{ Std. Error } & \multirow[b]{2}{*}{ Sig. } & \multicolumn{2}{|c|}{$95 \%$ Confidence interval } \\
\hline & & & & & & Lower Bound & Upper Bound \\
\hline \multirow[t]{20}{*}{ CLIM } & 1.00 & 2.00 & 3.44 & 5.70 & .965 & -12.00 & 18.87 \\
\hline & & 3.00 & 9.75 & 4.97 & .064 & -.40 & 19.89 \\
\hline & & 4.00 & -.58 & 5.32 & 1.000 & -14.92 & 13.76 \\
\hline & & 5.00 & 9.04 & 5.05 & .100 & -1.14 & 19.22 \\
\hline & 2.00 & 1.00 & -3.44 & 5.70 & .965 & -18.87 & 12.00 \\
\hline & & 3.00 & 6.31 & 4.41 & .710 & -8.27 & 20.89 \\
\hline & & 4.00 & -4.01 & 4.80 & .965 & -21.53 & 13.51 \\
\hline & & 5.00 & 5.60 & 4.50 & .790 & -9.00 & 20.20 \\
\hline & 3.00 & 1.00 & -9.75 & 4.97 & .064 & -19.89 & 40 \\
\hline & & 2.00 & -6.31 & 4.41 & 710 & -20.89 & 8.27 \\
\hline & & 4.00 & -10.32 & 3.91 & .196 & -23.67 & 3.02 \\
\hline & & 5.00 & -.71 & 3.53 & 999 & -9.01 & 7.60 \\
\hline & 4.00 & 1.00 & .58 & 5.32 & 1.000 & -13.76 & 14.92 \\
\hline & & 2.00 & 4.01 & 4.80 & 965 & -13.51 & 21.53 \\
\hline & & 3.00 & 10.32 & 3.94 & 196 & -3.02 & 23.67 \\
\hline & & 5.00 & 9.62 & 4.01 & .258 & -3.75 & 22.99 \\
\hline & 5.00 & 1.00 & -9.04 & 5.05 & .100 & -19.22 & 1.14 \\
\hline & & 2.00 & .560 & 4.50 & 790 & -20.20 & 9.00 \\
\hline & & 3.00 & .71 & 3.53 & 999 & -7.60 & 9.01 \\
\hline & & 4.00 & -9.62 & 4.01 & .258 & -22.99 & 3.75 \\
\hline \multirow[t]{20}{*}{ SPI } & 1.00 & 2.00 & -.13 & 1.21 & 1.000 & -2.92 & 2.66 \\
\hline & & 3.00 & .82 & 1.06 & 881 & -1.70 & 3.35 \\
\hline & & 4.00 & 1.32 & 1.13 & .595 & -1.29 & 3.92 \\
\hline & & 500 & 2.29 & 1.06 & .056 & $-4.13 E-02$ & 4.62 \\
\hline & 2.00 & 1.00 & 13 & 1.21 & 1.000 & -2.66 & 2.92 \\
\hline & & 3.00 & .95 & 94 & .848 & -1.73 & 3.64 \\
\hline & & 4.00 & 1.44 & 1.01 & .567 & -1.31 & 4.20 \\
\hline & & 5.00 & 2.42 & .95 & .061 & $-7.71 \mathrm{E}-02$ & 491 \\
\hline & 3.00 & 1.00 & -.82 & 1.06 & .881 & -3.35 & 1.70 \\
\hline & & 2.00 & -.95 & .94 & 848 & -3.64 & 1.73 \\
\hline & & 4.00 & .49 & 82 & 980 & -1.98 & 2.97 \\
\hline & & 5.00 & 1.46 & 74 & 330 & -.70 & 3.63 \\
\hline & 4.00 & 1.00 & -1.32 & 1.13 & 595 & -3.92 & 1.29 \\
\hline & & 2.00 & -1.44 & 1.01 & 567 & -4.20 & 1.31 \\
\hline & & 3.00 & -49 & .82 & 980 & -2.97 & 1.98 \\
\hline & & 5.00 & .97 & .83 & 742 & -1.29 & 3.23 \\
\hline & 5.00 & 1.00 & -2.29 & 1.06 & .056 & -4.62 & 4.13E-02 \\
\hline & & 2.00 & -2.42 & .95 & .061 & -4.91 & $7.71 E-02$ \\
\hline & & 3.00 & -1.46 & .74 & .330 & -3.63 & .70 \\
\hline & & 4.00 & -.97 & 83 & .742 & -3.23 & 1.29 \\
\hline
\end{tabular}


T-Test Hypotheses 5 - 12

Group Statistics

\begin{tabular}{|ll|r|r|r|r|}
\hline & status of participa & \multicolumn{1}{|c|}{$\mathbf{N}$} & Mean & Std. Deviation & $\begin{array}{c}\text { Std. Error } \\
\text { Mean }\end{array}$ \\
\hline RES & faculty & 48 & 1.19 & 1.21 & .18 \\
& student & 154 & 2.13 & 2.03 & .16 \\
\hline TRU & faculty & 48 & 2.46 & 2.07 & .30 \\
& student & 155 & 3.49 & 3.25 & .26 \\
\hline MOR & faculty & 48 & 1.96 & 1.75 & .25 \\
& student & 155 & 2.19 & 2.38 & .19 \\
\hline INP & faculty & 48 & 2.21 & 3.10 & .45 \\
& student & 155 & 4.10 & 3.69 & .30 \\
\hline GRO & faculty & 48 & 2.77 & 2.43 & .35 \\
& student & 155 & 2.90 & 2.82 & .23 \\
\hline COH & faculty & 48 & 2.46 & 2.40 & .35 \\
& student & 154 & 1.97 & 2.58 & .21 \\
\hline REN & faculty & 48 & 2.42 & 2.38 & .34 \\
& student & 155 & 3.17 & 3.10 & .25 \\
\hline CAR & faculty & 48 & 1.35 & 2.51 & .36 \\
& student & 155 & 2.05 & 2.72 & .22 \\
\hline CLIM & faculty & 48 & 16.81 & 13.69 & 1.98 \\
& student & 153 & 21.67 & 18.65 & 1.51 \\
\hline
\end{tabular}


Independent Samples Test

\begin{tabular}{|c|c|c|c|c|c|c|c|c|c|}
\hline & \multicolumn{2}{|c|}{$\begin{array}{l}\text { evene's Test for } \\
\text { uality of Varianc }\end{array}$} & \multicolumn{7}{|c|}{ t-test for Equality of Means } \\
\hline & \multirow[b]{2}{*}{$\mathbf{F}$} & \multirow[b]{2}{*}{ Sig. } & \multirow[b]{2}{*}{1} & \multirow[b]{2}{*}{ of } & \multirow[b]{2}{*}{ ig. (2-taile } & \multirow{2}{*}{$\begin{array}{c}\text { Mean } \\
\text { ifferenc }\end{array}$} & \multirow{2}{*}{$\begin{array}{l}\text { td. Error } \\
\text { ifferenc }\end{array}$} & \multicolumn{2}{|c|}{$\begin{array}{l}95 \% \text { Confidence } \\
\text { Interval of the } \\
\text { Difference }\end{array}$} \\
\hline & & & & & & & & Lower & Upper \\
\hline $\begin{array}{c}\text { RES Equal varia } \\
\text { assumed } \\
\text { Equal varia } \\
\text { not assume }\end{array}$ & 10.172 & .002 & $\begin{array}{l}-3.041 \\
-3.926\end{array}$ & $\begin{array}{r}200 \\
33.770\end{array}$ & $\begin{array}{l}.003 \\
.000\end{array}$ & $\begin{array}{l}-.94 \\
-.94\end{array}$ & $\begin{array}{l}.31 \\
.24\end{array}$ & $\begin{array}{l}-1.55 \\
-1.42\end{array}$ & $\begin{array}{l}-.33 \\
-.47\end{array}$ \\
\hline $\begin{array}{c}\text { TRU Equal varia } \\
\text { assumed } \\
\text { Equal varia } \\
\text { not assume }\end{array}$ & 11.007 & .001 & $\begin{array}{l}-2.070 \\
-2.598\end{array}$ & $\begin{array}{r}201 \\
23.986\end{array}$ & $\begin{array}{l}.040 \\
.010\end{array}$ & $\begin{array}{l}-1.03 \\
-1.03\end{array}$ & $\begin{array}{l}.50 \\
.40\end{array}$ & $\begin{array}{l}-2.01 \\
-1.82\end{array}$ & $\begin{array}{r}90 E-02 \\
-.25\end{array}$ \\
\hline $\begin{array}{|ll|}\text { MO } & \text { Equal varia } \\
& \text { assumed } \\
& \text { Equal varia } \\
& \text { not assume }\end{array}$ & 6.234 & .013 & $\begin{array}{l}-.633 \\
-.743\end{array}$ & $\begin{array}{r}201 \\
05.680\end{array}$ & $\begin{array}{l}.527 \\
.459\end{array}$ & $\begin{array}{l}-.24 \\
-.24\end{array}$ & $\begin{array}{l}.37 \\
.32\end{array}$ & $\begin{array}{l}-.97 \\
-.86\end{array}$ & $\begin{array}{l}.50 \\
.39\end{array}$ \\
\hline $\begin{array}{ll}\text { INP } & \text { Equal varia } \\
& \text { assumed } \\
& \text { Equal varia } \\
\text { not assume }\end{array}$ & 1.588 & .209 & $\begin{array}{l}-3.209 \\
-3.517\end{array}$ & $\begin{array}{r}201 \\
91.927\end{array}$ & $\begin{array}{l}.002 \\
.001\end{array}$ & $\begin{array}{l}-1.89 \\
-1.89\end{array}$ & $\begin{array}{l}.59 \\
.54\end{array}$ & $\begin{array}{l}-3.05 \\
-2.95\end{array}$ & $\begin{array}{l}-.73 \\
-.82\end{array}$ \\
\hline $\begin{array}{cl}\text { GR } & \text { Equal varia } \\
& \text { assumed } \\
& \text { Equal varia } \\
& \text { not assume }\end{array}$ & .430 & .513 & $\begin{array}{l}-.293 \\
-.318\end{array}$ & $\begin{array}{r}201 \\
89.747\end{array}$ & $\begin{array}{l}.770 \\
.752\end{array}$ & $\begin{array}{l}-.13 \\
-.13\end{array}$ & .45 & $\begin{array}{r}-1.02 \\
-.96\end{array}$ & $\begin{array}{l}.76 \\
.70\end{array}$ \\
\hline $\begin{array}{ll}\text { CO } & \text { Equal varia } \\
& \text { assumed } \\
& \text { Equal varia } \\
& \text { not assume }\end{array}$ & .108 & .743 & $\begin{array}{l}1.169 \\
1.216\end{array}$ & $\begin{array}{r}200 \\
83.826\end{array}$ & $\begin{array}{l}.244 \\
.227\end{array}$ & .49 & .42 & $\begin{array}{l}-.34 \\
-.31\end{array}$ & $\begin{array}{l}1.32 \\
1.29\end{array}$ \\
\hline $\begin{array}{c}\text { REN Equal varia } \\
\text { assumed } \\
\text { Equal varia } \\
\text { not assume } \\
\end{array}$ & 4.025 & .046 & $\begin{array}{l}-1.544 \\
-1.772\end{array}$ & $\begin{array}{r}201 \\
100.892\end{array}$ & $\begin{array}{l}.124 \\
.079\end{array}$ & $\begin{array}{l}-.75 \\
-.75\end{array}$ & .49 & $\begin{array}{l}-1.71 \\
-1.59\end{array}$ & $\begin{array}{r}.21 \\
98 E-02\end{array}$ \\
\hline $\begin{array}{l}\text { CAR Equal varia } \\
\text { assumed } \\
\text { Equal varia } \\
\text { not assume }\end{array}$ & 815 & .368 & $\begin{array}{l}-1.579 \\
-1.650\end{array}$ & $\begin{array}{r}201 \\
84.231\end{array}$ & $\begin{array}{l}.116 \\
.103\end{array}$ & $\begin{array}{l}-.70 \\
-.70\end{array}$ & .42 & $\begin{array}{l}-1.57 \\
-1.54\end{array}$ & .14 \\
\hline $\begin{array}{ll}\text { CLI } & \text { Equal varia } \\
& \text { assumed } \\
& \text { Equal varia } \\
& \text { not assume }\end{array}$ & 3.058 & .082 & $\begin{array}{l}-1.669 \\
-1.956\end{array}$ & $\begin{array}{r}199 \\
06.551\end{array}$ & $\begin{array}{l}.097 \\
.053\end{array}$ & $\begin{array}{l}-4.86 \\
-4.86\end{array}$ & $\begin{array}{l}2.91 \\
2.49\end{array}$ & $\begin{array}{r}-10.60 \\
-9.79\end{array}$ & $\begin{array}{r}.88 \\
61 E-02\end{array}$ \\
\hline
\end{tabular}


T-Test

status of participant $=$ faculty

Group Statistics

\begin{tabular}{|ll|r|r|r|r|}
\hline & relgious preference & $\mathrm{N}$ & Mean & Std. Deviation & $\begin{array}{c}\text { Std. Error } \\
\text { Mean }\end{array}$ \\
\hline RES & SDA & 41 & 1.24 & 1.28 & .20 \\
& non SDA & 4 & 1.00 & .82 & .41 \\
\hline TRU & SDA & 41 & 2.51 & 2.11 & .33 \\
& non SDA & 4 & 2.50 & 2.38 & 1.19 \\
\hline MOR & SDA & 41 & 2.10 & 1.81 & .28 \\
& non SDA & 4 & 1.50 & 1.29 & .65 \\
\hline INP & SDA & 41 & 2.54 & 3.24 & .51 \\
& non SDA & 4 & .25 & .50 & .25 \\
\hline GRO & SDA & 41 & 2.93 & 2.51 & .39 \\
& non SDA & 4 & 2.00 & 2.00 & 1.00 \\
\hline COH & SDA & 41 & 2.76 & 2.43 & 38 \\
& non SDA & 4 & 1.25 & 1.50 & .75 \\
\hline REN & SDA & 41 & 2.66 & 2.46 & 38 \\
& non SDA & 4 & 1.75 & .96 & .48 \\
\hline CAR & SDA & 41 & 1.56 & 2.66 & .41 \\
& non SDA & 4 & 25 & .50 & .25 \\
\hline CLIM & SDA & 41 & 18.29 & 14.02 & 2.19 \\
& non SDA & 4 & 10.50 & 9.11 & 4.56 \\
\hline
\end{tabular}

a. status of participant $=$ faculty 
Independent Samplest Test

\begin{tabular}{|c|c|c|c|c|c|c|c|c|c|}
\hline & \multicolumn{2}{|c|}{$\begin{array}{l}\text { evene's Test for } \\
\text { uality of Variand }\end{array}$} & \multicolumn{7}{|c|}{ t-test for Equality of Means } \\
\hline & \multirow[b]{2}{*}{$\mathbf{F}$} & \multirow[b]{2}{*}{ Sig. } & \multirow[b]{2}{*}{$t$} & \multirow[b]{2}{*}{ df } & \multirow[b]{2}{*}{ ig. (2-taile } & \multirow{2}{*}{$\begin{array}{c}\text { Mean } \\
\text { ifferenc }\end{array}$} & \multirow{2}{*}{$\begin{array}{l}\text { td. Error } \\
\text { ifferenc } \\
\end{array}$} & \multicolumn{2}{|c|}{$\begin{array}{c}95 \% \text { Confidence } \\
\text { Interval of the } \\
\text { Difference }\end{array}$} \\
\hline & & & & & & & & Lower & Upper \\
\hline $\begin{array}{c}\text { RES Equal varia } \\
\text { assumed } \\
\text { Equal varia } \\
\text { not assume }\end{array}$ & 2.515 & 120 & $\begin{array}{l}.371 \\
.537\end{array}$ & $\begin{array}{r}43 \\
4.592\end{array}$ & $\begin{array}{l}.712 \\
617\end{array}$ & $\begin{array}{l}.24 \\
.24\end{array}$ & $\begin{array}{l}.66 \\
.45\end{array}$ & $\begin{array}{r}-1.08 \\
-.96\end{array}$ & $\begin{array}{l}1.57 \\
1.44\end{array}$ \\
\hline $\begin{array}{l}\text { TRU Equal varia } \\
\text { assumed } \\
\text { Equal varia } \\
\text { not assume }\end{array}$ & .046 & .832 & $\begin{array}{l}.011 \\
.010\end{array}$ & $\begin{array}{r}43 \\
3.476\end{array}$ & $\begin{array}{l}.991 \\
.993\end{array}$ & $\begin{array}{l}.22 E-02 \\
.22 E-02\end{array}$ & $\begin{array}{l}1.12 \\
1.24\end{array}$ & $\begin{array}{l}-2.24 \\
-3.63\end{array}$ & $\begin{array}{l}2.26 \\
3.65\end{array}$ \\
\hline $\begin{aligned} \text { MO } & \text { Equal varia } \\
& \text { assumed } \\
& \text { Equal varia } \\
& \text { not assume }\end{aligned}$ & .873 & .355 & $\begin{array}{l}.640 \\
.848\end{array}$ & $\begin{array}{r}43 \\
4.255\end{array}$ & $\begin{array}{l}.526 \\
442\end{array}$ & 60 & $\begin{array}{l}.93 \\
.70\end{array}$ & $\begin{array}{l}-1.29 \\
-1.31\end{array}$ & $\begin{array}{l}2.48 \\
2.51\end{array}$ \\
\hline \begin{tabular}{|ll} 
INP & Equal varia \\
& assumed \\
& Equal varia \\
& not assume
\end{tabular} & 4.651 & .037 & $\begin{array}{l}1.395 \\
4.050\end{array}$ & $\begin{array}{r}43 \\
34.513\end{array}$ & $\begin{array}{l}170 \\
000\end{array}$ & $\begin{array}{l}2.29 \\
2.29\end{array}$ & $\begin{array}{r}1.64 \\
.56\end{array}$ & $\begin{array}{r}-1.02 \\
1.14\end{array}$ & $\begin{array}{l}5.59 \\
3.43\end{array}$ \\
\hline $\begin{array}{|cl|}\text { GR } & \text { Equal varia } \\
& \text { assumed } \\
& \text { Equal varia } \\
& \text { not assume } \\
\end{array}$ & 641 & .428 & $\begin{array}{l}.713 \\
.863\end{array}$ & $\begin{array}{r}43 \\
3.989\end{array}$ & $\begin{array}{l}.480 \\
437\end{array}$ & 93 & $\begin{array}{l}1.30 \\
1.07\end{array}$ & $\begin{array}{l}-1.69 \\
-2.06\end{array}$ & $\begin{array}{l}3.55 \\
3.91\end{array}$ \\
\hline $\begin{array}{cl}\text { CO } & \text { Equal varia } \\
& \text { assumed } \\
& \text { Equal varia } \\
& \text { not assume } \\
\end{array}$ & .936 & 339 & $\begin{array}{l}1.211 \\
1.792\end{array}$ & $\begin{array}{r}43 \\
4.705\end{array}$ & $\begin{array}{l}.232 \\
.137\end{array}$ & $\begin{array}{l}1.51 \\
1.51\end{array}$ & $\begin{array}{r}1.24 \\
.84\end{array}$ & $\begin{array}{r}-1.00 \\
-.70\end{array}$ & $\begin{array}{l}4.01 \\
3.71\end{array}$ \\
\hline $\begin{array}{c}\text { REN Equal varia } \\
\text { assumed } \\
\text { Equal varia } \\
\text { not assume }\end{array}$ & 2.709 & .107 & $\begin{array}{r}.728 \\
1.481\end{array}$ & $\begin{array}{r}43 \\
7.844\end{array}$ & $\begin{array}{l}.470 \\
.178\end{array}$ & .91 & $\begin{array}{r}1.25 \\
.61\end{array}$ & $\begin{array}{r}-1.61 \\
-.51\end{array}$ & $\begin{array}{l}3.42 \\
2.33\end{array}$ \\
\hline $\begin{array}{c}\text { CAR Equal varia } \\
\text { assumed } \\
\text { Equal varia } \\
\text { not assume }\end{array}$ & 3.371 & .073 & $\begin{array}{r}.976 \\
2.707\end{array}$ & $\begin{array}{r}43 \\
26.935\end{array}$ & $\begin{array}{l}.335 \\
.012\end{array}$ & $\begin{array}{l}1.31 \\
1.31\end{array}$ & $\begin{array}{r}1.34 \\
.48\end{array}$ & $\begin{array}{r}-1.40 \\
.32\end{array}$ & $\begin{array}{l}4.02 \\
2.30\end{array}$ \\
\hline $\begin{array}{ll}\text { CLI } & \text { Equal varia } \\
& \text { assumed } \\
& \text { Equal varia } \\
& \text { not assume }\end{array}$ & 1.718 & 197 & $\begin{array}{l}1.083 \\
1.542\end{array}$ & 4.528 & $\begin{array}{l}.285 \\
.190\end{array}$ & $\begin{array}{l}779 \\
7.79\end{array}$ & $\begin{array}{l}7.19 \\
5.05\end{array}$ & $\begin{array}{l}-6.71 \\
-5.62\end{array}$ & $\begin{array}{l}22.30 \\
21.20\end{array}$ \\
\hline
\end{tabular}

a.status of participant = faculty

status of participant $=$ student 
Group Statistics

\begin{tabular}{|ll|r|r|r|r|}
\hline & relgious preference & $N$ & Mean & Std. Deviation & $\begin{array}{c}\text { Std. Error } \\
\text { Mean }\end{array}$ \\
\hline RES & SDA & 76 & 2.37 & 1.66 & .19 \\
& non SDA & 78 & 1.90 & 2.33 & .26 \\
\hline TRU & SDA & 76 & 4.00 & 3.03 & .35 \\
& non SDA & 79 & 3.00 & 3.40 & .38 \\
\hline MOR & SDA & 76 & 2.29 & 2.01 & .23 \\
& non SDA & 79 & 2.10 & 2.70 & .30 \\
\hline INP & SDA & 76 & 3.96 & 3.07 & .35 \\
& non SDA & 79 & 4.23 & 4.22 & .47 \\
\hline GRO & SDA & 76 & 3.24 & 2.47 & .28 \\
& non SDA & 79 & 2.58 & 3.10 & .35 \\
\hline COH & SDA & 75 & 1.99 & 2.35 & 27 \\
& non SDA & 79 & 1.95 & 2.81 & .32 \\
\hline REN & SDA & 76 & 3.39 & 2.78 & .32 \\
& non SDA & 79 & 2.95 & 3.38 & 38 \\
\hline CAR & SDA & 76 & 2.18 & 2.56 & .29 \\
& non SDA & 79 & 1.92 & 2.88 & .32 \\
\hline CLIM & SDA & 75 & 22.77 & 14.59 & 1.68 \\
& non SDA & 78 & 20.62 & 21.91 & 2.48 \\
\hline
\end{tabular}

a. status of participant $=$ student 
Independent SamplesTest

\begin{tabular}{|c|c|c|c|c|c|c|c|c|c|}
\hline & \multicolumn{2}{|c|}{$\begin{array}{l}\text { evene's Test for } \\
\text { uality of Varianc }\end{array}$} & \multicolumn{7}{|c|}{ t-test for Equality of Means } \\
\hline & \multirow[b]{2}{*}{$F$} & \multirow[b]{2}{*}{ Sig. } & \multirow[b]{2}{*}{$t$} & \multirow[b]{2}{*}{ df } & \multirow[b]{2}{*}{ ig. (2-taile } & \multirow{2}{*}{$\begin{array}{c}\begin{array}{c}\text { Mean } \\
\text { ifferenc }\end{array} \\
\end{array}$} & \multirow{2}{*}{$\begin{array}{l}\text { td. Erro } \\
\text { ifferenc }\end{array}$} & \multicolumn{2}{|c|}{$\begin{array}{c}95 \% \text { Confidence } \\
\text { Interval of the } \\
\text { Difference }\end{array}$} \\
\hline & & & & & & & & Lower & Upper \\
\hline $\begin{array}{c}\text { RES Equal varia } \\
\text { assumed }\end{array}$ & 5.151 & .025 & 1.441 & 152 & .152 & .47 & .33 & -.17 & 1.12 \\
\hline $\begin{array}{l}\text { Equal varia } \\
\text { not assume }\end{array}$ & & & 1.447 & 39.045 & .150 & .47 & .33 & -.17 & 1.11 \\
\hline $\begin{array}{c}\text { TRU Equal varia } \\
\text { assumed }\end{array}$ & .822 & .366 & 1.931 & 153 & .055 & 1.00 & .52 & 33E-02 & 2.02 \\
\hline $\begin{array}{l}\text { Equal varia } \\
\text { not assume }\end{array}$ & & & 1.935 & 52.109 & .055 & 1.00 & .52 & 10E-02 & 2.02 \\
\hline 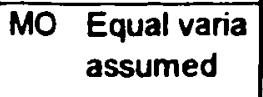 & 5.376 & .022 & .491 & 153 & .624 & .19 & .38 & -.57 & .95 \\
\hline $\begin{array}{l}\text { Equal varia } \\
\text { not assume }\end{array}$ & & & .494 & 43.865 & .622 & .19 & .38 & -.57 & .94 \\
\hline $\begin{array}{c}\text { INP Equal varia } \\
\text { assumed }\end{array}$ & 3.729 & .055 & -.449 & 153 & .654 & -.27 & .59 & -1.44 & .91 \\
\hline $\begin{array}{l}\text { Equal varia } \\
\text { not assume }\end{array}$ & & & -.452 & 42.678 & .652 & -.27 & .59 & -1.44 & .90 \\
\hline $\begin{array}{cc}\text { GR } & \begin{array}{l}\text { Equal varia } \\
\text { assumed }\end{array}\end{array}$ & 1.268 & .262 & 1.450 & 153 & .149 & 65 & .45 & -.24 & 1.55 \\
\hline $\begin{array}{c}\text { Equal varia } \\
\text { not assume }\end{array}$ & & & 1.457 & 47.762 & .147 & 65 & .45 & -.23 & 1.54 \\
\hline CO $\begin{array}{l}\text { Equal varia } \\
\text { assumed }\end{array}$ & 3.359 & .069 & .089 & 152 & .929 & $.73 E-02$ & .42 & -.79 & .86 \\
\hline $\begin{array}{l}\text { Equal varia } \\
\text { not assume }\end{array}$ & & & .090 & 49.636 & .929 & $.73 E-02$ & .42 & -.78 & .86 \\
\hline $\begin{array}{c}\text { REN Equal varia } \\
\text { assumed }\end{array}$ & 2.406 & .123 & .894 & 153 & .373 & .45 & .50 & -.54 & 1.43 \\
\hline $\begin{array}{l}\text { Equal varia } \\
\text { not assume }\end{array}$ & & & .898 & 49.476 & .371 & .45 & .50 & -.54 & 1.43 \\
\hline $\begin{array}{c}\text { CAR Equal varia } \\
\text { assumed }\end{array}$ & .466 & .496 & .593 & 153 & .554 & .26 & .44 & -.61 & 1.13 \\
\hline $\begin{array}{l}\text { Equal varia } \\
\text { not assume }\end{array}$ & & & .595 & 52.050 & .553 & .26 & .44 & -.60 & 1.12 \\
\hline \begin{tabular}{cl|}
$\mathrm{CLI}$ & $\begin{array}{l}\text { Equal varia } \\
\text { assumed }\end{array}$
\end{tabular} & 8.249 & .005 & .714 & 151 & .476 & 2.16 & 3.02 & -3.81 & 8.13 \\
\hline $\begin{array}{l}\text { Equal varia } \\
\text { not assume }\end{array}$ & & & .720 & 34.594 & .473 & 2.16 & 3.00 & -3.77 & 8.09 \\
\hline
\end{tabular}

a status of participant $=$ student 


\section{T-Test}

status of participant $=$ student

Group Statistics

\begin{tabular}{|ll|r|r|r|r|}
\hline & sex of respondent & $N$ & Mean & Std. Deviation & $\begin{array}{c}\text { Std. Error } \\
\text { Mean }\end{array}$ \\
\hline RES & female & 136 & 2.10 & 2.05 & .18 \\
& male & 18 & 2.39 & 1.97 & .47 \\
\hline TRU & female & 137 & 3.38 & 3.29 & .28 \\
& male & 18 & 4.33 & 2.87 & .68 \\
\hline MOR & female & 137 & 2.25 & 2.48 & .21 \\
& male & 18 & 1.78 & 1.44 & .34 \\
\hline INP & female & 137 & 4.26 & 3.75 & .32 \\
& male & 18 & 2.89 & 3.07 & .72 \\
\hline GRO female & 137 & 2.85 & 2.86 & .24 \\
& male & 18 & 3.33 & 2.50 & .59 \\
\hline COH & female & 136 & 1.91 & 2.57 & .22 \\
& male & 18 & 2.39 & 2.70 & .64 \\
\hline REN & female & 137 & 3.15 & 3.14 & .27 \\
& male & 18 & 3.33 & 2.87 & .68 \\
\hline CAR & female & 137 & 2.09 & 2.73 & .23 \\
& male & 18 & 1.78 & 2.69 & .63 \\
\hline CLIM & female & 135 & 21.60 & 18.95 & 1.63 \\
& male & 18 & 22.22 & 16.75 & 3.95 \\
\hline
\end{tabular}

a. status of participant $=$ student 
Independent Samples Test

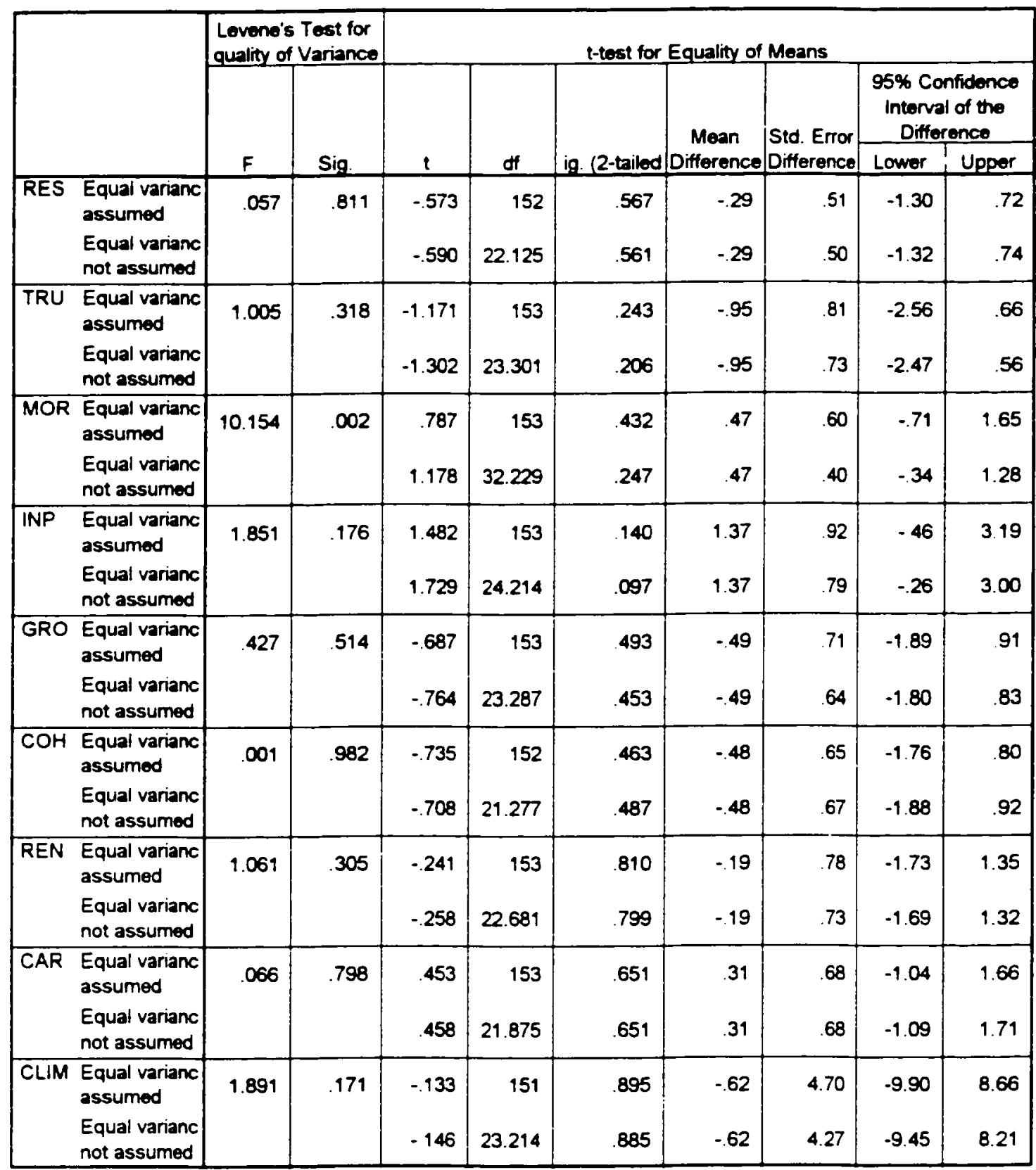

a. status of participant $=$ student 


\section{T-Test}

Group Statistics

\begin{tabular}{|ll|r|r|r|r|}
\hline & status of participant & \multicolumn{1}{|c|}{$\mathrm{N}$} & Mean & Std. Deviation & $\begin{array}{c}\text { Std. Error } \\
\text { Mean }\end{array}$ \\
\hline SPI & faculty & 49 & 31.69 & 2.29 & 33 \\
& student & 158 & 28.73 & 3.51 & 28 \\
\hline
\end{tabular}

Independent Samples Test

\begin{tabular}{|c|c|c|c|c|c|c|c|c|c|}
\hline & \multicolumn{2}{|c|}{$\begin{array}{l}\text { Evene's Test for } \\
\text { uality of Varianc }\end{array}$} & \multicolumn{7}{|c|}{ i-test for Equality of Means } \\
\hline & \multirow[b]{2}{*}{$F$} & \multirow[b]{2}{*}{ Sig. } & \multirow[b]{2}{*}{$t$} & \multirow[b]{2}{*}{ df } & \multirow[b]{2}{*}{ ig. (2-taile } & \multirow{2}{*}{$\begin{array}{l}\text { Mean } \\
\text { ifferenc }\end{array}$} & \multirow{2}{*}{$\begin{array}{l}\text { td. Error } \\
\text { ifferenc }\end{array}$} & \multicolumn{2}{|c|}{$\begin{array}{c}95 \% \text { Confidence } \\
\text { Interval of the } \\
\text { Difference }\end{array}$} \\
\hline & & & & & & & & Lower & Upper \\
\hline $\begin{array}{cl}\text { SPI } & \begin{array}{l}\text { Equal varian } \\
\text { assumed }\end{array}\end{array}$ & 7.443 & .007 & 5.558 & 205 & .000 & 2.97 & .53 & 1.91 & 4.02 \\
\hline $\begin{array}{l}\text { Equal varian } \\
\text { not assume }\end{array}$ & & & 6.893 & 23.101 & .000 & 2.97 & .43 & 2.11 & 3.82 \\
\hline
\end{tabular}

\section{T-Test}

\section{status of participant $=$ faculty}

Group Statistics

\begin{tabular}{|ll|r|r|r|r|}
\hline & relgious preference & \multicolumn{1}{|c|}{$\mathrm{N}$} & Mean & Std. Deviation & $\begin{array}{c}\text { Std. Error } \\
\text { Mean }\end{array}$ \\
\hline SPI & SDA & 42 & 31.79 & 2.38 & 37 \\
& non SDA & 4 & 31.00 & 1.63 & .82 \\
\hline
\end{tabular}

a. status of participant $=$ faculty

Independent Samples Test

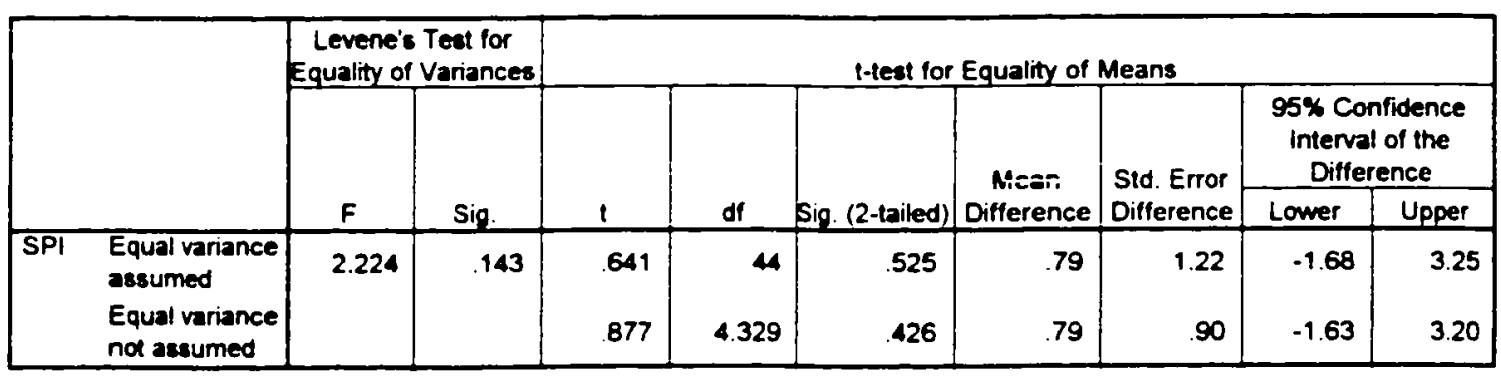

a. status of participant = faculty 
status of participant $=$ student

Group Statistics

\begin{tabular}{|ll|r|r|r|r|}
\hline & relgious preference & $\mathrm{N}$ & Mean & Std Deviation & $\begin{array}{c}\text { Std. Error } \\
\text { Mean }\end{array}$ \\
\hline SPI & SDA & 80 & 29.16 & 2.98 & .33 \\
& non SDA & 78 & 28.28 & 3.94 & 45 \\
\hline
\end{tabular}

a. status of participant $=$ student

Independent Samples Test

\begin{tabular}{|c|c|c|c|c|c|c|c|c|c|c|}
\hline & \multicolumn{2}{|c|}{$\begin{array}{l}\text { Levene's Test for } \\
\text { Equality of Variances }\end{array}$} & \multicolumn{7}{|c|}{ 1-test for Equality of Means } \\
\hline & & \multirow[b]{2}{*}{$F$} & \multirow[b]{2}{*}{ Sig. } & \multirow[b]{2}{*}{$t$} & \multirow[b]{2}{*}{ df } & \multirow[b]{2}{*}{ Sig. (2-tailed) } & \multirow{2}{*}{$\begin{array}{c}\text { Mean } \\
\text { Difference }\end{array}$} & \multirow{2}{*}{$\begin{array}{l}\text { Std. Error } \\
\text { Difference }\end{array}$} & \multicolumn{2}{|c|}{$\begin{array}{l}\text { 95\% Confidence } \\
\text { Interval of the } \\
\text { Difference }\end{array}$} \\
\hline & & & & & & & & & Lower & Upper \\
\hline SPI & $\begin{array}{l}\text { Equal variance } \\
\text { assumed }\end{array}$ & 4.799 & .030 & 1.585 & 156 & .115 & 88 & .56 & -.22 & 1.98 \\
\hline & $\begin{array}{l}\text { Equal variance } \\
\text { not assumed }\end{array}$ & & & 1.580 & 143.369 & .116 & .88 & .56 &. .22 & 1.98 \\
\hline
\end{tabular}

a. status of participant $=$ student 


\section{T-Test}

status of participant $=$ student

Group Statistics

\begin{tabular}{|ll|r|r|r|r|}
\hline & sex of respondent & $\mathrm{N}$ & Mean & Std Deviation & $\begin{array}{c}\text { Std. Error } \\
\text { Mean }\end{array}$ \\
\hline SPI female & 140 & 28.71 & 3.55 & .30 \\
& male & 18 & 28.89 & 3.25 & .77 \\
\hline
\end{tabular}

a. status of participant $=$ student

Independent Samples Test

\begin{tabular}{|c|c|c|c|c|c|c|c|c|c|c|}
\hline & \multicolumn{2}{|c|}{$\begin{array}{l}\text { Levene's Test for } \\
\text { Equality of Variances }\end{array}$} & \multicolumn{7}{|c|}{ t-test for Equality of Means } \\
\hline & & \multirow[b]{2}{*}{$F$} & \multirow[b]{2}{*}{ Sig. } & \multirow[b]{2}{*}{$t$} & \multirow[b]{2}{*}{ df } & \multirow[b]{2}{*}{ ig. (2-tailed) } & \multirow{2}{*}{$\begin{array}{c}\text { Mean } \\
\text { Difference }\end{array}$} & \multirow{2}{*}{$\begin{array}{l}\text { Std. Error } \\
\text { Difference }\end{array}$} & \multicolumn{2}{|c|}{$\begin{array}{l}\text { 95\% Confidence } \\
\text { Interval of the } \\
\text { Difference }\end{array}$} \\
\hline & & & & & & & & & Lower & Upper \\
\hline SPI & $\begin{array}{l}\text { Equal variance } \\
\text { assumed }\end{array}$ & .043 & .835 & -.206 & 156 & .837 & -.18 & .88 & -1.92 & 1.56 \\
\hline & $\begin{array}{l}\text { Equal variance } \\
\text { not assumed }\end{array}$ & & & -.221 & 22.541 & .827 & -.18 & .82 & -1.89 & 1.52 \\
\hline
\end{tabular}

a. status of participant $=$ student 


\section{REFERENCE LIST}




\section{REFERENCE LIST}

Alster, K. B. (1984). A critical analysis of the holistic health movement. Unpublished doctoral dissertation, Boston University.

Ameling, A., \& Povilonis, M. (2001). Spirituality, meaning, mental health, and nursing. Journal of Psychosocial Nursing, 39(4), 15-20.

Aylward, P. D. (2001). The Neuman Systems Model and global implications. In M. E. Parker (Ed.), Nursing theories and mursing practice (pp. 329-342). Philadelphia: F. A. Davis Company.

Barnum, B. S. (1996). Spirituality in mursing: From traditional to new age. New York: Springer.

Beare, P. G., \& Myers, J. L. (1990). Principles and practice of adult health mursing. St. Louis, MO: Mosby Company.

Berger, K. S. (1994). The developing person through the life span. New York: Worth Publishers

Bevis, E. O., \& Watson, J. (1989). Tow'ard a caring curriculum: A new' pedagogy for mursing. New York: National League for Nursing.

Bishop, A. H., \& Scudder, J. R. (1997). A phenomenological interpretation of holistic nursing. Journal of Holistic Nursing, 15(2), 103-111.

Blamires, H. (1963). The Christian mind: How should a Christian think? Ann Arbor, MI: Servant Books.

Bloesch, D. G. (1992). A theology of word and spirit: A uthority and method in theology: Downer Grove, IL: InterVarsity Press.

Bush, H. A. (1988). The caring teacher of nursing. In M. M. Leininger (Ed.), Care: Discovery and uses in clinical and community mursing (pp. 169-187). Detroit, MI: Wayne State University Press

Carney, G., \& Long, W. (1997). Yearning minds and burning hearts: Rediscove.ing the spirituality of Jesus. Grand Rapids, MI: Baker Books.

Carpenito, L. J. (1995). Nursing diagnosis: Application to mursing practice. Philadelphia: Lipincott. 
Carroll, B. (2001). A phenomenological exploration of the nature of spirituality and spiritual care. Mortality; 6(1), 81-99.

Cody, W. K. (2000). Paradigm shift or paradigm drift? A meditation of commitment and transcendence. Nursing Science Quarterly; 13(2), 93-102.

Covey, S. R. (1990). The 7 habits of highly effective people: Powerful lessons in personal change. New York: Franklin Covey Co

Cullen, K. W., \& Baranowski, T. (1999). Influence of school organizational characteristics on the outcomes of a school health promotion program. Journal of School Health, 69(9), 376-341.

Davidhizar, R., Bechtel, G. A., \& Cosey, E. J. (2000). The spiritual needs of hospitalized patients. American Journal of Nursing, 100(7), 24C-24D.

Dillard, N., \& Laidig, J. (1998). Curriculum development: An overview. In D. Billings \& J. A. Halstead (Ed.), Teaching in mursing: A guide for faculty (pp. 68-82). Philadelphia: W. B. Saunders Company.

Doenges, M. \& Moorhouse. M. (1996). Nurse's pocket guide: Diagnosis, interventions, and rationales $\left(6^{\text {th }}\right.$ ed.). Philadelphia: F. A. Davis.

Dossey, B. M. (1998). Holistic modalities and healing moments. American Journal of Nursing, 98(6), 44-47.

Dossey, B. M., \& Dossey, L. (1998). Attending to holistic care. American Journal of Nursing, 98(8), 35-38.

Dossey, B. M., Keegan, L., Guzzetta, C. E., \& Kolkmeier, L. G. (1995). Holistic mursing: A handbook for practice. Gaithersburg, MD: Aspen.

Douglass, H. (1998). Messenger of the Lord: The prophetic ministry of Ellen G. White. Nampa, ID: Pacific Press

Dunphy, L. H. (2001). Florence Nightingale caring actualized: A legacy for nursing. In M. E. Parker (Ed.), Nursing theories and mursing practice (pp. 31-55).

Philadelphia: F. A. Davis Company

Dysinger, P. W. (1997). Heaven's lifestyle today: Health in the comext of revelation I 4 : A biblical and modern science perspective. Silver Spring, MD: Ministerial Association, General Conference of Seventh-day Adventists.

Edgert, P. (1994, Spring). Assessing campus climate: Implications for diversity. New Directions for Institutional Research, 81, 51-62. 
Emblen, J., \& Pesut, B. (2001). Strengthening transcendent meaning: A model for the spiritual nursing care of patients experiencing suffering. Journal of Holistic Nursing, 19(1), 42-56.

Erickson, M. J. (1985). Christian theology. Grand Rapids, MI: Baker Book House.

Espeland, K. (1999). Achieving spiritual wellness: Using reflective questions. Journal of Psychosocial Nursing, 37(7), 36-40.

Estby, S. N., \& Freel, M. I. (1994). A delphi study of the basic principles and corresponding care goals of holistic nursing practice. Journal of Holistic Nursing, I2(4), 402-413.

Field, R. H. G., \& Abelson, M. A. (1982). Climate: A reconceptualization and proposed model. Human Relations, 35(3), 181-201.

Fink, E. L., \& Chen, S. S. (1995). A Galileo analysis of organizational climate. Human Communication Research, 2/(4), 494-322.

Finke, L. M. (1998). Teaching in nursing: The faculty role. In D. M. Billings \& J. A. Halstead (Ed.), Teaching in mursing: A guide for faculty (pp. 3-16). Philadelphia: W. B. Saunders Company.

Fitzgerald, A. D. (Ed.). (1999). Augustine through the ages: An encyclopedia. Grand Rapids, MI: William Eerdmans Publishing Company.

Frankl, V. (1963). Man's search for meaming. New York: Simon \& Schuster.

Franklin, J. L. (1975). Relations among four social-psychological aspects of organizations. Administrative Science Quarterly, 20, 422-433.

Freiberg, H. J., Driscoll, A., \& Knight, S. (1987). School climate (Hot Topics Series) Bloomington, IN: Phi Delta Kappa.

Gay, L. R., \& Airasian, P. (2000). Educational research: Competencies for analysis and application ( $6^{\text {th }}$ ed.). Upper Saddle River, NJ: Merrill.

General Conference of Seventh-day Adventists. (2000). Almmual statistical report. Retrieved from http://www.adventistarchives.org/docs/ASR/ASR2000.pdf.

General Conference of Seventh-day Adventists, Annual Council. (1996, October 4). Total commitment to God: A declaration of spiritual accountubility in the family Of God. Unpublished manuscript.

Griffith, J. (1999). The school leadership/school climate relation: Identification of school configurations associated with change in principals. Educational Administration Quarterly, 35(2), 267-292. 
Grigsby, K. A. (1991). Perceptions of the organization's climate: Influenced by the organizational structure? Journal of Nursing Education, 30(2), 81-87.

Gunnarson, B. K., \& Niles-Jolly, K. (1994). Creating the climate and culture of success. Organizational Dynamics, 23(1), 17-29.

Halpin, A. W., \& Croft, D. B. (1962). The organization climate of schools. Contact \#SAE 543-8639. U. S. Office of Education, Research Project.

Hancock, B. (2000). Are nursing theories holistic? Nursing Standard, I4(17), 37-41.

Hartley, M., \& Hoy, W. K. (1972). Openness of school climate and alienation of high school students. California Journal of Educational Research, 23, 17-24.

Howard, E., Howell, B., \& Brainard, E. (1987). Handbook for conducting school climate improvement projects. Bloomington, IN: The Phi Delta Kappa Educational Foundation.

Hoy, W. K., \& Clover, S. I. R. (1986). Elementary school climate: A revision of the OCDQ. Educational Administration Quarterly, 22, 93-1 10.

Hoy, W. K., \& Hannum, J. W. (1997). Middle school climate: An empirical assessment of organizational health and student achievement. Educational Administration Quarterly, 33(3), 290-312.

Hoy, W. K., \& Miskel, C. G. (2001). Educational administration: Theory, research, and practice $\left(6^{\text {th }}\right.$ ed.). New York: McGraw-Hill.

Hughes, L. C. (1993). Relationships among the organizational characteristics of baccalaureate schools of nursing and the student-perceived organizational climate for caring (Doctoral dissertation, University of Texas at Austin, 1993). Dissertation Abstracts International, 55(01), B6580.

Hungelmann, J., Kenkel-Rossi, E., Klassen, L., \& Stollenwerk, R. (1996). Focus on spiritual well-being: Harmonious interconnectedness of mind-body-spirit-use of the JAREL spiritual well-being scale. Geriatric Nursing, 17(6), 262-266.

Jacobs, D. J. (1993). Health and spirituality: The development and presemation of a seminar on the role of the doctrine of health in the message and mission of the Seventh-day Adventisi Church. Unpublished doctoral dissertation, Andrews University, Berrien Springs, MI.

Jemison, T. H. (1955). A prophet among you. Mountain View, CA: Pacific Press.

Johnson, B. C., \& Dreitcer, A. (2001). Beyond the ordinary: Spirituality for church leaders. Grand Rapids, MI: William B. Eerdmans Publishing Company. 
Johnson, M. B. (1988). The diffusion of an innovation: The holistic paradigm in nursing (Doctoral dissertation. University of Minnesota. 1988). Dissertation Abstracts International, No. $\mathbf{8 8 2 3 5 4}$

Johnson, W. L., \& Johnson, A. M. (1992). A study on the Kettering School Climate scale. Education, 1/2(4), 635-640

Johnson, W. L., Johnson, A. M., Kranch, D. A., \& Zimmerman, K. J. (1999). The development of a university version of the Charles F. Kettering climate scale. Educational and Psychological Measuremem, 59(2), 336-351.

Jones, P. S. (2001, June 22). Connectedness: Toward a theory of personal wholeness. Paper presented at the Japan Nursing Diagnosis Society Congress, Yokohama, Japan.

Jones, P. S., \& Meleis, A. I. (1993). Health is empowerment. Advances in Nursing Science, 15(3), 1-14.

Keighley, T. (2001). At the heart of nursing. Nursing Standard, I5(16), 24-25.

Kelley, E. (1980). Improving school climate: Leadership techniques for educators. Reston, VA: National Association of Secondary School Principals.

Kendrick, K. D., \& Robinson, S. (2000). Spirituality: its relevance and purpose for clinical nursing in a new millennium. Journal of Clinical Nursing, 9(5), 701-705.

King, H. E., Jones, P. S., \& Zhang, X. E. (Eds.). (2000). Seventh-day Adventist schools of mursing. Loma Linda, CA: Office of International Nursing Loma Linda University School of Nursing.

Kottkamp, R. B., \& Hoy, W. K., (1987). Secondary school climate: A revision of the OCQD. Educational Administration Quarterly; 23, 31-48.

Kreitner, R. (1995). Management ( $6^{\text {th }}$ ed.). Boston: Houghton Mifflin.

Laffrey, S. C., \& Kulbok, P. A. (1999). An integrative model for holistic community health nursing. Journal of Holistic Nursing, 17(1), 88-103.

Lean, P. S. (1964). One man in his time a pictorial review of the life of Jan Christian Smuts. Johannesburg, South Africa: The General Smuts War Veterans Foundation.

LeVasseur, J. (1998). Plato, Nightingale, and contemporary nursing. Image: Journal of Nursing Scholarship, 30(3), 281-285

Levin, J. (2001). God, faith, and health: Exploring the spirituality-healing commection. New York: John Wiley \& Sons. 
Lin, C. (1999). The association between organizational climate and quality management practices: A empirical study on small - and medium-sized manufacturing companies in Taiwan. Total Quality Management, 10(6), 863

Luan, J. (1995). Cabrillo students' campus climate survey [On-line]. U. S., Califormia, 08-00. (ERIC Document Reproduction Service No. ED405936)

Lubbert, V. M. (1995). Structure and faculty perception of climate in schools of nursing. Western Journal of Nursing Research. 17(3), 317-327.

Macrae, J. (1995). Nightingale's spiritual philosophy and its significance for modern nursing. Image: Journal of Nursing Scholarship, 27(1), 8-10.

Maddox, M. (2001). Circle of Christian caring: a model for parish nursing practice. Journal of Christian Nursing, 18(3), 11-3,45.

Martin, John. (1998). Organizational behavior. London: International Thomas Business Press

Martin, J., Samels, J. \& Associates. (1997). First among equals: The role of the Chief Academic Officer. Baltimore, MD: Johns Hopkins University Press.

Martsolf, D. S., \& Mickley, J R. (1998). The concept of spirituality in nursing theories: Differing world-views and extent of focus. Journal of Advanced Nursing, 27. 294-303.

Maslow, A. H. (1968). Toward a psychology of being $\left(2^{\text {nd }}\right.$ ed. $)$. New York: D. Van Noestrand Company.

Mattice. N. J. (1994). Campus climate survey [On-line]. (J. S., Califormia, 07-00. (ERIC Document Reproduction No. ED374854)

McDowell, J., \& Hostetler, B. (1998). The new' tolerance. Wheaton, IL: Tyndale Audio.

McGrath, A. E. (Ed.). (1993). The Blackw'ell encyclopedia of modern Christian thought. Oxford, UK: Blackwell Publishers.

Merriam-Webster's collegiale dictionary. (2001). Retrieved from http://www.m-w.com/cgi-bin/dictionary

Mohammadi, J., Shaffer, B., \& Farris, R. (1995). Climate study, Spring 1995 [Online]. U. S., Virginia, 00-00. (ERIC Document Reproduction No. ED382259)

Moller, M. (1999). Meeting spiritual needs of an inpatient unit. Journal of Psychosocial Nursing, 37(11), 5-10. 
Montgomery, C. L. (1992). The spiritual connection: Nurses' perceptions of the experience of caring. In D. A. Gaut (Ed.), The presence of caring in mursing (pp. 9-52). New York: National League for Nursing.

Mosby's medical, nursing. \& allied health dictionary ( $5^{\text {th }}$ ed.). (1998). New York: Mostry.

Moylan, L. B. (2000). Alternative treatment modalities: The need for a rational response by the nursing profession. Nursing Oullook, 48(6), 259-61.

Naisbitt, J., \& Naisbitt, P. A. (1990). Megatrends 2000. New York: William Morrow \& Co.

Narayanasamy, A. (1999). A review of spirituality as applied to nursing. International Journal of Nursing Studies, 36, 117-125.

Narayanasamy, A., \& Owens, J. (2001). A critical incident study of nurses' responses to the spiritual needs of their patients. Journal of Advanced Nursing, 33(4), 446455.

Neuman, B. (1995). The Neuman Systems Model ( $3^{\text {rd }}$ ed.). Norwalk, CT: Appleton \& Lange.

Newman, M. A. (1994). Health as expanding consciousness (2 ${ }^{\text {nd }}$ ed.). New York: National League for Nursing Press.

Nightingale, F. (1860/1969). Notes on mursing: What it is and what it is not. New York: Dover.

Noddings, N. (1992). The challenge to care in schools: An alternative approach to education. New York: Teachers College Press.

O'Neill, D. P., \& Kenny, E. K. (1998). Spirituality and chronic illness. Image: Journal of Nursing Scholarship, 30(3), 275-280.

Owens, R. G. (1998). Organizational behavior in education ( $6^{\text {th }}$ ed.). Boston: Allyn and Bacon.

Parker, Marilyn. (2001). Nursing theories and mursing practice. Philadelphia: Davis Company.

Parker, Martin. (2000). Organizational culture and identity. London: Sage Publications

Patterson, E. F. (1998). The philosophy and physics of holistic health care: Spiritual healing as a workable interpretation. Journal of Advanced Nursing, 27, 287-293. 
Pelletier, K. R. (1977). Mind as healer mind as slayer. New York: Dell Publishing Co.

Pelletier, K. R. (1990). Holistic medicine: From stress to optimum health. Gloucester, MA: Peter Smith.

Pelletier, K. R. (2000). The best alternative medicine. New York: Simon \& Schuster.

Peterson, E. H. (1994). Subversive spirituality. Grand Rapids, MI: William B. Eerdmans.

Pharris, M. D. (2001). Margaret A. Newman health as expanding consciousness. In M E. Parker (Ed.), Nursing theories and mursing practice (pp. 263-274). Philadelphia: F. A. Davis Company.

Phillips, D. C. (1976). Holistic thought in social science. Standford, CA: Standford University Press.

Piles, C. L. (1990). Providing spiritual care. Nurse Educator, 15(1), 36-41.

Pinsonneault, A., \& Ktaemer, K. L. (1993). Survey research methodology in management information systems: An assessment. Journal of Management Information Systems, 10(2), 75-106.

Plawecki, J. A. (1996). Holistic nursing-moving beyond a professional commitment. Journal of Holistic Nursing, 14(3), 171-173.

Price, J. L., Stevens, H. O., \& LaBarre, M. C. (1995). Spiritual caregiving in nursing practice. Journal of Psychosocial Nursing, 33(12), 5-9.

Puchalski, C. (1999). Medical schools teach compassion through taking a spiritual history. Spirituality \& Medicine Connection, 3, 1-3.

Ramsden, P. (1998). Learning to lead in higher education. London: Routledge.

Reed, P. G. (1998). A holistic view of nursing concepts and theories in practice. Journal of Holistic Nursing, 16(4), 415-419.

Robins, J. L. W. (1999). Synthesizing reductionism and holism: Integrative health care practice. National Academics of practice forum, /(3), 197-202.

Ross, L. (1995). The spiritual dimension: Its importance to patients' health, well-being and quality of life and its implications for nursing practice. Imternational Journal of Nursing Standards, 32(5), 457-468. 
Rowles, C. J., \& Brigham, C. (1998). Strategies to promote critical thinking and active learning. In D. M. Billings \& J. A. Halstead (Ed.), Teaching in mursing: A guide for faculn (3-16). Philadelphia: W. B. Saunders Company.

Santrock. J. W. W. (1999). Life span developmem ( $7^{\text {th }}$ ed.). New York: Mc Graw-Hill.

Sarkis, J. M., \& Skoner, M. M. (1987). An analysis of the concept of holism in nursing literature. Holistic Nursing Practice, 2(1), 61-69.

Schaeffer, F. A. (1971). True spirituality: Wheaton, IL: Tyndale House Publishers.

Schneider, B. (1983). Work climates: An interactionist perspective. In N. R. Feimer \& E. S. Geller (Eds.), Emironmental psychology: Directions and perspectives (pp. 106-128). New York: Praeger.

Schneider, B. (Ed.). (1990). Organizational climate and culture. San Francisco: Jossey-Bass.

Schneider, B., \& Brief, A. P. (1996). Creating a climate and culture for sustainable organizational change. Organizational Dynamics, 2t(4), 7-20.

Schubert, P. E. (1989). Mutual connectedness: Holistic nursing practice under varying conditions of intimacy (Doctoral Dissertation, University of California, San Francisco, 1989). Dissertation Abstracts Imernational, No. 9008980.

Schuster, F. E., \& Morden, D. L. (1997). Management, practice, organizational climate, and performance. Journal of Applied Behavioral Science, 33(2), 209-227.

Schuster, J. (1997). Wholistic care healing a "sick" system. Nursing Management, 29(6), 56-59.

Selanders, L. C. (1998). The power of environmental adaptation: Florence Nightingale's original theory for nursing practice. Journal of Holistic Nursing, 16(2), 247-263.

Seventh-day Adventist Church. (2002). Retrieved from http://www.adventist.org/name-mission

Shadur, \& Kienzle, M. A. (1999). The relationship between organizational climate and employee perceptions of involvement the importance of support. Group \& Organizational Management, 24(4), 479-504.

Sheidon. J. E. (2000). Spirituality as a part of nursing. Journal of Hospice and Palliative Nursing, 2(3), 101-108.

Shelly, J. A., \& Miller, A. B. (1999). Called to care: A Christian theology of mursing. Downers Grove, IL: InterVarsity Press. 
Shenkle, C. W., Snyder, R. S., \& Bauer, K. W. (1998, Summer). Measures of campus climate. New Directions for Institutional Research, 98, 81 -99.

Simpson, S. (1999). Holistic nursing-A return to healing. Creative Nursing, 5(3), 1618.

Sire, J. W. (1990). Discipleship of the mind: Learning to love God in the ways we think. Downers Grove, IL: InterVarsity Press.

Sire. J. W. (1997). The universe next door: A basic worldvien calalog ( $3^{\text {rd }}$ ed.) Downers Grove, IL: InterVarsity Press.

Smuts, J. C. (1973). Holism and evolution. Westpor, CT: Greenwood Press. (Original work published 1926)

Smuts, J. C. (1952). Jan Christian Smuts. London: Cassell \& Company.

Soeken, K., \& Carson, V. J. (1986, April). Study measures nurses' attitudes about providing spiritual care. Health Progress, 52-55.

Springett, R. M. (1989). Holistic healing and the New Age philosophy. Adventist Perspective, 3, 43-44.

Stranahan, S. (2001). Spiritual perception, attitudes about spiritual care, and spiritual care practices among nurse practitioners. Western Journal of Nursing Research. 23(1), 90-104.

Summer, C. H. (1998). Recognizing and responding to spiritual distress. American Journal of Nursing, 98(1), 26-31.

Swift, G. (1994). Connections: A contextual model for holistic nursing practice Journal of Holistic Nursing, /2(3), 265-281.

Tanner, C. A. (1990). Caring as a value in nursing education. Nursing Outlook, 38, 7072.

Taylor, E. J. (2002). Spiritual care: Nursing theory, research, and practice. Upper Saddle River, NJ: Prentice Hall.

Taylor, E. J., Amenta, M., \& Highfield, M. (1995). Spiritual care practices of oncology nurses. Oncology Nurse Forum, 22(1), 31-39.

Taylor, E. J., Highfield, M., \& Amenta, M. (1994). Attitudes and beliefs regarding spiritual care. Cancer Nursing. 17, 479-487. 
Taylor, E. J., Highfield, M. F., \& Amenta, M. (1999). Predictors of oncology and hospice nurses' spiritual care perspectives and practices. Applied Nursing Research, 12(1), 30-37.

Thomas, J., \& Retsas, A. (1999). Transacting self-preservation: A grounded theory of the spiritual dimensions of people with terminal cancer. International Journal of Nursing Studies, 36, 191-201.

Thornton, L., \& Gold, J. (2000). The art and science of whole-person caring. School Science and Mathematics, 6(11), 28-38.

Vasquez, M. (1993). The danger within. Boise, ID: Pacific Press.

Vasquez, M. (1996). New age holistic health: Implications of Seventh-day Adventist faith and practice. Unpublished doctoral dissertation, Andrews University, Berrien Springs, MI.

Wallis, C. (1991, November, 4). Why New Age medicine is catching on. Time, 68-73.

Walsh, B. J., \& Middleton, J. R. (1984). The transforming vision: Shaping a Christian world view. Downers Grove, IL: InterVarsity Press.

Watson, J. (1985). Nursing: Human science and human care; $A$ theory of mursing. Norwalk, CT: Appleton-Century-Crofts.

Watson, J. (2001). Jean Watson theory of human caring. In M. E. Parker (Ed.), Nursing theories and mursing practice (pp. 343-354). Philadelphia: F. A. Davis Company.

Webb, L. D., \& Norton, M. S. (1999). Human resources administration: Personmel isstues and needs in education. Upper Saddle River, NJ: Prentice-Hall.

Weiten, W., \& Lloyd, M. (1999). Psychology applied to modern life: Adjustmem at the turn of the century ( $6^{\text {th }}$ ed $)$. Pacific Grove, CA: Brooks/Cole.

White, E. G. (1888). The great controversy between Christ and Satan. Boise, ID: Pacific Press.

White, E. G. (1890). Patriarchs and prophets. Boise, ID: Pacific Press.

White, E. G. (1905). The ministry of healing. Boise, ID: Pacific Press.

White, E. G. (1912). Medical ministry. Boise, ID: Pacific Press.

White, E. G. (1923). Fundamentals of Christian education. Nashville, TN: Southern Publishing Association. 
White, E. G. (1938). Counsel on diets and foods. Washington, DC: Review and Herald.

White, E. G. (1947). The story of redemption. Washington, DC: Review and Herald.

White, E. G. (1952). Education. Mountain View, CA: Pacific Press.

White, E. G. (1977). Mind, character, and personality. (Vols. 1-2). Nashville, TN Southern Publishing Association.

White, T. H., Spencer, M. G., \& Peterson, M. W. (1993). Institutional climate and the quality of the academic workplace. The Review of Higher Education, I7(1), 6993.

Witcher, A. (1993). Assessing school climate: An important step for enhancing school quality. NASSP Bulletin, 77(554), 1-5.

Wright, K. B. (1998). Professional, ethical and legal implications for spiritual care in Nursing. Image, 30(1), 82-83.

Wright, M. G. M. (2000). A critical-holistic paradigm for an interdependent world. American Behavioral Scientist, 43(5), 808-824. 
VITA

Name: $\quad$ Edelweiss Rocco Ramal

Date of birth: January 14, 1950

Place of birth: Rio de Janeiro, Brazil

Education:

1972 Union College, Lincoln Nebraska

Bachelor of Science in Nursing

1974 Loma Linda University, Loma Linda, California

Master of Science in Nursing

1996 Montemorelos University, Montermorelos, N. L. Mexico

Master of Education

Work Experience:

Loma Linda University Medical Center, Loma Linda, CA

Staff nurse

1972-1974

Montemorelos University, Montemorelos, N.L. Mexico

Coordinator of BS nursing program 1974-1975

Assistant Professor of Nursing 1976-1980

Berrien General Hospital, Berrien Center, Michigan

Staff Development Director 1981-1982

Kanye Hospital School of Nursing, Botswana, Africa

Director of School of Nursing 1983-1986

Pacific Union College, Angwin, California

Assistant Professor of Nursing 1988-1991

Montemorelos University, Montemorelos, N. L. Mexico

Assistant Professor of Nursing 1992-1996

Coordinator of Curriculum Development and Evaluation of the School of Health Sciences 1997-1998

Professional Director of School of Nursing 1999-2001

Membership

Phi Lambda Theta

2002-

Publications

Ramal, E. (1996). An Adventist model for the integration of faith and learning in nursing. In $\mathrm{H}$. Rasi (Ed.) Christ in the classroom, 17 (pp. 269-286). Silver Spring, MD: Institute for Christian Teaching.

Ramal, E. (1995). Sano y salvo. Logos, 5(5), 8-10.

Rocco, E., Bennet, T. R., \& Power, G. (1975). Placental diffusing capacity in unanesthetized rabbits. American Journal of Physiology. 228(2), 465-469. 